\title{
IV. Familienbildung und -beratung: Profilierung eines neuen Politikfeldes zwischen Bund, Ländern, Kommunen und freien Trägern
}

„Es ist heute schon fast ein Gemeinplatz festzustellen, daß wir in einer Zeit tiefgreifender Umbrüche leben und auch im Hinblick auf die Gehalte und Formen von Ehe, Familie und Elternschaft kaum noch auf vorgezeichnete Umrisse und durch Generationen hindurch erprobte Verhaltensmuster oder auf allgemein als verbindlich anerkannte Normen zurückgreifen können." ${ }^{1}$ Mit diesen Worten beklagte der Staatssekretär im Familienministerium Heinrich Barth² 1967 die zunehmende Orientierungslosigkeit in Familienfragen. Die Aussage ist vor allem deshalb so bemerkenswert, weil sie sich deutlich von den dogmatischen Formulierungen, mit denen noch Franz-Josef Wuermeling ein Jahrzehnt zuvor die Grundlagen der Familie beschworen hatte, unterschied. Jener hatte lediglich auf die äußerlichen Gefährdungen der modernen Gesellschaft für die traditionelle Familie hingewiesen und seine Familienpolitik als eine Form des Schadensausgleichs hierfür angesehen. Inzwischen schienen aber ganze Wertgefüge und Lebenspläne ins Wanken geraten zu sein, die Orientierung an "Sitte und Tradition" reiche, so Barth, für eine Bewältigung des Lebens in der modernen Gesellschaft mit seinen neuen Herausforderungen offenbar nicht aus. Der Familienpolitiker sprach damit den traditionellen Normen teilweise ihre Geltung ab.

Barth beobachtete zudem, daß sich eine Kluft zwischen den Generationen auftat: Was für die Eltern noch als verbindliche Tradition galt, erkannten die Kinder nicht mehr an, Leitbilder, die noch vor kurzem in der Gesellschaft vermeintlich fest verankert gewesen waren, wurden plötzlich in Frage gestellt, und die Vermittlung grundlegender Wertvorstellungen über Ehe und Familie von einer Generation zur nächsten schien damit ernstlich gefährdet.

Hinzu kam ein weiteres Problem: Die Eltern waren nicht mehr die einzigen Vermittler von Wertvorstellungen und Bildungsinhalten, sondern standen in Konkurrenz mit anderen, teilweise auch kommerziellen Institutionen. Die "geheimen Miterzieher" gewannen zunehmend an Bedeutung im Leben der Kinder und Jugendlichen. Gemeint sind damit vor allem Schule, Medien und Freizeitorganisationen, die unabhängig vom Elternhaus und für die Eltern nahezu unkontrollierbar Einfluß auf die nachwachsende Generation ausübten. Barth zog daraus die Schlußfolgerung, daß die Familien professionelle Unterstützung beim Vollziehen des Wertewandels brauchten. Dies sah er als Aufgabe der Familienbildungsstätten

1 Barth, Aktivierung, S. $14 \mathrm{f}$.

2 Zur Biographie von Heinrich Barth vgl. Kapitel II, Fußnote 55. 
an. Mit seiner Argumentation ging Barth über die herkömmliche Begründung für die Arbeit der Familienbildungsstätten weit hinaus, wonach diese lediglich Wissenslücken füllen sollten. ${ }^{3}$

Barths Stellungnahme war kennzeichnend für die Situation am Vorabend der "Studentenrevolte“, die mit dem Stichwort „1968“ bezeichnet wird. Im nachhinein erscheint sie als ein Ereignis, bei dem traditionelle Familienstrukturen und deren Leitbilder auf einen Schlag zertrümmert wurden. Die Chiffre „1968“ steht dabei für kulturelle Revolution, Frauenemanzipation und sexuelle Befreiung. ${ }^{4}$ Bei genauerer Betrachtung muß man jedoch diesen Eindruck, der vor allem von den Zeitgenossen geprägt wurde, relativieren, denn viele gesellschaftliche und kulturelle Veränderungen hatten lange vor dem Stichjahr 1968 eingesetzt und traten im Rahmen der Studentenrevolte nur besonders medienwirksam ins Licht der Öffentlichkeit. Weitreichende gesellschaftliche Strukturveränderungen, die das traditionelle christlich-bürgerliche Familienleitbild in Frage stellten, reichen bis in die fünfziger Jahre und weiter zurück. Die 68er-Revolte wirkte nicht nur als Initialzündung für grundlegende Umwälzungen im Bereich der Sexualmoral, sondern auch als eine Art Katalysator für bereits seit längerem laufende gesellschaftliche Wandlungsprozesse.

Die Zahl der erwerbstätigen Ehefrauen und Mütter beispielsweise, die das herkömmliche Rollenverständnis durchbrachen und mit ihrer Erwerbsarbeit neue Konflikte und Herausforderungen in die Familien trugen, war wie oben dargelegt bereits im ersten Jahrzehnt der Geschichte der Bundesrepublik spürbar angestiegen. Auch der Abbau starrer Verhaltensregeln und das Aufweichen von hierarchischen Machtverhältnissen unter den Ehepartnern und zwischen Eltern und Kindern war ein langfristiger Wandlungsprozeß. Dieser Prozeß der "Informalisierung" sozialer Beziehungen, der auch in anderen gesellschaftlichen Bereichen zu beobachten war, prägte den Umgang der Ehepartner, veränderte aber auch das Verhältnis zwischen den Generationen. Durch den Rückzug der Eltern gewannen die Jugendlichen mehr Entscheidungsfreiräume. ${ }^{5}$

Die Restauration des traditionellen Familienleitbildes in den fünfziger Jahren hatte sich zudem auf brüchigem Boden vollzogen. Noch kurz zuvor hatte in der unmittelbaren Nachkriegszeit eine "Verwahrlosung der Sitten" die Basis der Familien erschüttert. Eltern waren ihren Kindern gegenüber machtlos und überfordert gewesen, die in Fragen der Sexualmoral eigene Wege gingen. ${ }^{6}$ Bei Männern, die aus dem Krieg zurückkamen, hatten Soziologen vielfach eine "Verrohung" des geschlechtlichen Verhaltens beobachtet. ${ }^{7}$ Viele Frauen - vor allem wenn ihre Ursprungsfamilie zerstört war - hatten zunächst die Wiederaufnahme ihrer traditionellen Geschlechterrolle abgelehnt. Angesichts der Vorgeschichte erscheint das

3 Vgl. beispielsweise noch die Argumentation von Martin Donath in ders., Eheseminare, S. 7.

4 Frevert, Umbruch, S. 643.

5 Vgl. Korte, Gesellschaft, S. 94-97.

6 Niehuss, Strukturgeschichte, S. 309.

7 Ebenda. 
Festhalten am Familienideal in den fünfziger und frühen sechziger Jahren in mancher Hinsicht eher wie ein äußerliches Korsett, das in Zeiten morsch gewordener Lebensrealitäten wieder künstlich Halt geben sollte.

Die Bilanz der empirischen Daten für die fünfziger und frühen sechziger Jahre fällt nicht zugunsten der etablierten Idealvorstellungen aus. Ein Indiz für die herrschende Doppelmoral ist beispielsweise der Umgang mit vorehelichem Geschlechtsverkehr. ${ }^{8}$ Einer Umfrage der Zeitschrift "Constanze“ zufolge bewerteten noch 194961 Prozent der Befragten die „freie Liebe“ nicht als unmoralisch. In einer anderen Umfrage aus demselben Jahr gaben rund 90 Prozent der Männer und rund 70 Prozent der Frauen an, vorehelichen Geschlechtsverkehr gehabt zu haben. Dieser freizügigen Nachkriegsphase, die etwa bis zur Währungsreform dauerte, folgte eine Phase, in der sich die Moralvorstellungen wieder spürbar verhärteten. Eine Umfrage in Darmstadt ergab beispielsweise 1950, daß inzwischen eine überwältigende Mehrheit der Befragten das „freie Zusammenleben von Mann und Frau" ablehnten. Verändert hatte sich allerdings in erster Linie das Leitbild, was vor allem dazu führte, daß Wertvorstellung und Praxis auseinanderfielen. Dies zeigte sich beispielsweise, als die beiden Kinsey-Reporte aus den Jahren 1948 und 1953 in Deutschland bekannt wurden, die zu dem Ergebnis kamen, daß in weiten Kreisen der Bevölkerung voreheliche Sexualkontakte „normal" seien. Zwar ließen sich die Zahlen aus den USA nicht unmittelbar auf die Situation in Deutschland übertragen, aber die Sozialwissenschaftler in der Bundesrepublik mußten doch eingestehen, daß der Trend auch hier in dieselbe Richtung ging. Vorehelicher Geschlechtsverkehr bei Jugendlichen war auch in den fünfziger und sechziger Jahren in der Bundesrepublik keine Ausnahmeerscheinung.

Angesichts dieser Entwicklungen erscheinen die grundstürzenden Prozesse während der "68er-Revolte" zumindest in langfristige gesellschaftliche Wandlungstrends eingebunden. Nur auf den ersten Blick mag der Bruch mit dem herkömmlichen Familienleitbild in den späten sechziger Jahren radikal erscheinen, vor allem weil der Heirats- und Babyboom der fünfziger und frühen sechziger Jahre auf einen Aufschwung des traditionellen Wertgefüges hindeutete. Auch die statistischen Zahlen scheinen den Trend zur leitbildkonformen Familienstruktur zu bestätigen. Die Daten sagen aber nicht viel über die Innenverhältnisse der Ehen und Familien aus. Die öffentliche Diskriminierung geschiedener Frauen und die wirtschaftliche Notsituation, in die Frauen infolge einer Scheidung vielfach gerieten, sprechen eher dafür, daß viele innerfamiliäre Probleme nicht in Form von Trennungen ausgetragen wurden, sondern ein Teil der Ehen selbst dann zum Schein aufrecht erhalten wurde, wenn die eheliche Lebensgemeinschaft schon lange nicht mehr bestand. ${ }^{9}$ Nicht ohne Grund prangerte die 68er-Bewegung gerade das Auseinanderfallen von Norm und Wirklichkeit und die herrschende Doppelmoral an.

$8 \mathrm{Vgl}$. zum folgenden ebenda, S. 312-314.

9 Delille/Grohn, Blick, S. 47 f., mit eindrucksvollem Fallbeispiel. 
Auch die "Familieneuphorie“, die sich an zahlreichen Artikelserien und Leserbrief-Anfragen in zeitgenössischen Frauenzeitschriften ablesen läßt, ${ }^{10}$ ist weniger ein Indiz für die sozialen Verhältnisse als ein Hinweis auf die hohen Idealvorstellungen. Die großen Erwartungen, die mit Ehe und Familie verbunden waren, trugen in gewissem Maß schon den Keim für tiefe Enttäuschungen in sich. Manche neuen Probleme, die das Geschlechterverhältnis dynamisierten, entstanden erst aus dieser Ambivalenz. ${ }^{11}$ Unerfüllte Erwartungen bildeten eine Ausgangsbasis für die "Sexualitätsdebatte" in der Bundesrepublik in den sechziger Jahren. Aufklärungsliteratur und -filme, wie beispielsweise die von Oswalt Kolle, reagierten in gewissem Maße auf diese gestiegenen Erwartungen und befriedigten ein Informationsbedürfnis. Die öffentliche Thematisierung der individuellen Sexualität - innerhalb und außerhalb der Ehe - bedeutete allerdings gegenüber dem prüden gesellschaftlichen Klima der fünfziger Jahre ${ }^{12}$ einen massiven Tabubruch. Die gezielte pornographische Provokation Kolles rief daher große Empörung hervor. Die sechziger Jahre bildeten in diesem Zusammenhang eine „Interimsphase", die Grenzen niederriß, aber die Dynamik doch im Zaum zu halten versuchte. ${ }^{13}$

Welche Ziele die Studentenrevolte im Hinblick auf die Geschlechterverhältnisse verfolgte, läßt sich anhand der drei Punkte des „Aktionsrats zur Befreiung der Frauen“, der im Januar 1968 ins Leben gerufen wurde, nachzeichnen:14 Es ging erstens um die Revolutionierung des Alltagslebens. Kritisiert wurde, daß Frauen und Kinder vom öffentlichen Leben ausgeschlossen seien. Zweitens sollten die Beziehungen zwischen Mann und Frau in der Partnerschaft aufgebrochen werden. Konkret erklärten die Verfasser des Aufrufs die Kindererziehung zum Politikum, für das auch Männer zuständig seien. Schließlich ging es drittens um Veränderungen in der Erziehung. In den traditionellen Erziehungssystemen, so lautete der Vorwurf, werde die „autoritäre Persönlichkeit“ reproduziert. Neue Einrichtungen - die sogenannten "Kinderläden" - sollten diese Situation durchbrechen und antiautoritäre Erziehungsmethoden erproben.

Diese Forderungen blieben weitgehend im studentischen Milieu der $68 \mathrm{er}-\mathrm{Be}-$ wegung verhaftet und erreichten die breite westdeutsche Gesellschaft erst verzögert und in gemäßigter Form. Auswirkungen der "sexuellen Revolution“ und der antiautoritären Erziehungsgrundsätze zeigten sich in der gesellschaftlichen Lebenswirklichkeit erst in den siebziger Jahren und rekurrierten nur in wenigen Punkten, wie z.B. der Kinderladenbewegung, unmittelbar auf die Initialwirkung von „1968“, die jedoch langfristig gesehen einen umfassenden Wertewandel forcierte. Die experimentierfreudige Sexualität war ebenfalls vor allem ein Phänomen der Jugendkultur der siebziger Jahre. Das zentrale Gründungsereignis der neuen

10 Vgl. Lott, Frauenzeitschriften; dies., Brigitte; Lehr, Nachrichten; neuerdings auch Horvath, Frauenleitbilder, und Seegers, Hör zu.

$11 \mathrm{Vgl}$. hierzu und zum folgenden Frevert, Umbruch, S. $652 \mathrm{f}$.

12 Vgl. dazu mit zahlreichen Argumenten v. a. aus dem Bereich der Aufklärung und des Umgangs mit Verhütungsmitteln Niehuss, Strukturgeschichte, S. 319-323.

13 Frevert, Umbruch, S. 653.

14 Vgl. dazu Schulz, Bräute, S. 100-106. 
Frauenbewegung mit großer gesellschaftlicher Breitenwirkung - die Debatte um den $\$ 218$ - fand auch erst einige Zeit später, Anfang der siebziger Jahre, statt, auch wenn sie ohne den Tabubruch von „1968" kaum denkbar gewesen wäre. Zwischen „1968“ und der neuen Frauenbewegung mit ihrem Ziel, die traditionellen Geschlechterverhältnisse aufzubrechen, gab es zwar keine kontinuierliche Linie, aber doch starke gegenseitige Bezüge. ${ }^{15}$

Die oben zitierte Stellungnahme Heinrich Barths ist ein Beleg dafür, daß die Politiker aus dem Wertewandel, den sie zu spüren glaubten, Konsequenzen zogen. Angesichts von sich auflösenden Wertbezügen kam hierbei den Familienbildungsstätten ${ }^{16}$ in den Augen der Familienpolitiker eine zentrale Bedeutung zu, da sie die einzigen Instanzen zu sein schienen, die auf die Veränderungen gestaltenden Einfluß nehmen konnten. Der Wertewandel im Bereich der Familien modifizierte die Rahmenbedingungen und schrieb den Institutionen der Familienbildung eine neue Funktion zu. Während die Anfänge der Familienbildung in der Bundesrepublik im Zeichen von Ergänzungsbildung und Fürsorge standen, erlangte sie um so mehr eine Schlüsselstellung im familienpolitischen Konzept, je stärker das traditionelle Familienideal in Frage gestellt wurde und dadurch eine Leerstelle zu entstehen drohte.

Einrichtungen der Familienbildung und -beratung befanden sich zumeist in kommunaler oder freier Trägerschaft. Sie unterstanden im allgemeinen der Kulturhoheit der Länder. Als Mitte der sechziger Jahre sowohl bei den Trägern selbst als auch in der Politik der Wunsch nach einer bundesweiten Koordination laut wurde, stieß die Systematisierung dieses Bereichs aufgrund der komplizierten Verflechtung der beteiligten Ebenen schnell auf Probleme, die aus der traditionell gemischten Organisation dieser Einrichtungen im föderativen System Westdeutschlands erwuchsen. Dieser Prozeß spiegelt exemplarisch die sozialpolitischen Problemlagen, die sich aus der föderalen Struktur der Bundesrepublik ergaben. Parallel zur inhaltlichen Umformung ergaben sich also für die Familienbildungseinrichtungen auch organisatorische Probleme, die die Entwicklung maßgeblich beeinflußten. Wie sich das für den Aufschwung der Familienbildungseinrichtungen auswirkte, soll im folgenden näher untersucht werden.

15 Ebenda, S. 97.

16 Bis Mitte der sechziger Jahre bestand das Netz der Familienbildungs- und -beratungseinrichtungen in der Bundesrepublik aus unterschiedlichsten Institutionen, die kaum systematisch zu unterscheiden waren. Wohlfahrtsverbände, Interessengemeinschaften, Gemeinden und Kommunen unterhielten diverse Formen von Einrichtungen mit uneinheitlichen Bezeichnungen. Hier soll allgemein der Begriff "Familienbildung und -beratung“ verwendet werden, der sich erst im Laufe des Systematisierungsprozesses der sechziger Jahre herausbildete. Unter ihm werden Mütterschulen, Ehe- und Elternschulen sowie Einrichtungen der Ehe-, Familien- und Jugendberatung zusammengefaßt. Innerhalb dieser Definition lassen sich die Institutionen in die Gruppe der präventiv ansetzenden „Bildungseinrichtungen“ und die der meist im Einzelfall reaktiven "Beratungseinrichtungen" einteilen. 


\section{Familien- und Eheberatung zwischen Tradition und neuen Herausforderungen}

\section{Familienberatung in den fünfziger und früben sechziger Jabren: ein neuer Anfang?}

Einrichtungen zur Familienbildung und -beratung wurden in Deutschland erstmals in der Weimarer Zeit in größerem Umfang politisch thematisiert. Damals waren vom „Bund für Mutterschutz und Sexualreform“ unter Helene Stöcker in vielen Städten Ehe- und Sexualberatungsstellen gegründet worden. Sie hatten sich vor allem mit der Beratung von Frauen in wirtschaftlicher Not beschäftigt. Im Zentrum hatten Fragen der Empfängnisverhütung und des Schwangerschaftsabbruchs gestanden. ${ }^{17}$ Daneben waren amtliche Eheberatungsstellen, die vor allem Fragen der Eugenik behandelten, entstanden. Die Gründung katholischer Beratungsstellen in den zwanziger Jahren ist als eine Gegenbewegung zur Zunahme dieser Beratungsformen zu verstehen. Sie befaßten sich vor allem mit Problemen innerhalb von Ehe und Familie. In der NS-Zeit übernahmen die staatlichen Gesundheitsämter die Eheberatungsstellen und instrumentalisierten sie zur Erfassung und Aussonderung im Sinne der nationalsozialistischen „Rassenhygiene“.

Nach 1945 wurden die amtlichen Sexualberatungsstellen der Weimarer Zeit nicht wieder eingerichtet. Die Kirchen und die paritätischen Träger hingegen knüpften an ihre Weimarer Traditionslinien an. Schon in den frühen fünfziger Jahren bildeten sich drei unterschiedliche Formen der Familienbildung und -beratung in der Bundesrepublik heraus: die in paritätischer Trägerschaft, die unter konfessionellem Dach sowie die Einrichtungen der „Deutschen Gesellschaft für Ehe und Familie" (später Pro Familia).

Als erster Zusammenschluß von Jugend- und Eheberatungsstellen bildete sich 1949 die paritätische „Deutsche Arbeitsgemeinschaft für Jugend- und Eheberatung“ (DAJEB). 1952 waren in der DAJEB nach eigenen Angaben 56 „näher bekannte" Beratungsstellen organisiert. 18 Mitte 1954 umfaßte diese Liste 49 Eheund Familienberatungsstellen und 38 "Arbeitsgemeinschaften", das heißt kirchliche Gemeinden und kommunale Jugend- und Gesundheitsämter, die unter anderem auch Beratungsstunden anboten. ${ }^{19}$ Damit war die DAJEB bis Mitte der fünfziger Jahre der stärkste Verband in diesem Bereich. Sie sah ihre Aufgabe anfangs vor allem in drei Punkten: in der Durchführung von Fachtagungen (1), in der Formulierung von Richtlinien für die Beratungsarbeit und der Standardisierung der Ausbildung von Eheberatern (2) und schließlich darin, ein Forum für Erfahrungsaustausch zu bieten (3). ${ }^{20}$ Den seit der Weimarer Zeit traditionellen Vorrang der

$17 \mathrm{Vgl}$. dazu von Soden, Sexualberatungsstellen.

18 Vgl. zu den Zahlen: Erfahrungen der Eheberatung im Jahre 1952. Zusammengestellt aus Tätigkeitsberichten von Eheberatungsstellen im Auftrage der DAJEB, in: Der öffentliche Gesundheitsdienst, 15 (1953), H. 9, S. 360-365, S. 363.

19 Jahresbericht der DAJEB 1953, BAK, B 189/2815.

20 Vgl. Denkschriften der DAJEB von 1949 und 1953. Zusammenfassung der Denkschrift von 1953 in: Jahresbericht der DAJEB 1953, BAK, B 189/2815. 
Ärzte bei der Beratung lehnten die in der DAJEB versammelten Organisationen ab. ${ }^{21}$ Sie strebten die Teamarbeit von Ärzten, Erziehern, Juristen, Seelsorgern und Eheberatern an. Diese Grundsatzentscheidung war für die Entwicklung in den sechziger Jahren von entscheidender Bedeutung.

Inhaltlich knüpfte die DAJEB an die Grundsätze des von Carl Coerper gegründeten „Deutschen Verbandes für psychische Hygiene“ von 1928 an. ${ }^{22}$ Der ehemalige Leiter des Kölner Gesundheitsamtes Coerper, der seit 1937 Leiter der NSVGauabteilung für Volksgesundheit im Gau Köln-Aachen gewesen war und als ein Vertreter der biologistischen Sozialhygiene galt, wurde 1949 auch erster Vorsitzender der DAJEB. ${ }^{23} \mathrm{Zu}$ den Gründungsmitgliedern gehörten neben Carl Coerper Jochen Fischer ${ }^{24}$ und der promovierte NS-Rassenhygieniker Lothar Loeffler ${ }^{25}$. Es fällt auf, daß hier vor allem Personen aus dem Umfeld der evangelischen Diakonie aktiv wurden, die in den frühen dreißiger Jahren an der Durchsetzung der Zwangssterilisation in den evangelischen Fürsorgeeinrichtungen beteiligt gewesen waren und sich bereits damals für eine breite Erfassung von gesundheitsstatistischen Daten eingesetzt hatten. Die Erfassung sozialstatistischer Daten, die die DAJEB in ihren Beratungsstellen einführte, erinnerte auch an die erbbiologischen

21 Fischer, Formen.

22 Vgl. Bericht der Jahrestagung der DAJEB 1953 in Detmold vom 8.-10. 5. 1953, S. $4 \mathrm{f}$, BAK, B 189/2815. Das Ziel der im „Deutschen Verband für psychische Hygiene“ zusammengeschlossenen Psychiater war eine möglichst umfassende „erbbiologische Bestandsaufnahme" von Patienten in Heil- und Pflegeanstalten und von der Bevölkerung. Vgl. Roth, Bestandsaufnahme, S. 59.

23 Carl Coerper (1886-1960), Arzt, seit 1918 Gesundheitsamt Barmen, 1920 Kreiskommunalarzt des Sprengels Düsseldorf-Land, 1926-1945 Beigeordneter für das Gesundheitsund Wohlfahrtswesen in Köln, nach 1945 in der Diakonie tätig. Vgl. Labisch/Tennstedt, Weg, S. 391 f.; Schleiermacher, Sozialethik, S. 150, Fußnote 72. Zu den Gründungsmitgliedern vgl. Becker, Eröffnung, S. 2-3.

24 Jochen Fischer war nach 1945 „beratender Sozialhygieniker" im „eugenischen Arbeitskreis" des Diakonischen Werkes, der sich mit der Rolle des Diakonischen Werkes in der NS-Zeit im Zusammenhang mit der Frage der eugenischen Sterilisationen befaßte. Vgl. Schleiermacher, Innere Mission, S. 87. Nach dem Tod Carl Coerpers wurde Fischer 1960 Vorsitzender der DAJEB.

25 Lothar Loeffler (1901-1983), Arzt, 1931 Privatdozent in Kiel, 1934 ordentlicher Professor in Königsberg und Leiter des erb- und rassenbiologischen Instituts, Leiter des Gauamtes für Rassenpolitik Ostpreußen, 1942 ordentlicher Professor in Wien und Leiter des Rassenpolitischen Institutes der Universität Wien. Loeffler wurde im Sommer 1939 durch den Reichsärzteführer Gerhard Wagner als einer der ersten Ärzte in den Plan zur Ermordung geistig behinderter Kinder eingeweiht, hat aber nach eigenen Angaben eine Mitwirkung abgelehnt. Vgl. Aktenvermerk der Staatsanwaltschaft Hannover über die Aussage von Lothar Loeffler, emeritierter Professor an der Universität Königsberg vom 4. 5. 1964, anläßlich der Hauptversammlung des Landgerichts Limburg gegen Hefelmann, Vernehmung Wentzler, 11. 10. 1963, Zentralstelle der Landesjustizverwaltung zur Verfolgung von NS-Verbrechen in Ludwigsburg, Aussagenslg. Euthanasie, Ordner Uta-We. Nach 1945 war Loeffler medizinischer Gerichtsgutachter in Hannoversch Münden, 1952 niedersächsischer Landesgesundheitsrat und ordentlicher Professor an der Technischen Universität Hannover, Mitarbeit im „Eugenischen Arbeitskreis“ des Diakonischen Werkes. Für die Hinweise auf Loefflers Tätigkeit in der NS-Zeit danke ich Winfried Süß. Vgl. zu Loeffler auch Schleiermacher, Innere Mission, S. 86f. 1963 wurde Loeffler Vorsitzender der DAJEB. 
Fragebögen früherer Zeiten. Die DAJEB sah sich daher in dieser Frage unter einem besonderen Rechtfertigungsdruck. Im Jahresbericht 1953 wurde beteuert, daß mit der Einführung und Benutzung des Berichtsformulars keine statistischen Erhebungen gewonnen werden sollten, da die "sehr differenzierte Art der Raterteilung und Hilfeleistung" dies ebensowenig gestatte, wie die ,individuelle Arbeitsweise und voneinander abweichende Organisationsform der einzelnen Beratungsstellen". Gerade wegen dieser Vielgestaltigkeit sei ein Austausch von Erfahrungen unter den Eheberatern unerläßlich, um die verantwortungsvolle Arbeit bei aller menschlichen und örtlichen Individualität fachlich zu bereichern. ${ }^{26}$ Nur zum internen Austausch sollten die Fragebögen angeblich dienen. Trotz dieser sachbezogenen Rechtfertigung stand wohl mehr hinter dem Projekt, weite Kreise der Bevölkerung in der Eheberatung zu erfassen. Führende Mitglieder der DAJEB wie Lothar Loeffler und Jochen Fischer arbeiteten nämlich in den fünfziger Jahren an dem Entwurf eines Sterilisationsgesetzes, das das nationalsozialistische "Gesetz zur Verhütung erbkranken Nachwuchses", das in der Bundesrepublik nur durch die Auflösung der NS-Erbgesundheitsgerichte faktisch aufgehoben war, formal aber erst 1974 außer Kraft trat, reaktivieren bzw. ersetzen sollte. Neben freiwilliger Sterilisation und "Anstaltsasylierung" bildete die Ehe- und Familienberatung die dritte tragende Säule ihres Konzeptes. ${ }^{27}$

Im Zentrum der Arbeit der DAJEB stand die Sexualpädagogik. Die Aufklärung und die Einführung in sexuelles Verhalten erfolge, so Lothar Loeffler, vor allem durch das Vorbild der Eltern. Die meisten Eltern erfüllten diese Erziehungsaufgabe jedoch nicht und seien auch nicht fähig dazu. ${ }^{28}$ Jochen Fischer schloß daraus: Unter diesem Aspekt sei der ,innere Substanzverlust der Familie“ bedrohlich, und er faßte seinen Befund in die knappen Worte: „Die Tradition ist hin.“ Während früher die traditionellen sexualpädagogischen Werte von einer Generation an die nächste weitergegeben worden seien, scheine nun die Kette unterbrochen und eine aktive Bestimmung der Werte notwendig. Eltern, Ärzte und Pädagogen müßten darauf achten, „daß in sexuellen Dingen psychische Infektion nicht aufkommt", erklärte Lothar Löffler ganz im Duktus der zwanziger Jahre auf einer Fortbildungstagung für Eheberater 1953. So beschäftigte sich die DAJEB auf ihren Jahrestagungen mit Fragen wie "Geschlechtliche Erziehung als Aufgabe vorbeugender Jugend- und Eheberatung" und „Verlobtenberatung und Eheanbahnung". Inhaltlich zielten die Tagungen und Lehrgänge eher auf die präventive Jugenderziehung zur Ehe als auf eine Hilfe bei Konflikten und Krisen bereits bestehender Ehen und Familien.29

26 Jahresbericht der DAJEB 1953, S. 6, BAK, B 189/2815.

27 In einem „Eugenischen Arbeitskreis“ des Diakonischen Werkes beriet der Präsident des Diakonischen Werkes Theodor Schober u. a. mit Jochen Fischer, Otmar v. Verschuer, dem Pastor Schlaich, Lothar Loeffler und dem Psychiater Enke in den fünfziger Jahren über eine Novelle des Sterilisierungsgesetzes. Schleiermacher, Innere Mission, S. 87.

28 Vgl. Bericht der Jahrestagung der DAJEB 1953 in Detmold vom 8.-10. 5. 1953, BAK, B 189/2815. Folgende Zitate von Lothar Loeffler und Jochen Fischer ebenda.

29 Die Beratung und Betreuung von Eheleuten, deren Ehe "in ernster Gefahr“" war, stand hinter präventiven Ansätzen erst an vierter und letzter Stelle des Aufgabenkatalogs, den die DAJEB 1953 in einer Denkschrift zusammenstellte. Vgl. Denkschrift über die Voraus- 
In der Praxis der Beratungsstellen spielten diese präventiven Fragen in den frühen fünfziger Jahren allerdings keine große Rolle. Die meisten Ratsuchenden übrigens waren es fast nur Frauen, die sich an die Beratungsstellen wandten - fragten nicht nach sexualpädagogischen Ratschlägen. Nur knapp drei Prozent aller Hilfesuchenden kamen wegen solcher Fragen in eine der Beratungsstellen. Das Thema rangierte damit nur an zwölfter Stelle der Probleme. Auch die Geburtenregelung stand entgegen den Erwartungen der Berater bei weitem nicht an erster Stelle. Aufklärung und Verhütung gehörten auch eher zum Problemkreis junger Paare. Die Ehepaare, die eine Beratungsstelle aufsuchten, waren aber in der Regel schon lange verheiratet, in der Mehrzahl der Fälle sogar über 20 Jahre. Es waren vor allem "eheliche Kontaktstörungen" und Untreue des Mannes, die fast die Hälfte der Frauen zu einem Besuch beim Eheberater veranlaßten. ${ }^{30}$

Mit ihrem Beratungsangebot wandten sich die Einrichtungen der DAJEB an die Frauen. „Von der Frau muß die Stärkung der Sitte, der ehelichen und familiären Ordnung wieder ausgehen", forderte Jochen Fischer auf der Fortbildungstagung 1953. „Das setzt ein entsprechendes Schwergewicht bei der Mädchenerziehung voraus. " 31 Die in der DAJEB zusammengeschlossenen Beratungsstellen folgten dabei einem ganz bestimmten Frauen- und Familienleitbild. Die Rolle der Mutter war demnach im Haus bei ihren Kindern. Auf der Jahrestagung der DAJEB 1956 erklärte Lothar Loeffler es zur "Jahrhundertaufgabe“, die Mütter aus dem Wirtschaftsleben herauszulösen. ${ }^{32}$ Mit Aus- und Fortbildungsveranstaltungen für Eheberater wollte die DAJEB die Beratungspraxis in ihrem Sinne nach diesem Leitbild steuern.

Schon bald nach dem Krieg richteten auch die Kirchen wieder erste Eheberatungsstellen ein. Mitte der fünfziger Jahre gab es bereits wieder etwa 70 katholische Eheberatungsstellen. ${ }^{33}$ Die katholischen Einrichtungen dominierten damit das Netz der Beratungseinrichtungen und hatten die paritätischen Einrichtungen von der Führungsposition verdrängt. ${ }^{34}$ Die Ausrichtung der Fortbildungsveran-

setzungen sachgemäßer Jugend- und Eheberatung (1953), Darstellung der Arbeitsbereiche, abgedruckt in: Jahresbericht der DAJEB 1953, S. 5, BAK, B 189/2815.

30 Gründe für den Besuch einer Eheberatungsstelle der DAJEB 1952: Eheliche Kontaktstörungen: 23\%, Untreue des Mannes: 21\%, Schwiegereltern: 7,5\%, Partnerwahl: 6,6\%, Unterhalt: 6,5\%, Alkohol (Sucht): 5\%, Finanzen: 4,4\%, Fehlformen der Sexualität: 4,2\%, Krankheit: 4,1\%, Wohnung: 4,0\%, Untreue der Frau: 3,1\%, Sexualpädagogik: 2,8\%, Geburtenregelung: 2,6\%, uneheliches/voreheliches Kind: 1,9\%, Erziehungsfragen: 1,9\%, Weltanschauung: 1,3\%. Angaben nach einer Erhebung der DAJEB 1952 unter 17 ihrer 56 Beratungsstellen (davon 6 mit Fragebogen). Vgl. Erfahrungen der Eheberatung im Jahre 1952, zusammengestellt aus Tätigkeitsberichten von Eheberatungsstellen im Auftrag der DAJEB, in: Der öffentliche Gesundheitsdienst, 15 (1953), H. 9. S. 360-365, hier S. 364.

31 Vgl. Bericht der Jahrestagung der DAJEB 1953 in Detmold vom 8.-10. 5. 1953, BAK, B 189/2815.

32 Bericht der Jahrestagung der DAJEB vom 3.-5. 5. 1956, BAK, B 189/2815.

$33 \mathrm{Vgl}$. zu den katholischen Eheberatungseinrichtungen Rölli-Alkemper, Familie, S. 360367.

34 Die genauen Zahlenangaben schwanken, was wohl vor allem darauf zurückzuführen ist, daß viele Beratungseinrichtungen nicht als Einzeleinrichtung institutionalisiert waren. Rölli-Alkemper spricht davon, daß evangelische und freieTräger gemeinsam rund halb so 
staltungen der oben erwähnten paritätischen „Deutschen Arbeitsgemeinschaft für Jugend- und Eheberatung" (DAJEB), die bis dahin ein Monopol in diesem Bereich unterhielt, bildete schließlich den Auslöser für einen eigenständigen Zusammenschluß der katholischen Institutionen. Auch katholische Eheberater hatten zunächst an den Fortbildungsveranstaltungen der DAJEB gerne teilgenommen. In diesen Fortbildungslehrgängen wurden jedoch auch Themen wie Geburtenkontrolle und Verhütung vermittelt. Daher sah sich die deutsche Bischofskonferenz veranlaßt, einen eigenen Fortbildungsverband einzurichten, in dem die Werte der katholischen Sexualmoral und des katholischen Leitbildes der kinderreichen Familie im Vordergrund standen. Ende 1952 wurde daher das „Katholische Zentralinstitut für Ehe- und Familienfragen“ gegründet. Leiter wurde der Mainzer Arzt Bernhard Korte. Neben Korte spielte Josepha Fischer-Erling, die Leiterin der Kölner Eheberatungsstelle, eine zentrale Rolle bei der Einrichtung der katholischen Eheberatungsstellen. Sie war auch die einzige Vertreterin der sozialen Praxis, die noch nach der Umwandlung des familienpolitischen Beirats beim Bundesfamilienministerium 1959 in ein reines Wissenschaftler-Gremium ihren Sitz behaupten konnte. ${ }^{35}$

Die evangelische Familienbildungsarbeit gewann gegenüber der DAJEB erst 1959 ein schärferes eigenständiges Profil, als sich als Trägerverband die „Konferenz für Evangelische Familienberatung " bildete. ${ }^{36}$ Es handelte sich dabei um eine Ausgliederung evangelischer Familienbildungsträger aus der DAJEB. Der erste Vorsitzende der evangelischen Konferenz, der Arzt und Psychotherapeut Guido Groeger, war ebenso wie Fischer bereits im Rahmen der DAJEB aktiv gewesen. Nach der Ausgliederung der evangelischen Träger war die DAJEB in ihrer Substanz erheblich ausgedünnt. Sie hatte etwa die Hälfte ihrer Mitglieder verloren. ${ }^{37}$

In der ersten Hälfte der sechziger Jahre vollzog sich in den paritätischen und konfessionellen Beratungsstellen ein Prozeß der Professionalisierung. Zu diesem Zweck verabschiedeten die drei Spitzenverbände 1964 erstmals „Richtlinien für die Anerkennung der Eheberatungsstellen für die Erteilung von Eignungsbestäti-

viele Einrichtungen unter sich gehabt hätten (Rölli-Alkemper, Familie, S. 362). Eine Zählung der DAJEB aus dem Jahr 1954 wies jedoch bereits 87 Einrichtungen allein in ihrer eigenen Trägerschaft aus; darunter befanden sich auch zahlreiche evangelische Einrichtungen. Diese Liste umfaßte jedoch 38 unselbständige Einrichtungen, die vermutlich in dem von katholischer Seite aufgestellten Vergleich nicht berücksichtigt wurden.

35 Vgl. Kapitel II.1., S. 100.

36 Bereits in den fünfziger Jahren fungierte die „Hauptstelle für Familienberatung“ in Düsseldorf als eine landeskirchliche Fachvereinigung im evangelischen Bereich. Vgl. Helene Große Schönepauck, Die Eheberatung (Umfang, Organisation, Erfahrungen, Erfolge) in Deutschland und in anderen Ländern, ohne Datum (1969), S. 8, BAK, B 189/2807. Die „Konferenz für Evangelische Familienberatung“ hieß ab 1964 „Evangelisches Zentralinstitut für Familienfragen“. Vgl. Evangelische Aktionsgemeinschaft für Familienfragen 1953-1966, zusammengestellt von Dr. Gertrud Grohmann, Maschinenschr. Manuskript, EAF-Archiv Bonn.

37 Vgl. Helene Große Schönepauck, Die Eheberatung (Umfang, Organisation, Erfahrungen, Erfolge) in Deutschland und in anderen Ländern, ohne Datum (1969), S. 5, BAK, B 189/ 2807. 
gungen an Eheberater". ${ }^{38}$ Sie sollten den professionellen Standard der Arbeit sichern und den Beruf des Eheberaters auf eine qualifizierte Basis stellen. Früher genügten für die Arbeit als Eheberater „seelische Gesundheit" und die „Fähigkeit, Vertrauen zu gewinnen“, ein „Wohlwollen für den Menschen“, Einfühlungsvermögen, Urteilsfähigkeit und Verschwiegenheit - alles Eigenschaften, die die "Denkschrift über Voraussetzungen sachgemäßer Jugend- und Eheberatung" 1953 als wünschenswerte Charakterzüge für Eheberater formuliert hatte. Fachlich hatten sich die Ausbildungsanforderungen bis 1964 auf eine frühere Berufsausbildung und Berufserfahrung beschränkt. Lediglich ein 14 Abende umfassender Ausbildungskurs hatte die Eheberater auf ihre künftige Arbeit vorbereitet. ${ }^{39}$ Seit dem 1. Januar 1966 mußte dagegen jeder Mitarbeiter einer Eheberatungsstelle eine „Eignungsbestätigung“ des für ihn zuständigen Verbandes vorweisen können. Die Ausbildung zum Eheberater umfaßte nun einen theoretischen Teil, der "Grundwissen in Ehe- und Familienkunde" vermitteln sollte, einen praktischen Teil, in dem die Beratungsarbeit unter Anleitung eines erfahrenen Eheberaters in einer Arbeitsgruppe eingeübt werden sollte, und schloß mit Kolloquien und schriftlichen Prüfungen ab. Die beiden konfessionellen Verbände führten die Ausbildungslehrgänge jeweils in eigener Regie durch. Die katholische wie die evangelische Seite entwickelten dafür einen detaillierten zwei- bzw. zweieinhalbjährigen Ausbildungsplan für Eheberater. ${ }^{40}$

Die beiden konfessionellen Zentralinstitute wandelten sich im Zuge der Professionalisierung von Interessenvertretungen und Diskussionsforen zu Ausbildungsstätten für den neuen Berufszweig des professionellen Eheberaters. Die Finanzierung hierfür trug weitgehend der Bund. Dies war eine der wenigen Möglichkeiten für die Bundesregierung, Zuschüsse an die Familienbildungsverbände zu vergeben, denn Bundesmittel waren prinzipiell an die Auflage gebunden, daß die geförderten Maßnahmen bundesweit wirksam sein mußten. Für die Förderung von einzelnen Beratungsstellen konnte daher kein Geld fließen. ${ }^{41}$

38 Rahmenordnung des Deutschen Arbeitskreises für Ausbildung der Eheberater vom 4. 2. 1964 in der Fassung vom 2.2.1966, abgedruckt in: Informationsrundschreiben der DAJEB, Nr. 74 vom März 1966, S. 14-17. Bereits am 2.3. 1963 hatte der Deutsche Arbeitskreis eine Grundsatzerklärung über "Wesen und Methode der Eheberatung“ veröffentlicht, die im Februar 1966 novelliert wurde.

39 Denkschrift über die Voraussetzungen sachgemäßer Jugend- und Eheberatung (1953), abgedruckt in: Jahresbericht der DAJEB 1953, S. 5, BAK, B 189/2815.

40 Die konfessionellen Verbände regelten die Ausbildungsfragen im Familienbildungsplan, hrsg. von der Arbeitsgemeinschaft für katholische Familienbildung (1967), S. 31-38, und in den Empfehlungen für die evangelische Eheberatung, Rahmenbestimmungen für die Ausbildung vom 5. 11. 1970, BAK, B 189/2809. Die DAJEB, die 1965 nur noch 20 Mitglieder umfaßte, hatte sich schon seit 1959 aus dem Bereich der Ausbildung von Eheberatern zurückgezogen, um sich stärker der Funktion als Fachverband für „Eheberatung auf christlicher Grundlage“ zuzuwenden. Die DAJEB führte daher zwischen 1959 und 1969 nur 5 örtliche Fortbildungslehrgänge durch. Zu den Zahlenangaben für 1965 vgl. Bericht der Bundesregierung über die Situation der Frauen in Beruf, Familie und Gesellschaft vom 14. 9. 1966, S. 32, BT-Drs. 5/909. Die Angaben zum Ausstieg aus dem Ausbildungsbereich nach: Loeffler, Rechenschaftsbericht, S. 8.

41 Helene Große Schönepauck, Die Eheberatung (Umfang, Organisation, Erfahrungen, Er- 
Mit der Professionalisierung des Eheberaters als eigenständiges Berufsbild lösten sich paritätische und konfessionelle Ehe- und Familienberatungsstellen zunehmend aus dem medizinischen Kontext, in dem die Ehe- und Familienberatung seit der Weimarer Zeit gestanden hatte. Der Prozeß zog weitreichende Konsequenzen nach sich, da bisher die Aufklärung über Sexualität und Verhütung vorwiegend bei den Medizinern gelegen hatte, die oft Arzt und Familienberater in einer Person gewesen waren. Im zunehmenden Wettstreit zwischen Ärzten und professionellen Eheberatern spiegelte sich der Zwiespalt zwischen medizinischen und moralischen Aspekten sexueller Beratung.

Seit Mitte der sechziger Jahre kam es zu einem verstärkten Ausbau der konfessionellen Familienberatungsstellen. 1969 existierten in der Bundesrepublik 150 katholische Beratungsstellen, 1971 waren es rund 180; auf evangelischer Seite zählte man 196992 Einrichtungen, 1971 gab es bereits 125.42 Die DAJEB hatte dagegen 1969 nur noch 21 Mitglieder. ${ }^{43}$ Aufgrund der intensiven Kooperation mit den konfessionellen Familienbildungsverbänden im Rahmen des Anfang der sechziger Jahre gegründeten Dachverbandes (Arbeitskreis für Jugend- und Eheberatung) behielt die DAJEB aber trotz ihrer relativ geringen Basis eine einflußreiche Rolle.

Auf katholischer Seite bedeutete der Ausbau gleichzeitig eine Verkirchlichung, denn die neuen Stellen wurden meist von den Diözesen gegründet. Bis Mitte der sechziger Jahre waren hingegen vor allem Laienverbände wie Caritas und Frauenverbände die Träger von katholischen Ehe- und Familienberatungsstellen gewesen. Das erhöhte Engagement der Amtskirche erklärte sich auch aus den Ergebnissen des Zweiten Vatikanischen Konzils. Dort war im Gegensatz zum traditionellen institutionellen Ansatz ein personales Bild der Ehe hervorgehoben worden, das auch eine Beratung einzelner Familienmitglieder ermöglichte. Damit konnte die katholische Amtskirche die Familienbildung, die auf diesem Ansatz basierte, in die Seelsorge integrieren. ${ }^{44}$

Nicht nur quantitativ dominierten die katholischen Einrichtungen die Szenerie, auch konzeptionell versuchten sie sich in der zweiten Hälfte der sechziger Jahre an die Spitze der Diskussion zu stellen. Im Jahr 1965 bildete sich aus katholischen Erwachsenenbildungseinrichtungen, Verbänden und wissenschaftlichen Forschungsinstituten, die in der Familienbildung engagiert waren, die „Arbeitsgemeinschaft katholischer Familienbildung ".45 Wenig später gab die deutsche Bischofskonferenz die Erstellung eines Familienbildungsplanes in Auftrag. Die

folge) in Deutschland und in anderen Ländern, ohne Datum (1969), S. 10, BAK, B 189/ 2807.

42 Daten für 1969 ebenda, S. 5 und 9. Daten für 1971 nach Rölli-Alkemper, Familie, S. 365.

43 Loeffler, Rechenschaftsbericht, S. 8.

44 Vgl. dazu Rölli-Alkemper, Familie, S. 365-367. Der Autor vertritt die These, daß die Durchsetzung des personalen Eheverständnisses in der katholischen Kirche und ihren Organisationen an der Basis bereits in den fünfziger Jahren vollzogen wurde, während die Kirchenspitze erst im Zuge des Zweiten Vatikanischen Konzils zum personalen Eheverständnis fand.

45 Vgl. Vorwort zum Familienbildungsplan, hrsg. von der Arbeitsgemeinschaft für katholische Familienbildung (1967), S. 5. 
frisch gegründete katholische Arbeitsgemeinschaft machte sich sofort an die Arbeit. Die rasche Entwicklung ist vor allem deshalb erstaunlich, weil die diesbezüglichen Verhandlungen im Zweiten Vatikanischen Konzil zu diesem Zeitpunkt noch im Gange waren. Diese Tatsache spricht dafür, daß für die Bildung des neuen katholischen Verbandes, der die Familienbildung in Westdeutschland maßgeblich prägte, nicht das Konzil und seine Ergebnisse, sondern anfangs eine Laienbewegung und zumindest zu einem gewissen Teil auch politische Gründe ausschlaggebend waren. ${ }^{46}$ Als staatliche Stellen mit der gezielten Förderung von $\mathrm{Fa}$ milienbildungseinrichtungen begannen, wollten sich auch die Einrichtungen der katholischen Familienbildung und -beratung ihren Anteil sichern.

Der Familienbildungsplan, den die „Arbeitsgemeinschaft für katholische Familienbildung " 1967 vorlegte, war der erste Plan dieser Art in der Bundesrepublik.47 Er bezog sich auf ehevorbereitende, ehebegleitende und Elternbildungsmaßnahmen. Konkret zielte das Programm darauf, dort einzugreifen, wo familienbezogene Kenntnisse und Verhaltensformen von einer Generation auf die andere nicht in traditioneller Weise weitergegeben wurden. Die Eltern könnten ihren Kindern nicht die notwendigen Fähigkeiten vermitteln, die diese später für eine „zeitgerechte Gestaltung und zukunftsgerichtete Entfaltung " in Ehe und Familie bräuchten, konstatierten die Autoren. Besonders kritisch wurde hier der Bereich der sexuellen Aufklärung gesehen. Aber auch praktische Haushaltsführung sollte gelehrt werden. Durch die Bildungsmaßnahmen sollte die Institution Familie befähigt werden, ihre gesellschaftlichen Funktionen, und hier an erster Stelle die der Kindererziehung, in Zukunft weiterhin und besser zu erfüllen. Hilfe zur Selbsthilfe war dabei das Motto. Man distanzierte sich dadurch von den etatistischen Ansätzen, die die Aufgaben, die die Familie nicht bewältigte, auf gesellschaftliche Institutionen übertragen wollten. Sollten die Bildungsmaßnahmen nicht lediglich vermeintlich althergebrachte Funktionen der Familie in anachronistischer Weise zementieren, dann erhob der Gedanke der katholischen Familienbildung den weitreichenden Anspruch, gesellschaftliche Veränderungen zu erkennen, unterstützend zu begleiten und in eine bestimmte Richtung zu lenken.

Der katholische Familienplan umfaßte ,alle ehe- und familienbezogenen Bildungs- und Erziehungsbemühungen einschließlich der Erziehung und Bildung durch die Familie selbst ${ }^{\text {“ }}{ }^{48}$ Dieser weitgespannte Ansatz integrierte also Kinder-

46 Dies führte allerdings dazu, daß in den katholischen Familienbildungseinrichtungen lange Zeit Ratlosigkeit über den Umgang mit Fragen der Empfängnisverhütung herrschte. Der quantitative Ausbau der katholischen Beratungseinrichtungen in den mittleren sechziger Jahren führte in dieser Frage nicht zu einer Meinungsführerschaft der katholischen Einrichtungen. Erst 1974 entwickelte die katholische Kirche in Deutschland auf der Synode in Würzburg ein den modernen Verhältnissen angepaßtes Leitbild in dieser Frage. Vgl. Rölli-Alkemper, Familie, S. 393-400.

47 Familienbildungsplan, hrsg. von der Arbeitsgemeinschaft für katholische Familienbildung (1967).

48 Rüberg, Ehe- und Familienbildung, S. 10. Rüberg war Vorsitzender des Katholischen Zentralinstituts für Ehe- und Familienfragen in Köln und als Mitglied der Arbeitsgemeinschaft für katholische Familienbildung Mitverfasser des Familienplans. Der weite Begriff der Familienplanung geht maßgeblich auf seinen Vorschlag zurück, vgl. dazu Rüberg, Einheit. 
garten, Schule, Jugendverband, Pfarrei, verschiedene Erwachsenenbildungsinstitutionen und die Familie selbst als Sozialisationsinstanzen. Der Familienbildungsplan gliederte sich systematisch nach Lebensphasen. Innerhalb jedes Bereichs verknüpfte der Plan die Ansätze verschiedener Träger und versuchte, sie zu koordinieren und aufeinander abzustimmen. Beginnend in der Familie, wo die Eltern den Kindern ein gutes Vorbild sein und ihnen möglichst gute Bildungschancen eröffnen sollten, und der Schule, wurde zunehmend das Panorama der außerschulischen Bildungseinrichtungen, die Mädchen ab dem Alter von 15 Jahren, Jungen ab dem 17. Lebensjahr besuchen sollten, ausgebreitet. Den Abschluß der ehevorbereitenden Bildung bildete ein Brautleutekurs. Die anschließende ehebegleitende Bildung sollte eine gute Partnerschaft zwischen den Ehegatten fördern und bildete die zweite Säule des Familienbildungsplans. Auch die Beratung der „alten Ehepaare“, die nach dem Auszug der Kinder wieder allein waren, gehörte dazu. Schließlich war die Elternbildung der dritte Schwerpunkt des Programms. Hier fanden sich auch - allerdings zum Teil mit neuen pädagogischen Inhalten - die klassischen Kurse zur Säuglings- und Kinderpflege, die auch die alten traditionellen Mütterschulen schon im Repertoire gehabt hatten.

1968, also nur ein Jahr später, gaben das katholische Zentralinstitut für Eheund Familienfragen und das evangelische Zentralinstitut für Familienberatung gemeinsam "Grundsatzüberlegungen zu Familienbildung und Familienberatung" heraus. „Ehe- und Familienbildung“, hieß es darin, „läßt sich nur rechtfertigen, wenn sie von Bedürfnissen ausgeht. [...] Ehe- und Familienbildung arbeiten daran, dazu zu befähigen, die eigenen und die Bedürfnisse des Gegenüber zu befriedigen (Kinder, Ehepartner, andere). “49

In diesen Sätzen zeigte sich ein grundlegender Wandel im Selbstverständnis der Familienbildung. Grundsätzlich sind unterschiedliche Positionen gegenüber den gesellschaftlichen Veränderungen denkbar. Vom konservativen Ansatz, die Veränderungen aufzuhalten, über die neutrale, veränderungsbegleitende Haltung bis hin zur Beeinflussung von Veränderungen in bestimmte Richtungen kann die Palette reichen. Versucht man, den katholischen Familienbildungsplan und die ökumenischen Grundsätze zur Familienbildung in diese Skala einzuordnen, dann zeigt sich, daß das Ziel des katholischen Plans von 1967 war, Einfluß auf die gesellschaftlichen Veränderungen zu nehmen, um sie letztlich wieder rückgängig zu machen. Am Ende sollte das christliche Leitbild im Bereich der Sexualität und die unauflösliche Ehe wieder etabliert werden. Die überkonfessionellen Grundsätze von 1968 dagegen betonten die Orientierung an den Bedürfnissen der Menschen. Sie setzten sich mit den problematischen Folgen der Veränderungen auseinander, anstatt diese umkehren zu wollen. Ihr Gestaltungsanspruch trat hinter den veränderungsbegleitenden Charakter zurück.

${ }^{49}$ Grundsatzüberlegungen zu Familienbildung und Familienberatung, hrsg. v. Evangelischen Zentralinstitut für Familienberatung in Berlin in Zusammenarbeit mit dem Katholischen Zentralinstitut für Ehe- und Familienfragen in Köln, abgedruckt in: EHE, 1968, H. 2, S. 66, zitiert nach Duß-v.Werth, Schwerpunkte, S. 5. 


\section{Sexualpädagogik in Zeiten der "Anti-Baby-Pille" und sexueller Revolution}

Diese Entwicklung im Bereich der konfessionellen Träger ist vor dem Hintergrund zu sehen, daß die Fragen der Familienbildung und -beratung durch die 1961 auf dem deutschen Markt erfolgte Einführung der "Antibabypille, „Anovlar“ neue Brisanz erhalten hatten. Kam die Verbreitung zunächst nur zögerlich in Gang, so setzte ab Mitte der sechziger Jahre eine breite Akzeptanz in der bundesdeutschen Bevölkerung ein. ${ }^{50}$

Die Frage der Empfängnisverhürung drängte die klassischen Themen der Familienbildung zunehmend an den Rand. Noch 1959 hatten die Familienbildungsverbände die Kriegsfolgen - Flüchtlingselend, Heimkehrerschicksale, Wohnungsnot und die Folgen der oft übereilten Kriegstrauungen - und die damit verbundenen Belastungen für Ehe und Familie als Hauptaspekt ihrer Arbeit genannt. ${ }^{51}$ In seine 1965 verabschiedeten Leitsätze schloß der Dachverband der deutschen Familienbildungsstätten aber bereits ein grundsätzlich positives Votum für die Empfängnisregelung mit ein: „Empfängnisregelung als Ausdruck verantwortlicher Elternschaft ist ethisch geboten, soweit die physische und psychische Integrität der Person nicht verletzt wird; sie bedarf des Einvernehmens beider Ehepartner." 52 Scharf wandten sich die Leitsätze allerdings gegen weitergehende Eingriffe in die Sexualität wie Sterilisation, Kastration und Schwangerschaftsabbruch.

Zwei verschiedene Handlungsfelder schienen sich hier für die Ehe- und Familienberatungsstellen zu eröffnen: zum einen die Frage der innerfamiliären und schulischen Geschlechtserziehung Jugendlicher und zum anderen die Aufklärung und Beratung in Fragen der Geburtenkontrolle, die hauptsächlich Erwachsene betraf. Vor allem im zweiten Bereich trafen die konfessionellen und paritätischen Träger der Familienbildungsstätten auf einen starken Konkurrenten: die Pro Familia.

Unter dem Vorsitz von Hans Harmsen ${ }^{53}$ wurde 1952 die „Deutsche Gesellschaft für Ehe und Familie", später Pro Familia, die deutsche Tochtergesellschaft der „Planned Parenthood Federation“, gegründet. Sie bildete neben den paritätischen und den konfessionellen Einrichtungen eine dritte Gruppe von bundesdeutschen Familien- und Eheberatungsstellen, die sich in Ansatz und Ziel deutlich von allen anderen Institutionen unterschied. Dem christlichen Begriff der „verantworteten Elternschaft" setzte Pro Familia den der "bewußten Elternschaft" entgegen. ${ }^{54}$ Die „bewußte Elternschaft" umfaßte auch eine gezielte Geburtenpla-

50 Sieg, Anovlar, S. 141. Vgl. dazu auch Dose, Implantation.

51 Antrag der Arbeitsgemeinschaft für Jugend- und Eheberatung, des Katholischen Zentralinstituts für Ehe- und Familienfragen und der Inneren Mission/Hilfswerk der evangelischen Kirche an den Haushaltsausschuß des Deutschen Bundestages auf Einordnung der Jugend-, Ehe- und Familienberatung in die Aufgaben des Bundesministeriums für Familien- und Jugendfragen vom 25. 2. 1959, BAK, B 136/6134.

52 Leitsätze des Deutschen Arbeitskreises Jugend-, Ehe- und Familienberatung zur Verantwortung für Ehe und Familie vom 11. 9. 1965, abgedruckt in: Informationsrundschreiben der DAJEB Nr. 74 vom März 1966, S. 18-20.

53 Zur Biographie Hans Harmsens vgl. Kapitel II.1, S. 99, Fußnote 69.

${ }^{54}$ Schreiben Jochen Fischers an das Sozialamt der Evangelischen Kirche in Westfalen vom 19. 2. 1954 zur Entwicklung von Pro Familia, BAK, B 189/2815. Fischer informierte das 
nung und -kontrolle, was in der Praxis dazu führte, daß in den Beratungsstellen von Pro Familia auch Verhütungsmittel verkauft bzw. ausgegeben wurden. Mit zwei Argumenten warb Pro Familia für Familienplanung: erstens sei der hohen Abtreibungszahl nur durch umfangreiche Propagierung von Verhütungsmitteln zu begegnen, zweitens argumentierte sie neomalthusianisch, daß die Begrenzung der Nahrungsmittel auf der Welt eine Beschränkung der Geburten erfordere.

In Westdeutschland berief sich Pro Familia vor allem auf das Argument der Abtreibungsprophylaxe. Meist waren die Beratungsstellen in Gesundheitsämtern und Frauenkliniken eingerichtet. Die Einbindung der „Ehe- und Sexualberatungsstellen" in öffentliche Einrichtungen gab ihnen einen quasi-amtlichen Charakter. Ihre Mitarbeiter waren überwiegend Ärzte und sie erreichten - im Gegensatz zu Beratungsstellen anderer Träger - eher die Zielgruppe der jungen Menschen, die präventive Beratung suchten..$^{55}$ Pro Familia paßte weder mit ihrem familienplanerischen Leitbild noch mit ihrer Bevorzugung ärztlicher Berater in das ganzheitliche christliche Konzept der übrigen westdeutschen Familienbildung und -beratung. Die DAJEB und die konfessionellen Träger distanzierten sich lange Zeit von den in ihren Augen einseitigen Beratungsmethoden von Pro Familia.

Die in Pro Familia zusammengeschlossenen Institutionen entwickelten sich bis Ende der sechziger Jahre nur langsam und weitgehend unabhängig von den anderen Verbänden. Pro Familia unterhielt anfangs hauptsächlich intensive Kontakte mit ihren ausländischen Schwesterorganisationen und war regelmäßig an bevölkerungspolitischen Kongressen im Ausland beteiligt. In der familienpolitischen Szene in Westdeutschland spielte sie dagegen zunächst eine untergeordnete Rolle, obwohl ihr erster Vorsitzender Hans Harmsen Mitglied im wissenschaftlichen Beirat des Bundesfamilienministeriums war. ${ }^{56}$

1953 zählte Jochen Fischer, der die Entwicklung der Pro Familia kritisch beobachtete, nur in vier westdeutschen Städten derartige Einrichtungen: in Kassel, Berlin, Bremen und Hamburg. ${ }^{57}$ Das Netzwerk der Beratungsstellen wurde erst ab Mitte der sechziger Jahre ausgebaut. Staatlich unterstützt wurde eine selbständige

Sozialamt in dem Schreiben über die „Deutsche Gesellschaft für Ehe und Familie“, die sich inzwischen in „Pro Familia“ umbenannt hatte.

55 Fischer, Formen.

56 Interessant wäre die Frage nach der Rolle von Pro Familia in der Entwicklungspolitik. International war die Dachorganisation Planned-Parenthood-Federation seit ihrer Gründung 1948 in die Entwicklung von Bevölkerungskontrollprogrammen involviert. Vgl. dazu Jütte, Lust, S. $276 \mathrm{f}$.

57 Nach Delille/Grohn gab es auch in Kiel eine Beratungsstelle von Pro Familia. Vgl. dies., Blick, S. 84. Weitere Zahlenangaben nach: Schreiben Jochen Fischers an das Sozialamt der Evangelischen Kirche in Westfalen vom 19.2. 1954 zur Entwicklung der Pro Familia, BAK, B 189/2815 (1954); Bericht der Bundesregierung über die Situation der Frauen in Beruf, Familie und Gesellschaft vom 14. 9. 1966, BT-Drs. 5/909 (1966); Bundesmitgliederversammlung der Pro Familia in München vom 24.-25. 10. 1969, ACDP, I-204-002/2, NL Margarethe Engländer (1968); Ergänzende gesellschaftliche Maßnahmen zur Reform der Strafrechtsvorschriften zum Schwangerschaftsabbruch vom 8. 8. 1973, BAK, B 189/14698 (1973). 
Einrichtung von Pro Familia erstmals 1965 in Berlin. 581966 gab es in der Bundesrepublik in sieben Städten Niederlassungen von Pro Familia, zwei Jahre später waren es bereits 25 Einrichtungen. Bis 1973 erhöhte sich diese Zahl auf etwa 50 Beratungsstellen.

Mit der Nachfrage nach der „Anti-Baby-Pille“ war ab Mitte der sechziger Jahre auch das Interesse an konkreter Information über Empfängnisverhütung gestiegen, die die Einrichtungen von Pro Familia expliziter als alle anderen Träger auf ihre Fahnen geschrieben hatte. Die Konzentration auf Ärzte als Ehe- und Familienberater erwies sich nun als strategischer Vorteil. Da die erste Pille in der Bundesrepublik, „Anovlar", verschreibungspflichtig war, hatten in der Regel Ärzte den ersten Kontakt mit Frauen, die die Pille einnehmen wollten. Im Gegensatz zu anderen Methoden der Verhütung mußte sich das Paar bzw. die Frau, wenn sie die Pille benutzen wollte, zwangsläufig an einen Arzt wenden. An ihn richtete auch der Hersteller von „Anovlar“, die Schering AG, ihr Aufklärungsmaterial.59 Der Ansatz von Pro Familia mit dem Schwerpunkt in der ärztlichen Beratung stand im Einklang mit dem Vorgehen der Schering AG. Die übrigen Familienbildungsverbände wollten ein Beratungsmonopol der Ärzte hingegen nicht akzeptieren, drohte dadurch doch der gerade erst als eigenständigem professionellem Berufszweig etablierten Familien- und Eheberatung das Arbeitsfeld zu entgleiten. Sie forderten daher eine fachübergreifende Kooperation von Medizin, Psychologie, Pädagogik, Soziologie, Rechtswissenschaft, Ethik und Theologie. ${ }^{60}$

Um das Feld nicht allein den Ärzten und Pro Familia zu überlassen, veranstaltete der Dachverband der Familienbildungseinrichtungen unter anderem ab 1967 Klausurtagungen mit bekannten Gynäkologen zum Thema Familienplanung und Empfängnisregulierung. Nicht zuletzt im Rahmen dieser Tagungen entwickelten die konfessionellen und paritätischen Träger ein gewisses "Vertrauensverhältnis“ zu Pro Familia, was schließlich darin mündete, daß Pro Familia im November 1968 in den Dachverband der Familienbildungsstätten, den „Arbeitskreis Jugend-, Ehe- und Familienberatung ", aufgenommen wurde. ${ }^{61}$ Der Dachverband betonte in seiner Stellungnahme dazu, daß „das gemeinsame Ziel konstruktiver Arbeit und Hilfe für Jugend, Ehe und Familie" Pro Familia mit den anderen Familienberatungsstätten verbinde, wenn auch in der Familienplanung einerseits und der Eheberatung andererseits unterschiedliche Schwerpunkte der Arbeit bestünden. ${ }^{62} \mathrm{Zu}$ einer Verstärkung der Kooperation trugen auch die Gesprächsrunden im Bundesfamilienministerium ab 1967 bei, bei denen Pro Familia - auf Drän-

58 Mitteilung des Berliner Senators für Gesundheitswesen an das baden-württembergische Innenministerium vom 6. 2. 1967, BayHStA, MArb VI/275.

59 Sieg, Anovlar, S. 138-140.

60 Leitsätze des Deutschen Arbeitskreises Jugend-, Ehe- und Familienberatung zur Verantwortung für Ehe und Familie vom 11. 9. 1965, abgedruckt in: Informationsrundschreiben der DAJEB Nr. 74 vom März 1966, S. 18-20.

61 Vgl. dazu Loeffler, Rechenschaftsbericht, S. 18.

62 Vgl. Briefwechsel zwischen dem Arbeitskreis Jugend-, Ehe- und Familienberatung und Pro Familia im November 1968, abgedruckt in: Informationsrundschreiben der DAJEB, Nr. 92/93 vom November 1968, S. 48 f. 
gen der sozialdemokratischen Gesundheitsministerin - erstmals gemeinsam mit den übrigen Trägerverbänden an einem politischen Verhandlungstisch saß.63

In der Bundespolitik hatte die Familienbildung und -beratung bis Anfang der sechziger Jahre ein Schattendasein geführt. Traditionell war sie als Teilgebiet der gesundheitlichen Aufklärung dem Gesundheitssektor zugeordnet und daher im Innenministerium verankert. Der entsprechende Haushaltsposten enthielt jedoch jahrelang keine Zuweisungen. Noch 1959 erklärte die zuständige Abteilung des Innenministeriums, es seien in diesem Jahr ebenso wie in den vergangenen Jahren keine Zuschüsse für die Förderung der Jugend-, Ehe- und Familienberatung ausgewiesen worden. ${ }^{64}$ Die Deutsche Arbeitsgemeinschaft für Jugend- und Eheberatung (DAJEB), der paritätische Familienbildungsverband, habe zwar seit 1951 jährlich 5000 bis 6000 DM erhalten, die Unterstützung sei jedoch aus Mitteln zur „Förderung der volksgesundheitlichen Bestrebungen und der Bekämpfung menschlicher Krankheiten" finanziert worden. Angesichts dieser Umstände erhob das Innenministerium auch keine Einwände, als der Posten 1959 dem Familienministerium zugeschlagen wurde. ${ }^{65}$ Erst mit dem Übergang ins Familienressort begann eine systematische Förderung der Familienbildung und -beratung auf Bundesebene. Das Familienministerium stellte für Zuschüsse für Ehe- und Elternberatung 1960 den zehnfachen Betrag der bisherigen Mittel, 50000 DM, in den Haushalt ein. 66

Die Familienbildung bekam nun einen neuen, nicht mehr von einem gesundheitspolitischen Blickwinkel bestimmten Akzent, weil sie in den Kontext der Mütterschulen, die schon länger vom Familienministerium unterstützt wurden, eingeordnet wurde. Die Mütterschulen standen für einen speziellen Teilbereich der Familienbildung, der sich deutlich von der sexualpädagogischen Ausrichtung der Beratungseinrichtungen der DAJEB, die das Innenministerium gefördert hatte, unterschied. In den Kursen der Mütterschulen ging es vor allem um die

${ }^{63}$ Helene Große Schönepauck, Die Eheberatung (Umfang, Organisation, Erfahrungen, Erfolge) in Deutschland und in anderen Ländern, ohne Datum (1969), S. 11, BAK, B 189/ 2807.

64 Schreiben des Bundesinnenministeriums, Abt. Z 6, an den Staatssekretär des Bundeskanzleramtes vom 29. 7. 1959, BAK, B 136/6134. Die Zuordnung zum Gesundheitssektor war darin begründet, daß das Gesetz zur Bekämpfung der Geschlechtskrankheiten aus dem Jahr 1953 in $\$ 15$, Abs. 3 „die Aufklärung und Belehrung der Bevölkerung, insbesondere der älteren Jugend in Schulen, Betrieben und Vereinigungen, über das Geschlechtsleben des Menschen und das Wesen und die Gefahren der Geschlechtskrankheiten“ als Aufgabe der Gesundheitsämter vorsah. Dies schien offenbar der dem sexualpädagogischen Ansatz der DAJEB nächstgelegene Haushaltsposten zu sein.

65 Die Initiative zu dieser Umbuchung ging von den freien Trägerverbänden aus. Vgl. den Antrag der Arbeitsgemeinschaft für Jugend- und Eheberatung, des Katholischen Zentralinstituts für Ehe- und Familienfragen und der Inneren Mission/Hilfswerk der evangelischen Kirche an den Haushaltsausschuß des Deutschen Bundestages auf Einordnung der Jugend-, Ehe- und Familienberatung in die Aufgaben des Bundesministeriums für Familien- und Jugendfragen vom 25. 2. 1959, und Schreiben des Bundesinnenministeriums, Abt. Z 6, an den Staatssekretär des Bundeskanzleramtes vom 29.7. 1959, beide BAK, B 136/6134.

66 Schreiben des Bundesfamilienministeriums an das Bundeskanzleramt vom 10.11. 1959, BAK, B 136/6134. 
Ausbildung von Mädchen und Frauen in hauswirtschaftlicher Praxis und Kindererziehung. Die Vorbereitung auf den „Beruf der Mutter“ war das Ziel der Mütterschulkurse, nicht so sehr die sexualpädagogische Aufklärung.

Schon seit 1957 hatte man im Bundesfamilienministerium eine Möglichkeit gefunden, mit Geldern des Bundesjugendplanes für außerschulische Mädchenbildung auch die Familienbildung zu fördern. Bei wohlwollender Interpretation konnte das dort angestrebte Ziel einer „pädagogischen und wirtschaftlichen Grundausbildung zur Entfaltung der spezifischen Anlagen des Mädchens" auch zugunsten von Familienbildungsmaßnahmen ausgelegt werden. Ein Teil dieser Mittel sollte daher nach dem Willen des Bundesfamilienministers Wuermeling für Eheberatung und Bräutekurse verwendet werden.67

Diese Zuschüsse kamen nur der Mädchenförderung zugute. Das bedeutete eine zweifache Einschränkung: Erstens schloß dieser Ansatz Kurse für junge Männer aus. Der Gedanke, daß auch männliche Jugendliche an die Aufgaben der Familie herangeführt werden müßten, schlug sich nur zögernd nieder. Zwar legte der Aktionsausschuß für Jugendfragen 1959/60 im Rahmen des 10. Bundesjugendplanes ein im Ansatz geschlechtsneutrales Sonderprogramm „Erziehung zu Ehe und Familie" im Umfang von 100000 DM auf. Aber auch zu den Vorverhandlungen über die Vergabe dieser Mittel lud der Familienminister bezeichnenderweise Vertreterinnen der Mütterschulen in sein Haus ein. ${ }^{68}$ Wieder stand also die Mädchenund Frauenbildung im Zentrum. Im Laufe der Gespräche einigten sich die Mütterschulverbände mit dem Familienministerium auf die Zusammenstellung eines „Dozentenprogramms“, wonach der Bund die Personalkosten fester Mitarbeiter der Mütterschulen teilweise übernehmen sollte. ${ }^{69}$

Neben der anfänglichen Konzentration auf Mädchen und Frauen gab es bei der Finanzierung über den Bundesjugendplan eine zweite Einschränkung, die für die Familienbildungseinrichtungen mindestens ebenso gravierend war: Mittel des

$67 \mathrm{Vgl}$. Schreiben des Bundesfamilienministeriums an Anne Marie Heiler mit Informationen für einen Bericht über Sexual Education vor dem Moral Welfare-Ausschuß beim International Council of Women vom 15. 11. 1956, S. 5, BAK, B 189/2933. Die Gelder zur Mädchenförderung im Bundesjugendplan flossen allerdings auch nicht in voller Summe von 1,5 Mio. DM in die Familienbildung. Vielmehr stand wohl nur ein kleiner Teil der Summe hierfür zur Verfügung. Vgl. den Vermerk des Jugendreferenten im Bundesfamilienministerium vom 14.10. 1959 zum Entwurf eines Grußwortes des Ministers anläßlich der 10-Jahresfeier der Deutschen Arbeitsgemeinschaft für Jugend- und Eheberatung in Detmold am 30. 10. 1959, BAK, B 189/2815.

68 Vermerk vom 14. 3. 1961 über die Besprechung mit Vertretern der Mütterschulverbände am 22. 2. $1961 \mathrm{im}$ Bundesfamilienministerium, BAK, B 189/2870. Die Gespräche und Vorbereitungsarbeiten für ein Anlaufen des Programms wurden mehrfach zurückgestellt, weil sich die Staatssekretärin Gabriele Wülker dafür aussprach, die Ergebnisse eines Forschungsprojektes abzuwarten, dessen Abschluß sich immer wieder verzögerte. Erst nach dem Ausscheiden der Staatssekretärin wurden die Vorbereitungen für das Programm verstärkt. Vermerk des Jugendreferenten im Bundesfamilienministerium vom 14. 10. 1959 zum Entwurf eines Grußwortes des Ministers anläßlich der 10-Jahresfeier der Deutschen Arbeitsgemeinschaft für Jugend- und Eheberatung in Detmold am 30.10. 1959, BAK, B $189 / 2815$.

69 Vermerk vom 14. 3. 1961 über die Besprechung mit Vertretern der Mütterschulverbände am 22. 2. 1961 im Bundesfamilienministerium, BAK, B 189/2870. 
Bundesjugendplans konnten nur für Maßnahmen verwendet werden, deren Zielgruppe unter 25 Jahre alt war. Die Hauptklientel von Mütterschulen und Familienbildungseinrichtungen war jedoch in zunehmendem Maße älter. ${ }^{70}$ Erst als Anfang der sechziger Jahre der reguläre Haushaltsposten für Familienbildungsmaßnahmen vom Innenministerium ins Familienministerium übergegangen war, erhielt die Familienabteilung dadurch eigene Mittel, die altersunabhängig vergeben werden konnten. Mit diesem Geld förderte das Familienministerium nun ähnlich wie im „Dozentenprogramm" des Bundesjugendplans die Aus- und Fortbildung der Mitarbeiter der Trägerverbände der Familienbildung. 1960 standen aus dem Sonderprogramm des Bundesjugendplans und dem regulären Haushaltsposten insgesamt 150000 DM für Familienbildung im Bundesetat zur Verfügung. Bis Anfang der siebziger Jahre stieg diese Summe relativ kontinuierlich auf fast das Fünfzehnfache (2,1 Mio. DM). ${ }^{71}$

Im Bundesfamilienministerium rangierte das Thema Familienbildung bis Mitte der sechziger Jahre am unteren Ende der Prioritätenliste. Auch Bruno Heck, seit 1962 Familienminister, stellte zunächst wie sein Vorgänger die wirtschaftlichen Familienhilfen in den Mittelpunkt seiner Arbeit. ${ }^{72}$ Das änderte sich jedoch nach der Einführung des Zweitkindergeldes und der Übernahme des Kindergeldes in den Bundeshaushalt. Die Reform des Familienlastenausgleichs - das bis dahin wichtigste Projekt der Bundesfamilienpolitik - schien damit 1964 zu einem gewissen Abschluß gekommen zu sein. Das Bundesfamilienministerium wandte sich nun verstärkt anderen Themen zu. Zum neuen Arbeitsschwerpunkt erklärte Bruno Heck 1965 die „Stärkung der Erziehungskraft" der Familie. „Nachdem wir in den letzten Jahren unser Augenmerk vor allem auf die materielle Sicherung der Familie gerichtet haben," erklärte Heck 1965 auf der Jahrestagung der DAJEB, „werden wir nunmehr die Stärkung ihrer Erziehungskraft als das Hauptziel der familienpolitischen Bemühungen ansehen. Denn nur, wenn materielle Hilfsmaßnahmen und geistige und persönliche Hilfen sich sinnvoll ergänzen, können sie sich für das Leben der Familie voll auswirken. "73 Zeitgemäße Familienpolitik, er-

70 Datenreihen über die Sozial- und Altersstruktur der Ratsuchenden liegen allerdings nur für die paritätischen Mütterschulen vor. Demnach stieg der Anteil der Verheirateten und der über 25jährigen bis Mitte der siebziger Jahre an. Schymroch, Mütterschule, S. 69. Vgl. dazu auch S. 260.

71 Schreiben von Helene Große Schönepauck an das Bundespräsidialamt vom 21. 3. 1972, BAK, B 189/2809. Die Gespräche mit den Mütterschulvertretern wurden seitens des Bundesfamilienministeriums von der Oberregierungsrätin Helene Große Schönepauck geführt, die das Referat für Ehe-, Familien- und Erbrecht, Ehe- und Elternberatung, Mutterschutz, Frauenfragen und Familienerholung leitete. Die Juristin Große Schönepauck war seit der Gründungszeit des Ministeriums Leiterin dieses Referats des Bundesfamilienministeriums und blieb während des ganzen Untersuchungszeitraums für Fragen der Familienbildung zuständig. Vgl. Geschäftsverteilungspläne des Bundesfamilienministeriums bis 1974, BAK, B 153/B 189.

72 Vgl. Bruno Heck auf dem Parteitag der CDU in Nord-Württemberg im März 1963. Diese Äußerungen waren die ersten grundsätzlichen Stellungnahmen Hecks nach seiner Amtsübernahme. Vgl. dazu auch Heck, Zukunft, S. 1703-1705; ders., Flickwerk, S. 18.

73 Bruno Heck in seinem Grußwort an die Jahrestagung der DAJEB vom 27.-29. 5. 1965, BAK, B 189/2815. 
klärte er an anderer Stelle, dürfe sich nicht darin erschöpfen, die wirtschaftliche und soziale Situation der Familie zu verbessern und den Familienlastenausgleich zu fördern. Sie müsse die Kirchen und die zur Hilfe bereiten Kräfte der Gesellschaft auffordern und unterstützen, das ihre zu tun, um den Eltern das Rüstzeug zu vermitteln, das diese bräuchten, um ihren vielfältigen Aufgaben bei der Erziehung der Kinder, bei der Vorbereitung der Jugend auf Ehe und Familie und bei einer partnerschaftlichen Gestaltung ihrer Ehe gewachsen zu sein. ${ }^{74}$ Damit eröffnete Heck das erste auf Bundesebene allein im Familienressort verankerte Handlungsfeld der Familienpolitik.

Mehrere Aspekte trugen zur Konjunktur dieses Themas bei. Einmal lag der Auf- und Ausbau eines Netzes an Beratungsstellen im sozialpolitischen Zeitgeist. Außerdem stieg seit Anfang der sechziger Jahre die Verunsicherung in Familienfragen, und damit gewann die Beratung durch Mütterschulen und vor allem durch sexualpädagogische Ehe- und Familienberatungsstellen an Bedeutung. Gleichzeitig hatten, wie oben dargelegt, die Beratungsstellen, die sich vor allem mit Aufklärung und Familienplanung befaßten, einen quantitativen Ausbau und einen qualitativen Professionalisierungsschub erfahren, wozu in nicht unerheblichem Maß die zunehmende Verbreitung der "Pille“ beigetragen hatte. Ein vierter, politikstrategischer Aspekt kam hinzu: Mit der stärkeren Betonung sexueller Probleme näherte sich die Familienberatung wieder dem Gesundheitssektor an, so daß hier eine Aufsplitterung drohte, die die traditionelle Mütter- und Familienbildung in den Familienbereich, die Sexualpädagogik in den Gesundheitsbereich verlagert hätte. Dieser Ressortkonflikt brach verstärkt nach der Bildung der Großen Koalition 1966 auf. Wie bereits oben ausführlich dargestellt, vertraten nun Gesundheits- und Familienministerium aufgrund der verschiedenen parteipolitischen Besetzung unterschiedliche ideologische Konzepte. ${ }^{75}$ Auch aus diesem Grund war es nicht anders zu erwarten, als daß Heck versuchte, den gesamten Bereich der Familienbildung und -beratung als Einheit in seiner Kontrolle zu behalten.

Die sexualpädagogischen Beratungseinrichtungen waren zu dieser Zeit nicht leicht als solche zu identifizieren. In der Bundesrepublik war inzwischen ein bunter Flickenteppich an Einrichtungen entstanden: Mütterschulen, Eheberatungsstellen, sexualpädagogische Aufklärungsbüros, Mütterheime, Erziehungsberatungsstellen, Familienbildungsstätten und zahllose ähnliche Institutionen bei Kirchengemeinden, Kommunalämtern, Kliniken und Verbandshäusern boten in Fragen der Ehe, Familie und Sexualität ihre Hilfe an. Die Grenzen waren fließend. Mit zunehmender Bedeutung dieses Bereichs stellte die unübersichtliche Trägerlandschaft nicht nur für die Ratsuchenden, sondern auch für die Träger selbst ein erhebliches Problem dar. In einer Handreichung klagte beispielsweise der Familienbund der deutschen Katholiken, das Vielerlei der augenblicklichen Formen mache Sorge. Die gleichen Begriffe würden für völlig verschiedene Aktivitäten angewandt. Notwendig sei eine Absprache über die Bezeichnung der Institutionen

${ }^{74}$ Familienbildung und Familienberatung - Schwerpunkte deutscher Familienpolitik, Referat von Bruno Heck vor der Evangelischen Aktionsgemeinschaft für Familienfragen am 18. 10. 1966 in Hannover, Maschinenschr. Manuskript, S. 1 f., FDK/Berlin, Ordner EAF. 75 Vgl. Kapitel II.1., S. $96 \mathrm{f}$. 
und Methoden. ${ }^{76}$ Nicht zuletzt waren aufgrund der Undurchsichtigkeit in diesem Bereich kaum staatliche Fördermittel zu bekommen. Bereits im Frühjahr 1965 hatte Familienminister Bruno Heck auf katholischer Seite angefragt, an welche Stelle er sich für die Vergabe von Fördermitteln für familienpädagogische Maßnahmen eigentlich wenden müsse. ${ }^{77}$

Neben den verschiedenen Beratungseinrichtungen hielten sich auch andere Institutionen und Gruppen für den Bereich der Sexualpädagogik zuständig. Wer sollte die Jugendlichen über sexuelle Fragen aufklären: das Elternhaus, die Schule, eine sexualpädagogische Beratungsstelle oder vielleicht sogar der anonyme Kummerkasten einer Jugendzeitschrift? Wo konnten sich Erwachsene über Verhütungsmethoden informieren: beim Arzt, beim Pfarrer, in Eheberatungsstellen oder vielleicht in einem Kino-Aufklärungsfilm? Neben der Frage der finanziellen Förderung war hier ein Regelungsbedarf entstanden, um unterschiedliche Formen der Familienbildung und -beratung klarer zu trennen, Seriöses von Unseriösem zu unterscheiden und den Einrichtungen jeweils spezifische Aufgabenbereiche zuzuweisen.

Ein Gremium, das sich für die Diskussion über diese Fragen anbot, war der Beirat beim Familienministerium. In einer Besprechung vereinbarten die Familienbildungsträger und der Minister, daß die Familienbildungsverbände Beobachter in die Sitzungen des Beirats entsenden sollten. Als der Ministerialbeamte Max Wingen diesen Wunsch im Dezember 1965 dem Beirat vortrug, lehnten die Beiratsmitglieder dies jedoch rundweg ab. Der Beirat sei ein wissenschaftliches Gremium, dem keine Organisationsvertreter angehören sollten, erklärten sie. ${ }^{78} \mathrm{Hier}$ zeigte sich, daß das Verfahren, ein politisches Thema im Beirat zur Sprache zu bringen, indem der Minister Verbandsvertretern als informellen Teilnehmern im Gremium das Wort erteilte, Mitte der sechziger Jahre offenbar nicht mehr funktionierte. Wollte man ein neues Thema auf die Agenda des Beirats setzen, mußte die Autonomie der dort versammelten Wissenschaftler zumindest nach außen hin gewahrt bleiben. Heck ging daher bei seinem zweiten Versuch einen anderen Weg: In der nächsten Beiratssitzung im März 1966 stand ein Fachreferat von Franz Pöggeler von der Bundesarbeitsgemeinschaft für katholische Erwachsenenbildung auf der Tagesordnung. Pöggeler, der die Zusammenhangslosigkeit der diversen Institutionen und Aktivitäten der Familienbildung beklagte und vom Staat eine Art Vermittlerrolle forderte, traf nun bei den Beiratsmitgliedern auf offene Ohren. ${ }^{79}$ Angeregt durch die anschließende Diskussion, beschloß der Beirat die Bildung einer „kleinen Kommission“ zum Thema Familienbildung. ${ }^{80}$

76 Wüst, Erziehungskraft, S. 37.

77 Rölli-Alkemper, Familie, S. 391.

78 Ergebnisprotokoll vom 16.12. 1965 über die Sitzung des Wissenschaftlichen Beirats für Familienfragen beim Bundesministerium für Familie und Jugend am 30.11. 1965, S. 15, BAK, B 153/683.

79 Franz Pöggeler: Familienbildung in einem demokratischen Bildungswesen. Vortrag vor dem Wissenschaftlichen Beirat für Familienfragen am 17.3. 1966, Anlage zum Ergebnisprotokoll der Sitzung des Wissenschaftlichen Beirats vom 17.3. 1966, BAK, B 153/704.

80 Mitglieder der Kommission waren Ludwig Neundörfer, Jakob David, Josepha FischerErling und als beiratsfremde Teilnehmer Franz Pöggeler (Bundesarbeitsgemeinschaft für 
So war es im zweiten Anlauf doch noch gelungen, den Beirat für das Thema zu begeistern. Aus dem ungeschickten Verfahren des Bundesfamilienministers, der Meinung der Verbandsvertreter im wissenschaftlichen Beirat Gehör zu verschaffen, spricht auch die unklare Vorstellung Bruno Hecks von der Arbeit und Funktion des Beirats im politischen Prozeß. Letztlich suchte Heck weniger wissenschaftliche Information als vielmehr, wie schon sein Vorgänger Wuermeling, einen Platz für Gespräche im vorparlamentarischen Raum. Daß der Beirat seit der Reform von 1959 hierfür der falsche Ort war, hatte sich nun deutlich gezeigt. Daraufhin ging der Bundesfamilienminister neue institutionelle Wege: Er installierte in seinem Ministerium quasi einen zweiten, verbandlichen Beirat.

Im Juni 1967 lud Bruno Heck die Trägerverbände der Familienbildungseinrichtungen zu einer ersten „Gesprächsrunde zu Fragen der Familienbildung und Familienplanung" ein. Unter den Teilnehmern der Gesprächsrunde befanden sich nicht nur die Vertreter der Familienbildungsverbände einschließlich Pro Familia, sondern auch ein Mitglied des Volkshochschulverbandes und der Staatssekretär im Bundesgesundheitsministerium, Ludwig von Manger-König. ${ }^{81}$ Die Anwesenheit des Staatssekretärs aus dem Gesundheitsministerium verweist noch einmal darauf, daß auch das Gesundheitsressort hier Ansprüche erhob, die Integration von Pro Familia war ebenfalls seitens des Gesundheitsministeriums befördert worden. ${ }^{82}$ In der Vielfalt der beteiligten Gruppen an den Gesprächsrunden mit Trägern der Familienbildung und Familienplanung im Bundesfamilienministerium spiegelt sich, wie unscharf der landläufige Begriff von eben dieser Familienbildung und -planung war. Das Verdienst der familienpädagogischen Gespräche, die zwischen 1967 und 1969 im Bundesfamilienministerium stattfanden, ${ }^{83}$ lag daher vor allem darin, die verschiedenen Bereiche, die bis dahin recht konturlos

katholische Erwachsenenbildung) und Liselotte Nold (evangelische Arbeitsgemeinschaft für Mütterschulung). Vgl. Ergebnisprotokoll der Sitzung des Wissenschaftlichen Beirats für Familienfragen beim Bundesministerium für Familie und Jugend am 17. 3. 1966, S. 10, $\mathrm{BAK}, \mathrm{B} 153 / 704$. In der nächsten Zeit waren die Beratungen des Beirats allerdings vor allem durch Vorarbeiten für den ersten Bundesfamilienbericht und die turbulenten Planungen für eine Reform des Familienlastenausgleichs dominiert. Da für die Folgezeit bisher keine Protokolle der Beiratssitzungen gefunden werden konnten und die Kommission in den übrigen Fachakten bisher nicht gefunden wurde, konnte das weitere Schicksal der Kommission leider nicht erhellt werden.

81 Erstes Gespräch mit Trägern der Familienbildung und Familienplanung im Bundesfamilienministerium vom 27.6. 1967, BAK, B 189/2816. Vgl. auch den Bericht über das erste Gespräch in: Informationen des Bundesministeriums für Familie und Jugend, Nr. 10/1967 vom 4. 10. 1967.

82 Schreiben von Käte Strobel an Bruno Heck vom 21. 4. 1967, BAK, B 189/2816.

83 Die letzte Sitzung scheint am 28. 5. 1969 im Bundesfamilienministerium stattgefunden zu haben. Zu dieser Sitzung finden sich leider keine Unterlagen in den Akten des Bundesfamilienministeriums. Die Jahresberichte der DAJEB berichten aber zu diesem Zeitpunkt ein letztes Mal von einem solchen Treffen. Vgl. Informationsrundschreiben der DAJEB, Nr. 105/106 vom Dezember 1970, S. 32-38, S. 34. Für 1970 werden an derselben Stelle des Jahresberichtes die fünf Arbeitsgruppen im Bundesfamilienministerium genannt, die familienpolitische Grundsatzthesen entwickeln sollten. Sie sind wohl aus den Besprechungen hervorgegangen. $\mathrm{Zu}$ den Arbeitsgruppen entsandte die DAJEB ebenfalls Vertreter. Vgl. Kapitel II.1., S. $111 \mathrm{f}$. 
unter der Bezeichnung Familienbildung subsumiert worden waren, begrifflich und in der Folge auch organisatorisch klarer zu trennen. Unterschieden wurde nun zwischen Gesundheitserziehung (1), Geschlechtserziehung (2), Familienberatung (3) und Familienplanung (4). ${ }^{84}$ Während für die Gesundheitserziehung das Gesundheitsministerium verantwortlich sein sollte, waren für die Geschlechtserziehung - zumindest was den Sexualkundeunterricht in den Schulen betraf - vor allem die Länder zuständig. Für das Familienministerium blieben daher nur die Bereiche Familienberatung und Familienplanung. In diesem begrifflichen und organisatorischen Koordinatensystem mußten die Familienbildungsverbände ihre Position bestimmen. Schon bald zeigte sich, daß für eine effiziente Interessenvertretung die Gesprächsrunde im Bundesfamilienministerium kein besonders günstiger Ort war.

Das wichtigste Thema der Konferenzen mit Trägern der Familienbildung im Bundesfamilienministerium war die Geschlechtserziehung. ${ }^{85}$ Dieser Bereich umfaßte zum einen die Aufklärung im Elternhaus und zum zweiten den Aufklärungsunterricht in der Schule. In beiden Bereichen sahen die Familienbildungsstätten Aufgaben für sich: bei der Beratung der Eltern, wie sie ihre Kinder an sexuelle Fragen heranführen sollten, aber auch was den Schulunterricht betraf, nahmen die Familienbildungsstätten eine wichtige Rolle für sich in Anspruch. Sie boten sich hier in verschiedenen Schlüsselpositionen als Vermittler an, etwa zwischen Schule und Elternhaus sowie bei der Fortbildung der Lehrer. Fragen der schulischen Geschlechtserziehung fielen aber wie erwähnt schwerpunktmäßig in die Länderkompetenz, und die Kultusministerkonferenz kam schließlich einer Initiative der Gesprächsrunde zuvor.

Am 3. Oktober 1968 verabschiedete die Kultusministerkonferenz, die sich bereits seit Mitte der sechziger Jahre mit dieser Frage beschäftigte, Richtlinien zur Sexualerziehung. ${ }^{86}$ Diese Richtlinien der Kultusminister führten Sexualkunde als Unterrichtsfach ein und legten inhaltliche Rahmenvorgaben fest. Bereits im ersten Schuljahr sollten Kinder den Unterschied zwischen den Geschlechtern kennenlernen und über die Mutterschaft „Bescheid wissen“. Bis zur sechsten Klasse standen die biologischen "Grundtatsachen“ der Fortpflanzung, Menstruation, Pollution und Fragen der Pubertät auf dem Programm. In der neunten und zehnten Klasse sollten neben Zeugung, Schwangerschaft und Geburt auch das gegenseitige soziale Verhalten der Geschlechter, soziale und rechtliche Grundlagen des Familienlebens sowie sozialethische und strafrechtliche Probleme behandelt werden hierunter fiel neben Promiskuität, Prostitution, Homosexualität, Vergewaltigung, Abtreibung, Kuppelei, Verbreiten von Geschlechtskrankheiten und Triebverbrechen auch die Empfängnisverhütung. Der Kanon verteilte sich über den Biolo-

84 Vgl. Tagesordnung für das dritte Gespräch der auf dem Gebiet der Familienberatung tätigen Verbände am 22.1. 1968, BAK, B 189/2816.

85 Vgl. Beantwortung der Großen Anfrage der Abgeordneten Kühn, Stingl, Frau Schroeder, Dr. Jungmann, Adorno und der Fraktion der CDU/CSU betr. Situation der Kinder in der BRD vom 30. 11. 1967, BT-Drs. 5/2441.

86 Empfehlungen zur Sexualerziehung in den Schulen. Beschluß der Kultusministerkonferenz vom 3. 10. 1968, abgedruckt in: Informationsrundschreiben der DAJEB, Nr. 98/99 vom August 1969, S. 20-24. 
gieunterricht, die Sozial- und Gemeinschaftskunde, den Religionsunterricht und, soweit vorhanden, Unterrichtsgebiete wie Gesundheitslehre, Familienhauswesen, Säuglingspflege und Kindererziehung.

Die Empfehlungen des familienpädagogischen Arbeitskreises zu dem Thema waren nur einen Tag vor dem Beschluß der Richtlinien der Kultusminister, am 2. Oktober, verabschiedet worden und sie erreichten die Kultusminister nicht mehr rechtzeitig. ${ }^{87}$ Die Vorschläge des familienpädagogischen Arbeitskreises flossen daher in die Empfehlungen der Kultusministerkonferenz nicht ein. Der Beschluß der Kultusministerkonferenz regelte auch die Frage der Vorbereitung der Lehrer auf die neuen Fächer innerhalb der Lehreraus- und -fortbildung. Hier hatten die Familienbildungsstätten mit ihren Richtlinien versucht, einen Fuß in die Tür zu stellen. In den Richtlinien der Kultusministerkonferenz spiegelten sich aber nur ältere Vorschläge der Familienbildungsverbände über die inhaltliche Ausgestaltung des Aufklärungsunterrichts.

Die Vertreterin des Familienministeriums Große Schönepauck selbst regte angesichts dieses Mißerfolges an, ob es nicht günstiger sei, den Arbeitskreis an anderer Stelle als beim Bund zu institutionalisieren. Zumindest für die zukünftige Arbeit sei es wichtig, Einfluß auf die Ausgestaltung der Richtlinien, die nun in der Hand der Länder liege, zu nehmen. ${ }^{88}$ In Nordrhein-Westfalen beispielsweise hatte schon im Mai 1968 ein Arbeitskreis für Ehe- und Familienberatung seine Arbeit aufgenommen. ${ }^{89} \mathrm{Im}$ Dezember 1968 begann auch in Bayern ein solcher Arbeitskreis mit Gesprächen. ${ }^{90}$ Auch der bayerische Landesbeirat für Familienfragen beschäftigte sich Anfang der siebziger Jahre mit dem Problemkreis. ${ }^{91}$ An den Gesprächen im Bundesfamilienministerium waren die traditionellen Familienverbände dagegen bis 1970 nicht beteiligt. ${ }^{92}$

87 Arbeitskreis für Geschlechtererziehung und Familienplanung beim Bundesministerium für Familie und Jugend: Rahmenrichtlinien zur Geschlechtererziehung in der Schule vom 2. 10. 1968, Anlage zum 5. Gespräch über Grundfragen der Geschlechtererziehung und Familienplanung im Bundesfamilienministerium vorn 2. 10. 1968, BAK, B 189/2819.

88 Schreiben von Helene Große Schönepauck, Bundesfamilienministerium, an die Teilnehmer der Gespräche mit Trägern der Familienbildung und Familienplanung vom 12. 11. 1968, BAK, B 189/2819.

89 Bericht über die Mitgliederversammlung der DAJEB auf der Jahrestagung am 17. 5. 1969 in Detmold, in: Informationsrundschreiben der DAJEB, Nr. 100/101/102 vom Dezember 1969, S. 65-72, S. 67.

90 Mitglieder des bayerischen Arbeitskreises waren nur Vertreter konfessioneller Verbände. Vgl. Schreiben des Gründungsvorsitzenden Helmut Harsch an das bayerische Innenministerium vom 14. 6. 1969, BayHStA, MArb 3238.

91 Vermerk über die Sitzung des Landesbeirats vom 26.1. 1967; Resolution des Landesbeirats vom 17. 11. 1967, beides BayHStA, MArb 3231; Vermerk vom 31. 8. 1972 über die Sitzung des Landesbeirats für Familienfragen am 21.7. 1972, BayHStA, MArb 3230; auch in Niedersachsen und Hamburg existierten Ende der sechziger Jahre Landesarbeitsgemeinschaften. Vgl. Helene Große Schönepauck, Die Eheberatung (Umfang, Organisation, Erfahrungen, Erfolge) in Deutschland und in anderen Ländern, ohne Datum (1969), S. 5, BAK, B 189/2807.

92 Das hatte wohl vor allem zwei Gründe. Zum einen leisteten die Familienverbände im Gegensatz zu den Familienbildungsstätten keine konkrete soziale Arbeit, sondern waren nur Interessenvertreter. In den Gesprächen ging es aber um eine verbesserte Koordination der praktischen Arbeit der Familienbildungsstätten. Zum anderen nahmen, wie weiter oben 
Ein zweites Debakel der Gesprächsrunde im Bundesfamilienministerium ließ nicht lange auf sich warten. Kurz nach dem Scheitern der Einflußnahme auf die Sexualkunde-Richtlinien traf in der familienpädagogischen Gesprächsrunde die Nachricht ein, daß die Bundeszentrale für gesundheitliche Aufklärung in Zusammenarbeit mit der Kultusministerkonferenz einen stark biologisch ausgerichteten "Sexualkunde-Atlas" für den Aufklärungsunterricht in den Schulen herauszugeben plane. ${ }^{93}$ Noch im April 1967 hatte Familienminister Bruno Heck an seine sozialdemokratische Kollegin im Gesundheitsministerium Käte Strobel geschrieben, daß die Familienberatung seiner Ansicht nach zu den Aufgaben des Familienministeriums gehöre, und daß Aufklärungsfragen in erster Linie unter dem Gesichtspunkt der Familienberatung zu beurteilen seien. ${ }^{94}$ Diese Feststellung richtete sich vor allem gegen den von Strobel geplanten Arbeitsschwerpunkt „Sexualpädagogik und Familienplanung", der im Rahmen der damals gerade neu zu errichtenden Bundeszentrale für gesundheitliche Aufklärung verfolgt werden sollte. Im Dezember 1967 hieß es jedoch in einem Exposé des Bundesgesundheitsministeriums, die vier Komplexe Familienberatung, Empfängnisregelung, Geschlechtererziehung und Gesundheitserziehung müßten als eine Einheit verstanden werden. ${ }^{95}$ Dies interpretierte man im Familienministerium als Angebot zur künftigen Kooperation. Mit einem Alleingang seitens des Gesundheitsministeriums hatte danach offenbar niemand mehr gerechnet. An den Sitzungen des familienpädagogischen Arbeitskreises im Familienministerium hatten auch Vertreter des Gesundheitsministeriums teilgenommen, ohne die eigenen Pläne zu einem Buch über sexuelle Aufklärung zu erwähnen. Als im Januar 1969 das Bundesfamilienministerium aus Pressemeldungen erfuhr, daß in der Bundeszentrale für gesundheitliche Aufklärung das Projekt des "Sexualkunde-Atlas“ kurz vor dem Abschluß stünde, beanspruchte es als federführendes Ministerium zumindest eine Beteiligung am weiteren Verfahren.96

erwähnt, die Familienverbände die Familienbildung nur zögernd als politisches Handlungsfeld wahr.

93 Schreiben des Staatssekretärs im Bundesfamilienministerium, Heinrich Barth, an das Bundesgesundheitsministerium vom 29.1. 1969, nach: Warum wurde das Familien- und Jugendministerium ausgeschaltet? Sonderbare Praktiken bei der Entstehung des Sexualkundeatlasses, in: Stimme der Familie, 16 (1969), Nr. 7/8, S. 57. Bei dem Artikel handelt es sich um eine gekürzte Stellungnahme des Bundesfamilienministeriums.

94 Vermerk Staatssekretär Heinrich Barth vom 7. 4. 1967 über ein Schreiben Bruno Hecks an Käte Strobel, BAK, B 189/2816.

95 Exposé zu Fragen der Familienberatung, der Empfängnisregelung, der Geschlechtererziehung und der Gesundheitserziehung von Bernhard E. Zoller, Bundesgesundheitsministerium, vom 23. 12. 1967, BAK, B 189/2816. Seit der Antwort des Familienministers auf die Große Anfrage zur Situation der Kinder in der BRD vom 30. 11. 1967, BT-Drs. 5/2441, beanspruchte das Bundesfamilienministerium in Grundsatzfragen der Geschlechtererziehung die Federführung. Vgl. Schreiben des Staatssekretärs im Bundesfamilienministerium, Heinrich Barth, an das Bundesgesundheitsministerium vom 29.1. 1969, nach: Warum wurde das Familien- und Jugendministerium ausgeschaltet? Sonderbare Praktiken bei der Entstehung des Sexualkundeatlasses, in: Stimme der Familie, 16 (1969), Nr. 7/8, S. 57.

96 Zum Konflikt zwischen Gesundheits- und Familienministerium vgl. die Darstellung im Schreiben des Bundesfamilienministeriums an den FDK zum Sexualkundeatlas ohne Datum, Abschrift, FDK/Berlin, Ordner AKF 1966-1973. 
Außesplanmäßig wurde das Thema sofort auf die Tagesordnung des nächsten Gesprächs des Arbeitskreises für Familienbildung im Familienministerium am 12. März 1969 gesetzt. In der Sitzung wandten sich aber die Vertreter des Gesundheitsministeriums gegen Ergänzungen und Änderungen, die die Herausgabe des Buches verzögern würden. Auch ein persönlicher Appell der christdemokratischen Familienministerin Aenne Brauksiepe an ihre sozialdemokratische Kollegin Käte Strobel, in dem sie darum bat, Passagen über sozial-ethische und anthropologische Aspekte einzufügen, brachte keinen Erfolg. ${ }^{97}$ Am 29. Mai durften Vertreter des familienpädagogischen Arbeitskreises immerhin an einer Sitzung der ständigen Kommission der Ländervertreter bei der Bundeszentrale für gesundheitliche Aufklärung teilnehmen, die über den vorläufigen Entwurf des „Sexualkunde-Atlas", der ihnen seit zehn Tagen vorlag, diskutierten. Die Ländervertreter zeigten jedoch kein Interesse an einer konstruktiven Beteiligung von Bundesgremien, sei es des familienpädagogischen Arbeitskreises oder des Familienministeriums selbst, auch wenn sie inhaltlich ähnliche Vorbehalte gegen die einseitige biologische Grundrichtung des "Sexualkunde-Atlas" hatten.98 Änderungen waren nun im Grunde auch nicht mehr möglich. Die Zeit drängte, denn die Wahlen zum Bundestag, für die sich die SPD durch das Projekt familienpolitisch profilieren wollte, standen im Herbst bevor.

Am 12. Juni 1969 präsentierte Käte Strobel den „Sexualkunde-Atlas“ der Öffentlichkeit. Erst nach der Pressekonferenz erhielt das Bundesfamilienministerium ein Exemplar zugesandt. Der Affront war enorm. Daran konnte auch die Kritik einiger Länder wenig ändern, die eine Einführung des „Sexualkunde-Atlas“ in ihren Schulen ablehnten. ${ }^{99}$ Familienministerin Aenne Brauksiepe war es nicht gelungen, ihre sachliche Zuständigkeit für die Geschlechtserziehung einzufordern. Auch der familienpädagogische Arbeitskreis im Bundesfamilienministerium war nun bereits zum zweiten Mal vor den Kopf gestoßen worden. Und zum zweiten Mal war deutlich geworden, daß die Länder und die Kultusministerkonferenz sich dem Bundesfamilienministerium und seinen Gremien nicht unterordnen würden. Sie hatten die seit Jahren über das Thema beratende Gesprächsrunde zur Geschlechtererziehung einfach übergangen.

Angesichts der komplizierten Kompetenzverteilung zwischen Bund, Ländern und freien Trägern verwundert es nicht, daß sich auch das föderative politische Koordinationsgremium, die Konferenz der familienpolitischen Referenten der Länder, Ende der sechziger Jahre mit dem Sektor der Familienbildung und -beratung befaßte. ${ }^{100}$ Konkreter Anlaß für die Beschäftigung mit dem Thema war ein

97 Gespräch zwischen Aenne Brauksiepe und Käte Strobel vom 30.4. 1969, nach: Warum wurde das Familien- und Jugendministerium ausgeschaltet? Sonderbare Praktiken bei der Entstehung des Sexualkundeatlasses, in: Stimme der Familie, 16 (1969), Nr. 7/8, S. 57.

98 Vgl. dazu den Bericht über den Verlauf der Sitzung der Länderkommission in: Warum wurde das Familien- und Jugendministerium ausgeschaltet? Sonderbare Praktiken bei der Entstehung des Sexualkundeatlasses, in: Stimme der Familie, 16 (1969), Nr. 7/8, S. 57.

99 Vgl. Weitere Ablehnung des Sexualkunde-Atlas, in: Stimme der Familie, 16 (1969), Nr. 10, S. 71.

100 Kurzprotokoll über die 6. Konferenz für Familienfragen am 7.11. 1968 im Bundesministerium für Familie und Jugend, BAK, B 153/706. 
Urteil des Bundesverfassungsgerichts vom 18. Juli 1967, das das Finanzierungsgefüge aus Bundes- und Landesmitteln in Bewegung brachte: Das Urteil begrenzte die Bundesförderung explizit auf Maßnahmen, deren Wirkungsbereich sich auf die Bundesrepublik als Ganzes erstreckte. ${ }^{101}$ Dem Bundesfamilienministerium waren nach dem Urteil des Bundesverfassungsgerichtes für eine finanzielle Förderung der Familienbildung die Hände fast vollständig gebunden und die sozialdemokratischen Familienministerinnen mußten daher ab 1969 andere Verfahren finden, um Einfluß auf die Entwicklung des Familienbildungssektors zu nehmen.

Als nach dem Regierungswechsel 1969 die neue Familienministerin Käte Strobel den Beginn einer „rationalen“ Ära der Familienpolitik und den Abschied von der „Familienideologie“ zum neuen Programm erklärte, bedeutete das für die Familienbildung eine schwerwiegende Herausforderung. ${ }^{102}$ Rationalität sollte sich in der Familienpolitik in zweifacher Weise auswirken: Zum einen sollten rationale Verfahren der politischen Willensbildung entwickelt werden. Hierfür spielte die systematische Integration wissenschaftlicher Erkenntnisse eine zentrale Rolle. Aufgabe der Wissenschaft sei es, „die für die Politik notwendigen Grundtatsachen" zu ermitteln und gesellschaftliche Wertentscheidungen und Handlungshypothesen zu überprüfen, erklärte Strobel. Zum anderen sollten die Wirkungen familienpolitischer Handlungen überprüfbar sein. Dafür mußten konkrete politische Ziele formuliert werden, an denen man die Effekte familienpolitischer Maßnahmen messen konnte. Sowohl aufgrund ihrer stark wertbezogenen Ausgangsbasis als auch bei der Erfolgskontrolle geriet die Familienbildung hier in Rechtfertigungsdruck. Empirisch meßbar war letztlich weder das Defizit, auf das die Familienbildung reagierte, noch der Effekt, den die Maßnahmen hatten. Als die Familienministerin im Juli 1970 eine Sachverständigenkommission mit der Abfassung eines zweiten Bundesfamilienberichts beauftragte, legte sie den Kommissionsmitgliedern daher dieses Thema besonders ans Herz. ${ }^{103}$

Eine erste wissenschaftliche Grundlage im Bereich der Familienbildung hatte bereits eine Studie des Deutschen Jugendinstituts zwei Jahre früher geliefert. Die Studie erschien 1973 in der Publikationsreihe des Bundesfamilienministeriums im Rahmen des „Familienzwischenberichts“. ${ }^{104}$ Im Sinne der angestrebten Erfolgskontrolle mahnte der Verfasser Klaus Wahl darin vor allem einen Punkt an: Bestimmte gesellschaftliche Gruppen, wie Angehörige der unteren Schichten und Familien mit vielen Kindern, nutzten die Bildungs- und Beratungsangebote kaum, obwohl Wahl gerade bei ihnen einen besonderen Informations- und Hilfsbedarf annahm. Wahl forderte daher die Politik auf, die Struktur des bisherigen Angebots entsprechend zu verändern. Er stellte auch die traditionell fast ausschließlich

101 BVerfG-Urteil vom 18.7. 1967 zum Jugendwohlfahrts- und Bundessozialhilfegesetz vom 18. 7. 1967, BVerfGE 22, S. 180-220.

102 Strobel, Abschied. Folgende Zitate ebenda. Vgl. zum Konzept der rationalen Familienpolitik auch Wingen, Umrisse.

103 Schreiben des Bundesfamilienministeriums an die Sachverständigen der Kommission zur Erstellung des zweiten Bundesfamilienberichtes vom 31. 7. 1970, BAK, B 189/15739.

104 Wahl, Familienbildung. Vgl. zum folgenden ebenda, S. 89-93. Zum Familienzwischenbericht vgl. Kapitel II.1., S. $121 \mathrm{f}$. 
freie Trägerschaft der Beratungsstellen in Frage, da die eminenten „Bildungsdefizite" im Familiensektor einen quantitativen und qualitativen Ausbau des Netzes an Einrichtungen erforderten. Dies könne nur die öffentliche Hand gewährleisten.

Ein Hauptproblem bestand für den Autor darin, daß sich gerade die gesellschaftlichen Gruppen, die schwer für den Besuch einer Familienbildungsveranstaltung zu gewinnen waren, über Medien informierten. Kummerkästen und Expertenfragestunden in der Presse boten anonyme und damit leicht anzunehmende Hilfe in Lebensfragen an. Die tatsächlich in den Zeitschriften veröffentlichten Briefwechsel stellten dabei nur einen kleinen Ausschnitt dar. Wahl forderte hier eine Koordination mit den Beratern der Medien. Mit dieser Forderung lief er bei den freien Trägern offene Türen ein. Die DAJEB führte bereits seit 1964 Kontaktgespräche mit Pressevertretern, um die professionellen Standards der institutionellen Eheberatung auch in den Medien zu sichern. Ähnlich wie Wahl vermutete auch Lothar Loeffler schon damals, daß die schriftliche Beratung durch die Illustrierten die Beratungsarbeit der Eheberatungsstellen im Umfang übertraf. 105

$\mathrm{Zu}$ einem Ausbau staatlicher Familienbildungs- und -beratungsstellen mit Hilfe von Bundesmitteln kam es letztlich nicht. Auch eine direkte Einflußnahme auf die bestehenden Einrichtungen oder Träger war kaum möglich. Dem stand die Kulturhoheit der Länder entgegen, die die Familienbildung als Teil des allgemeinen Bildungswesens für sich beanspruchten. Vor allem in den konservativ regierten Ländern stieß die sozialdemokratische Familienministerin, die die Einrichtungen von Pro Familia und deren Ansatz der Familienplanung bevorzugte, auf hartnäkkigen Widerstand. 106 In dieser Situation bot sich als Ausweichstrategie die Förderung als „Modellprojekt der Bundesregierung“ an. Diese Modellprojekte wurden für drei Jahre - an der Zuständigkeit der Länder vorbei - aus Bundesmitteln finanziert. Dann mußten sie entweder von den Länderhaushalten übernommen werden oder liefen aus. Im Bereich der Familienpolitik initiierte der Bund solche Modellmaßnahmen vor allem im Bereich der Schwangerschaftskonfliktberatung und der Kinderbetreuung. ${ }^{107}$

Auch der zweite reguläre Familienbericht, der 1974 fertiggestellt wurde, hatte einen Schwerpunkt auf der „pädagogischen Interventionsform“, also bei Maßnahmen, die die Handlungsfähigkeit der Familienmitglieder qualitativ verbessern sollten. ${ }^{108}$ Die Verfasser malten das Szenario einer Verfallsgeschichte, in der die Familie in zweifacher Hinsicht isoliert wurde: Durch die Schrumpfung zur "Kernfamilie" habe sie wesentliche Funktionen verloren und sei nun reduziert auf den emotionalen Bereich, der ihre Stabilität stark gefährde. Außerdem hätten sich

105 Vgl. Bericht über drei Kontaktgespräche der DAJEB mit Vertretern der Presse, in: Informationsrundschreiben der DAJEB, Nr. 75/76 vom April 1966, S. 1-40.

106 Vgl. dazu Kapitel IV.2., S. 278-284.

107 Bundesministerium für Jugend, Familie und Gesundheit, Zweiter Familienbericht, Stellungnahme der Bundesregierung, S. XIVf. und Kapitel IX.

108 Vgl. dazu Kaufmann, Elemente, S. 80-86; Lüscher, Wissenssysteme, S. 200-202; Gross, Selbstbestimmung, S. 300-302. 
die nachbarschaftlichen Beziehungen aufgelöst. Für beides konnten die Familienbildungsstätten Lösungsangebote vorlegen: Durch den Kontakt zu Familien mit ähnlichen Problemen in den Beratungsstellen würden die Familien die nachbarschaftliche Isolation überwinden. Für die Probleme, die sich aus den übersteigerten emotionalen Erwartungen ergaben, sollten die Familienbildungsstätten inhaltliche Beratung anbieten. ${ }^{109}$ Hier bestand allerdings Reformbedarf bei den Familienbildungsträgern. Schon Klaus Wahl hatte in seiner Untersuchung festgestellt, daß vor allem die konfessionellen Einrichtungen noch dem Leitbild traditioneller Arbeitsteilung in Familie und Gesellschaft verhaftet und ,weitgehend auf die Vermittlung herkömmlicher Hausfrauenkenntnisse und Fertigkeiten praktisch-handwerklicher Art, und zwar gerade an Frauen" ausgerichtet waren. ${ }^{110}$ Die DAJEB hatte hingegen schon 1963 ihre Jahrestagung unter das Leitthema gestellt, wie die Familien- und Eheberatung den Mann erreichen könne.111

Nicht nur über die Verbände und ihre Beratungsstellen versuchte das Ministerium für Jugend, Familie und Gesundheit, die Familien in Deutschland zu erreichen. Unter der ersten sozialdemokratischen Familienministerin begannen auch direkte staatliche Informationskampagnen in Aufklärungs- und Verhütungsfragen. Die Aufklärungsaktionen des Familienministeriums Anfang der siebziger Jahre waren im gesundheitspolitischen Teil des Ministeriums verankert und wurden größtenteils von der Bundeszentrale für gesundheitliche Aufklärung entwickelt und verbreitet. Die Vereinigung von Familien- und Gesundheitsressort in der sechsten Legislaturperiode unter dem gemeinsamen Dach eines Ministeriums verschleierte also letztlich nur die weiterhin andauernde Differenzierung zwischen biologischer Aufklärung und ethisch-moralisch orientierter Familienbildung, die die neue Familienministerin Käte Strobel schon zuvor als Leiterin des Gesundheitsressorts angestrebt hatte.

Strobel setzte ihre in der Zeit der Großen Koalition als Gesundheitsministerin begonnene Aufklärungspolitik nun auch als Familienministerin fort. Mit zahlreichen Broschüren, Handzetteln, Postern und Anzeigen wollte man vor allem junge Menschen über sexuelle Fragen aufklären. Gleichzeitig wurde aber auch ein Ausbau der institutionellen Familienbildung und -beratung befürwortet. Richteten sich die Aufklärungskampagnen, die die Bundeszentrale für gesundheitliche Aufklärung verbreitete, vor allem präventiv an Jugendliche und junge Erwachsene, so sollte die Schwangerschaftskonfliktberatung im konkreten Problemfall beratend weiterhelfen. Die Familienbildung hingegen umfaßte vor allem nicht-sexuelle Fragen wie psychologische Partnerschaftshilfen und Erziehungsberatung für Eltern.

109 Bundesministerium für Jugend, Familie und Gesundheit, Zweiter Familienbericht, Stellungnahme der Bundesregierung, S. IX.

110 Wahl, Familienbildung, S. 65.

111 Bericht über die Jahrestagung mit Mitgliederversammlung am 24.-25. 5. 1963 in Detmold, Gesamtthema: Der Mann, in: Informationsrundschreiben der DAJEB, Nr. 60/61 vom Januar 1964, S. 1-40. 


\section{Kontexte der Familienbildung und -beratung}

\section{Mädchen-und Frauenbildung: Mütterscbulen als Stabilisierungsfaktor der traditionellen innerfamiliären Rollenverteilung}

Die Tradition der Mütterschulen reicht bis in die Zeit des Ersten Weltkrieges zurück. Die erste deutsche Mütterschule wurde 1917 von der Kindergärtnerin Luise Lampert in Stuttgart gegründet. ${ }^{112}$ Lampert sah die Mütterschule nicht als Fürsorgeeinrichtung, sondern als Bildungsstätte, in der Kenntnisse vor allem über Schwangerschaft und Geburt sowie über Pflege und Erziehung des Säuglings und Kleinkindes vermittelt werden sollten. Sie griff damit eine Konzeption auf, die Friedrich Fröbel im Rahmen seiner Kindergarten-Pädagogik entwickelt hatte. Fröbel, der auch als „Vater der Mütterschule“ gilt, hatte seine Idee der „Kindergärten" eng mit dem Gedanken verbunden, gleichzeitig Mütter für eine gute Kindererziehung auszubilden. Er wollte die Frau zu einer "geistigen Mütterlichkeit“ erziehen, das heißt zu einer mütterlichen inneren Haltung, die unabhängig von der tatsächlichen biologischen Mutterschaft war. Fröbels Ansatz zielte darauf, durch den Kindergarten das Zusammenleben von Eltern und Kindern neu zu beleben und zu verbessern: Der Kindergarten bildete in diesem Sinn eine Ergänzung der Familie, nicht einen Ersatz. Daher waren regelmäßige Besprechungen mit den Müttern notwendiger Bestandteil der Kindergartenarbeit. Auf dieses Konzept von Fröbel war es zurückzuführen, daß bis weit in die bundesrepublikanische Geschichte hinein zwischen den paritätischen Mütterschulen und dem PestalozziFröbel-Verband der Kindergärten ein sehr enger Kontakt bestand. ${ }^{113}$

Konkreter sozialer Anlaß für die Gründung der ersten Mütterschulen war die hohe Säuglingssterblichkeit während und nach dem Ersten Weltkrieg gewesen, deren Ursachen Kinderärzte und Fürsorgerinnen vor allem in schlechter Ernährung, desolaten Wohnverhältnissen und mangelhaften Kenntnissen in Hygiene-, Pflege- und Erziehungsfragen gesehen hatten. Paritätische, evangelische und kommunale Träger eröffneten nach dem Ende des Ersten Weltkriegs zahlreiche Mütterschulen. In katholischer Trägerschaft gab es hingegen in der Weimarer Zeit keine festen derartigen Einrichtungen. Ab 1934 begann der nationalsozialistische „Reichsmütterdienst“ mit der Gleichschaltung aller bestehenden Mütterschulen. Die Nationalsozialisten bauten das Netz der Mütterschulen, die nun nach völkischer Ideologie arbeiteten, stark aus, so daß bei Kriegsende schätzungsweise über 400 Mütterschulen im Deutschen Reich bestanden. ${ }^{114}$ Nach dem Kriegsende 1945 lösten die Alliierten zunächst alle bestehenden Mütterschulen auf, da sie als NS-Bildungsstätten eingestuft wurden. Erst ab 1947 wurden die Einrichtungen wieder an die alten Träger übergeben. Gleichzeitig entstanden zahlreiche neue

112 Zur Entwicklung der Mütterschulen in der Weimarer Zeit und im Nationalsozialismus vgl. Schymroch, Mütterschule, S. 11-55.

113 Vgl. die regelmäßigen Berichte über Tagungen der Mütterschulen in den Blättern des Pestalozzi-Fröbel-Verbandes.

114 Vgl. Schymroch, Mütterschule, S. 45-55. Zu den Zahlenangaben Miedaner, Mütterschule, S. 272. 
Mütterschulen. Die „Zweite Phase der Mütterschulbewegung“115 nach 1945 zerfällt daher in zwei Entwicklungsstränge, die auch unterschiedlichen Ansätzen folgten.

Auf der einen Seite gab es die aus der akuten Sozialarbeit meist in Flüchtlingsund DP-Lagern erwachsenen Mütterschulen, die Nothilfe mit sozialpädagogischem Hintergrund anboten. Auch der Anfang der Münchner Mütterschule lag beispielsweise in den späten vierziger Jahren in den Flüchtlingslagern. 1949 begannen Mitarbeiterinnen des Pestalozzi-Fröbel-Verbands mit Unterstützung der Militärregierung und des Amerikanischen Frauenbunds damit, Beratungsveranstaltungen in acht Lagern in und um München abzuhalten. ${ }^{116}$ Vor allem die Erzieherin Lotte Geppert ${ }^{117}$ baute hier in ehrenamtlichem Einsatz die Mütterarbeit auf. Auch das Frauenreferat des Bayerischen Rundfunks engagierte sich in diesen Lager-Mütterschulen, was der Einrichtung zu einer gewissen Publizität verhalf. 118 Ab Januar 1950 stand auch eine Transportmöglichkeit und ein Raum in München zur Verfügung, wo gleich der erste Säuglingskurs für junge Bräute und werdende Mütter abgehalten wurde. Solche Kursprogramme bildeten allerdings zunächst die Ausnahme. Im allgemeinen gab es keine Kurse mit festem Lehrplan, sondern offene Gesprächsangebote in wöchentlichem oder vierzehntägigem Abstand. Ziel war zunächst ganz unbestimmt, „den entwurzelten Familien die Bewältigung der neuen Situation zu erleichtern." 119 Die Mütterschulen paßten sich der veränderten familiären Lebensform und der besonderen Alltagssituation der Mütter in den Lagern und ihren Bedürfnissen an. Das Angebot stieß auf rege Nachfrage. Statt der üblichen Kursstärke mit zwölf bis 15 Teilnehmern bestanden die Gruppen in den Lagern aus 35 bis 40 Müttern. 120

Die ursprüngliche Aufgabe der gesellschaftlichen Integration von Notunterkunftsbewohnern spaltete sich mit der Zeit in zwei Zweige auf: Zum einen gingen die geselligen Nachmittage zur Einführung in die neue Umgebung bei zunehmender Integration der Teilnehmerinnen in ein Mütterbildungs-Kursprogramm zur Säuglingspflege, zur Gesundheitspflege und zu Erziehungsfragen über. Sobald ein

115 Schymroch, Mütterschule, S. 56.

116 Zu den Anfängen der Münchner Mütterschule im Oktober 1949 vgl. Geppert, Bericht, und den Jahresbericht der Münchner Mütterschule zum 25. Jubiläum 1974, BayHStA, MArb VI/149/1.

117 Lotte Geppert (1883-1968) gründete nach mehreren Jahren Lehrtätigkeit am Münchner Institut für soziale Arbeit und praktischer Arbeit als Kindergärtnerin in Berlin und München 1923 in Nürnberg den Sonderkindergarten „Sonnengarten“. Regelmäßig bot sie hier ergänzende Mütterkurse an. 1928 baute sie in Wien gemeinsam mit Luise Lampert eine Mütterschule mit angeschlossenem Kindergarten auf, in deren Konzept sich eine Akzentverschiebung vom Kindergarten zur Mütterschule abzeichnete. 1933 wurde Lotte Geppert als Halbjüdin von den Nationalsozialisten aus ihren Ämtern vertrieben und emigrierte in die Schweiz. Nach ihrer Rückkehr nach München unterrichtete sie 19461953 wieder an der Sozialen Frauenschule. 1949 gründete sie die Münchner Mütterschule, die sie bis 1961 leitete. Vgl. dazu Berger, Frauen, S. 45-49.

118 Die Journalistin Elisabeth von Kleist arbeitete seit 1949 in einem oberbayerischen Lager, das von der Münchner Mütterschule betreut wurde. Vgl. Kleist, „Mütterschule“.

119 Jahresbericht 1974 der Münchner Mütterschule zum 25. Jubiläum, BayHStA, MArb VI/ $149 / 1$.

120 Geppert, Mütterschularbeit, S. 89. 
Raum und Maschinen zur Verfügung standen, wurden auch Nähtage veranstaltet. Auf der anderen Seite blieb die Arbeit mit sozialen Randgruppen, die aufgrund von Alter, Krankheit oder „sozialer Unfähigkeit" nur schwer in die Gesellschaft integrierbar waren. ${ }^{121}$ Hier ging es weniger darum, die Frau auf ihre Rolle in der Familie vorzubereiten, als um eine Kontaktaufnahme und gesellschaftliche Eingliederungsmaßnahmen. „So versucht die Mütterschule in einer derartigen DP-Siedlung durch eine, vom üblichen Unterricht abweichende Pflege der deutschen Sprache etliche Mütter zu einem besseren Kontakt mit ihrer Umwelt und von hier aus zu einer allmählichen Eingliederung in das ihnen immer noch fremde Land zu bringen",122 hieß es in einem Bericht von Lotte Geppert noch 1956. Auch diese Sprachschulung hatte jedoch familienfördernde Aspekte, wie Geppert betonte: „Nur so kann einer zerstörenden Spaltung zwischen den Eltern und den Kindern vorgebeugt werden; denn die Kinder müssen ja in Sprache und Arbeitsprozeß der neuen Heimat hineinwachsen. "In der Münchner Mütterschule konzentrierte sich die Arbeit auch in den fünfziger Jahren weiter auf diese Art der sozialen Integration. Das Kurskonzept aus den Lagern konnte dabei fortgeführt und weiterentwickelt werden. Das nächste Projekt von Lotte Geppert war eine Mütterschule im Rahmen eines Mütterheims des Paritätischen Wohlfahrtsverbands, das 50 jungen Frauen mit Säuglingen und Kleinkindern Unterkunft bot. Wichtiges Element der Arbeit war hier - wie schon in der Lagerarbeit - das „Miteinander der Hausbewohner mit der ,Außenwelt “", also die gesellschaftliche Integration einer sozialen Randgruppe. ${ }^{123}$

Die zweite Gruppe der Mütterschulen bildeten die wiederbelebten Einrichtungen der Weimarer Zeit. Sie fühlten sich dem Bildungsauftrag stärker verpflichtet als die Nothilfeeinrichtungen. Mütterbildung wurde dabei als präventive Bildungsarbeit im Sinne einer vorbeugenden Fürsorge verstanden und damit im Bereich der Sozialpädagogik verankert. Durch die Mütterschulung sollten Fürsorgefälle gar nicht erst entstehen. Die erste gemeinsame Denkschrift der westdeutschen Mütterschulen aus dem Jahr 1953, an deren Formulierung vor allem die Leiterinnen der schon länger bestehenden Einrichtungen beteiligt gewesen waren, erklärte dazu: „Der Mutter als Mittelpunkt und Hauptgestalterin der Familie werden damit besondere Aufgaben gestellt, die sie aufgrund von Instinkt und Tradition allein in vielen Fällen nicht lösen kann, weil die Situation der Familie und ihre eigene Stellung in der Familie sich weithin verändert haben. - Sie bedarf daher oft der Hilfe, um diese Lage zu sehen und richtig zu verstehen - zu erkennen, was für Forderungen sie ihr stellt und Wege zur Lösung zu finden. So ist Mütterbildung eine der dringendsten Forderungen der Gegenwart. Dabei steht an zentraler Stelle die Mütterschule, die in ihren Bemühungen um die Stärkung und Sicherung der Familie zugleich vorbeugende Fürsorge auf weite Sicht leistet." 124 Als Aufgaben-

121 Ebenda, S. 90.

122 Ebenda.

123 Zur Mütterschule im Mütterheim vgl. Geppert, Mütterheim.

124 Die Mütterschule in unserer Zeit. Denkschrift, verabschiedet von der Arbeitstagung der Mütterschulen des Bundesgebietes vom 15.-18.6. 1953, abgedruckt in: Blätter des PFV, Neue Folge der Zeitschrift „Kindergarten“, 4 (1953), S. 135-136, S. 135. An der Abfassung der Denkschrift waren maßgeblich beteiligt: Elfriede Basse (Mütterschule Braunschweig), Helene Börner (Mütterschule Bremen), Lotte Geppert (Mütterschule 
bereiche der Frau in der Familie definierte die Denkschrift Haushaltsführung, Säuglings- und Kinderpflege, häusliche Gesundheits- und Krankenpflege, Erziehungsfragen und die Gestaltung von Familienleben und Heim. Auf diese Tätigkeitsfelder sollte auch das Bildungsangebot der Mütterschulen zielen. Zunächst dominierten im Kursangebot Koch-, Näh- und Hauswirtschaftseminare. Säuglingspflege und Erziehungsfragen, die während der Gründungsphase in den zwanziger Jahren eine wichtige Rolle gespielt hatten, verloren in den fünfziger Jahren zunächst an Bedeutung.

Gegenüber dem traditionellen Konzept, das die Frauen vor allem auf ihre Mütterrolle vorbereiten wollte, konstatierte die Denkschrift 1953 eine bewußte Akzentverlagerung: „Mehr und mehr geht der Blick von den Aufgaben der Frau hin zur Familie als solcher und zur Sicherung ihres Bestandes." Im Programm der Münchner Mütterschule von 1955 findet man allerdings kaum einen Niederschlag dieser Schwerpunktverschiebung. Mit Unterricht in Pflege und Erziehung des Säuglings, des Kleinkindes und des Schulkindes, Beratung zur Gesundheitspflege und Näh- und Strickkursen bot Lotte Geppert die klassischen Mütterschulkurse an. Auch standen diese Seminare ebenso wie "Großmütternachmittage" und die "Jugendabende für die Mutter von morgen " ganz in der Tradition, nur Frauen anzusprechen und die Frauen nur in ihrer Rolle als Mutter wahrzunehmen. ${ }^{25}$ Andere Mütterschulen berichteten auf einer bundesweiten Tagung 1953 jedoch bereits von erfolgreich durchgeführten Veranstaltungen, an denen auch Männer teilgenommen hatten. Diese Ausweitung zur "Elternbildung" spiegelte sich in Säuglingspflegekursen für den "werdenden Vater", wie es sie in Wuppertal, Hannover und Bochum gab, und in Junggesellen- und Männerkochkursen in Ulm und Lübeck.

Anfangs waren vor allem paritätische Verbände und kommunale Träger in die nach 1945 entstandene Lücke im Mütterschulbereich eingesprungen, die katholischen Träger faßten dagegen in diesem Bereich nur sehr langsam Fuß. Das war nicht zuletzt darauf zurückzuführen, daß es innerhalb der katholischen Organisationen umstritten war, welcher Verband für die Mütterbildung zuständig sein sollte. Der (politische) katholische Deutsche Frauenbund konkurrierte hier mit dem (kirchlichen) Zentralverband der katholischen Frauen- und Müttergemeinschaften. Erst Anfang der fünfziger Jahre, nach einer Intervention des Paderborner Erzbischofs Lorenz Jaeger, einigten sich beide Verbände auf eine gemeinsame Verantwortung in diesem Bereich. Erst im Mai 1953 wurde in Köln das erste katholische Mütterbildungswerk in der Bundesrepublik gegründet. ${ }^{126}$

Als die paritätischen und evangelischen Träger ihr Angebot immer weiter ausbauten, gerieten die katholischen Verbände in Zugzwang, so daß nun verstärkt auch katholische Mütterschulen entstanden. ${ }^{127}$ Allein in den nächsten drei Jahren

München), Selma Hohagen (Mütterschule Wuppertal), Gertrud Kleber (Mütterschule Stuttgart) und Elisabeth von Peinen (Mütterschule Frankfurt). Vgl. dazu Schymroch, Mütterschule, S. $106 \mathrm{f}$.

125 Programm der Münchner Mütterschule vom September 1955, BayHStA, MArb 2648.

126 Vgl. Rölli-Alkemper, Familie, S. 352.

127 Die Träger, die sich 1956 zu einer Arbeitsgemeinschaft zusammenschlossen, waren: Zentralverband der katholischen Frauen- und Müttergemeinschaften Deutschlands, Katholi- 
wurden rund 30 katholische Mütterschulen in der Bundesrepublik gegründet, den wichtigsten regionalen Schwerpunkt bildete hier Nordrhein-Westfalen. ${ }^{128}$ Die Konzentration auf Nordrhein-Westfalen ist wohl auf ein Zusammentreffen von mehreren günstigen Bedingungen zurückzuführen. Zum einen fand die Arbeit der katholischen Mütterschulen in Maria Laarmann, 1947 bis 1956 als Ministerialrätin im Arbeits- und Sozialministerium des Landes für die Gruppe "Jugend und Familie" zuständig, eine frühe Fürsprecherin. ${ }^{129}$ Hinzu kam, daß der Raum KölnBonn ein Zentrum katholischer Sozialarbeit war. Hier befand sich unter anderem auch das Wirkungsfeld von Josepha Fischer-Erling, die eine der Schlüsselfiguren der katholischen Eheberatung war und diesen Zweig der Familienbildung im Beirat des Bundesfamilienministeriums vertrat.

Außerdem erließ Nordrhein-Westfalen 1960 auch als erstes Bundesland „Richtlinien zur Ausgestaltung von Einrichtungen der Mütter- und Elternbildungsschulen", in denen auch die Finanzierung der Mütterschulen durch Landesmittel geregelt wurde. 1961 förderte das Land die Investitionen der Mütterschulen mit rund einer Mio. DM und die Betriebskosten mit etwa $900000 \mathrm{DM}$ - und damit mit wesentlich höheren Beträgen als die anderen Bundesländer. Nach amtlicher Zählung gab es in Nordrhein-Westfalen zu diesem Zeitpunkt 52 Mütterschulen, davon 29 in katholischer, zehn in evangelischer Trägerschaft, sieben unterstanden der Arbeiterwohlfahrt, zwei dem Deutschen Roten Kreuz, und vier Einrichtungen wurden von Kommunen getragen. ${ }^{130}$ Nordrhein-Westfalen war zu diesem Zeitpunkt das einzige Bundesland, in dem Landesmittel den größten Anteil an staatlichen Zuschüssen bildeten. ${ }^{131}$

Die wirtschaftliche Förderung der Mütterschulen war prinzipiell Ländersache. Als 1961 vom Bundesfamilienministerium erstmals das sogenannte „Dozentenprogramm" für Mütterschulen aufgelegt wurde und sich Mütterschulträger im Bundesfamilienministerium trafen, um über die Verteilung der im Rahmen dieses Programms zur Verfügung gestellten Mittel zu beraten, zeigte sich allerdings, daß als einziges Bundesland Nordrhein-Westfalen eine systematische Förderung dieser Einrichtungen betrieb. Dort wurden Mütterschulen nach dem Volkshochschulgesetz unterstützt und erhielten darüber hinaus Zuschüsse vom Sozialministerium. ${ }^{132}$ Daneben gaben nur die Länder Bayern, Schleswig-Holstein und Hes-

scher Frauenbund, Bund der Deutschen Katholischen Frauenjugend, Deutscher Caritasverband und Katholischer Mädchenschutzverband.

128 Vgl. Bericht vom Vertreter der obersten Landesjugendbehörden Hans Alfken (Niedersachsen) über die Mütterschulen in den einzelnen Ländern auf der Sitzung der Sonderkommission „Vorbereitung der Jugend auf Ehe und Familie" am 13.11. 1961 im Bundesfamilienministerium, BAK, B 189/2933. Demnach befanden sich 52 der 101 Mütterschulen in Nordrhein-Westfalen, davon 29 in katholischer Trägerschaft. Diese Angaben können nur als Orientierungsgrößen dienen, da die Berichte anderer Länder teilweise unvollständig waren oder gar nicht vorlagen.

129 Schymroch, Mütterschule, S. 71, Fußnote 7.

130 Niederschrift über die Sitzung der Sonderkommission „Vorbereitung der Jugend auf Ehe und Familie" am 13. 11. 1961 im Bundesfamilienministerium, BAK, B 189/2933.

131 Nave-Herz, Elternschule, S. 51.

132 Vermerk vom 14. 3. 1961 über die Besprechung mit Vertretern der Mütterschulverbände am 22. 2. 1961 im Bundesfamilienministerium, BAK, B 189/2933. 
sen überhaupt Berichte über die Situation im Mütterschulbereich ab. Hessen unterstützte die zehn bekannten Mütterschulen mit 41000 DM, SchleswigHolstein gab für sechs Mütterschulen einen Zuschuß von insgesamt 75000 DM. Bayern berichtete zwar von acht Mütterschulen, konnte jedoch keine Fördermittel aufweisen. ${ }^{133}$

Drei Jahre später, im Jahr 1964, zeigte sich die Diskrepanz noch einmal deutlich bei der ersten Konferenz für Familienfragen mit Ländervertretern im Bundesfamilienministerium. In Nordrhein-Westfalen betrug der Haushaltsansatz für Mütterschulen inzwischen insgesamt über 2,3 Mio. DM, in Bayern wurden Einzelveranstaltungen maximal bis zur Hälfte der Kosten unterstützt und einzelne Mütterschulen erhielten Zuschüsse in der Höhe zwischen 2000 und 4000 DM. Eine genaue Gesamtbezifferung konnte das zuständige Innenministerium nicht vornehmen. ${ }^{134}$ Die Forderung nach einer besseren Koordination der Länder im Bereich der Förderung der Familienbildung, eines der Ziele der Konferenzen, war also nicht aus der Luft gegriffen.

Eine Zusammenstellung von Förderungsmaßnahmen der Länder für 1968 zeigte, daß der entsprechende Haushaltsansatz in Nordrhein-Westfalen mit inzwischen über 5,7 Mio. DM weiterhin viel höher lag als in den anderen Bundesländern. Weit abgeschlagen folgten Hessen mit 512000 DM, Berlin mit 347400 DM und Niedersachsen mit 344750 DM. Bayern und Rheinland-Pfalz standen mit 72000 DM Etat für die Mütterschulen nicht viel besser da als das Saarland (65000 DM).135 Die Länder, allen voran Nordrhein-Westfalen, beriefen sich bei ihrer Förderung auf die Kulturhoheit, die ihnen im Bildungssektor den Vorrang vor Bundesregelungen einräumte.

Nach dem verzögerten Start entwickelten sich die katholischen Institutionen zu einer Form der Mütterschulen, die sich in ihrem frauenbezogenen Kursprogramm zunehmend von den paritätischen und evangelischen Einrichtungen unterschied. Traditionell suchte die katholische Kirche den Zugang zur Familie über die Frau. ${ }^{136}$ Das Festhalten am dahinterstehenden christlichen Frauenleitbild der opferbereiten Mutter zeigte sich vor allem im Kursprogramm. Familienfördernde Angebote der Verbände im Bereich der Familienpflege, Eheberatung, Mütterschulen und Müttererholung wandten sich an Frauen. Das Kursspektrum umfaßte pädagogische Arbeitskreise zur Ehe- und Familienberatung, Kurse zur Heimgestaltung, zur kulturellen und musischen Erziehung, Werkkurse und Anleitungen

133 Niederschrift über die Sitzung der Sonderkommission „Vorbereitung der Jugend auf Ehe und Familie" am 13.11. 1961 im Bundesfamilienministerium, Bericht des Ministerialdirektors Hans Alfken über die Situation der Ehe- und Familienvorbereitung in den Bundesländern, BAK, B 189/2870.

134 Kurzprotokoll über die 1. Sitzung der Konferenz für Familienfragen mit Vertretern der Länder im Bundesfamilienministerium vom 23. 4. 1964, Nordrhein-Westfalen und Bayern, BAK, B 189/6321.

135 Synopse der Förderungsmaßnahmen der Länder auf dem Gebiet der Familienbildung und Familienberatung 1968, BAK, B 189/2823. Vgl. auch Angaben von Ministerialrätin Dr. v. Loeper vom Arbeits- und Sozialministerium NRW, Kurzprotokoll über die 5. Konferenz für Familienfragen am 17.5. 1968 im Bundesministerium für Familie und Jugend, S. 12, BayHStA, MArb VI/275.

136 Vgl. zum folgenden Rölli-Alkemper, Familie, S. 347-360. 
für die Gestaltung von Festen und Feiern. Daneben standen Kurse zur Krankenund Säuglingspflege und zur Gesundheitserziehung. Die hauswirtschaftliche Sparte umfaßte praktische Koch- und Nähkurse, aber auch Anleitungen zur Haushaltsführung. In einigen größeren Mütterschulen gab es Anfang der sechziger Jahre bereits Veranstaltungen, die die Teilnehmerinnen „für die Aufgabe der Frau im öffentlichen Leben aufschließen" sollten. ${ }^{137}$ Es wurden dazu "sozial caritative, sozialpolitische und staatsbürgerliche Arbeitskreise" eingerichtet. Der 1956 gegründete Verband „Arbeitsgemeinschaft zur Förderung der katholischen Mütterschulen“ gab jedes Jahr einen Bildungsplan für Mütterschulen heraus, der einen jugend- und familienpädagogischen sowie einen hauswirtschaftlichen Teil enthielt. Der Bildungsplan stimmte die Kurse so aufeinander ab, daß nach dreibis viersemestriger Aufbauarbeit ein allerdings nicht näher spezifiziertes „Bildungsziel" erreicht sein sollte. Ab 1957 führte die Arbeitsgemeinschaft auch Schulungskurse für ihre Mitarbeiter in einem eigenen Fortbildungszentrum in Altenberg bei Köln durch.

Der Ausbau der katholischen Mütterschulen erfolgte in zwei Schüben. Bereits Mitte der fünfziger Jahre hatten die katholischen Träger ihren Rückstand aus der Nachkriegszeit mehr als aufgeholt und unterhielten über die Hälfte aller Mütterschulen in Westdeutschland. ${ }^{138}$ In einem zweiten Schub ab Anfang der sechziger Jahre verdoppelte sich die Zahl der katholischen Einrichtungen nochmals innerhalb von fünf Jahren. ${ }^{139}$ Diese Neugründungswelle tritt vor allem deshalb markant hervor, weil im gleichen Zeitraum die Zahl der Einrichtungen anderer Träger nahezu stagnierte. Der Ausbau der katholischen Mütterschulen muß vor dem Hintergrund der in den sechziger Jahren anhaltenden Diskussion über außerschulische Mädchenbildung interpretiert werden. Ziel konservativer Bestrebungen war es, Mädchen eine geschlechtsbezogene Ausbildung für ihre zukünftige Rolle als Hausfrau und Mutter zu geben und das gesellschaftliche Ansehen dieser Ausbildung auf ein ähnliches Niveau wie das einer beruflichen Ausbildung zu heben. Die Arbeit in den katholischen Mütterschulen sollte eine eigenständige, religiös fundierte Frauenbildung für die Aufgaben in Ehe, Familie und Haushalt vermitteln. ${ }^{140}$

137 Vgl. Bericht über die Arbeit in den katholischen Mütterschulen, Stand vom 1. 12. 1961, S. 2, BAK, B $189 / 2933$.

138 Vgl. Vermerk vom 14.3. 1961 über die Besprechung mit Vertretern der Mütterschulverbände am 22. 2. 1961 im Bundesfamilienministerium, BAK, B 189/2933. Demnach gab es in Westdeutschland 1961 rund 100 Mütterschulen, was mit der Angabe bei Schymroch, Mütterschulen, S. 73, die 101 Einrichtungen zählt, in etwa übereinstimmt. Zur Zahl der katholischen Mütterschulen vgl. Bericht über die Arbeit in den katholischen Mütterschulen, Stand vom 1. 12. 1961, BAK, B 189/2933. Nach dieser Quelle gab es 1961 in der Bundesrepublik 51 katholische Mütterschulen. Vgl. dagegen Rölli-Alkemper, Familie, S. 353-355, der den Befund, daß die Hälfte aller Mütterschulen in katholischer Trägerschaft stand, erst ab Mitte der sechziger Jahre festmacht.

139 Vgl. Übersicht bei Schymroch, Mütrerschule, S. 73. Die Zahlen von Schymroch liegen etwas über den Angaben, die Rölli-Alkemper für denselben Zeitraum macht. Rölli-Alkemper, Familie, S. 354.

140 Vgl. Bericht über die Arbeit in den katholischen Mütterschulen, Stand vom 1. 12. 1961, BAK, B 189/2933. 
Aussagen über die Altersstruktur der Teilnehmer sind schwierig zu ermitteln. Die konfessionellen Mütterschulen führten nur selten und nicht nach einheitlichen Kriterien Befragungen unter ihren Besuchern durch. 1954 erhoben die in der paritätischen „Arbeitsgemeinschaft der Mütterschulen“ zusammengeschlossenen Einrichtungen stichprobenhaft Daten. ${ }^{141}$ Alle befragten Personen waren weiblich. 6,5 Prozent der Teilnehmerinnen waren jünger als $20 \mathrm{Jahre,} \mathrm{der} \mathrm{größte} \mathrm{Anteil} \mathrm{war}$ mit 42,3 Prozent der der Frauen zwischen dem 21. und dem 30. Lebensjahr. Über ein Drittel (34,3 Prozent) waren 30 bis 45 Jahre alt, weitere 17 Prozent waren älter als 45 Jahre. Die Hälfte der Teilnehmerinnen war bereits verheiratet bzw. verwitwet oder geschieden. Vergleicht man diese Altersdaten mit denen der Mütterschulen der konfessionellen Dachverbände, dann zeigen sich Unterschiede. Waren in den paritätischen Institutionen in den fünfziger Jahren über die Hälfte der Teilnehmerinnen jünger als $25 \mathrm{Jahre}$, so lag der Anteil dieser Altersgruppe in den evangelischen Schulen nur bei 34 Prozent, in den katholischen sogar nur bei 31 Prozent. ${ }^{142}$ Das mag zum Teil mit dem unterschiedlichen Kursangebot zusammenhängen. Die christlichen Mütterschulen, in besonderem Maß die katholischen, boten überwiegend Kurzkurse und Einzelveranstaltungen an. Die paritätischen Einrichtungen konzentrierten sich dagegen auf Seminare, die mehrere Wochen dauerten und aufeinander aufbauten. An einem solchen Einführungsseminar in die Aufgaben der Hausfrau und Mutter konnten ältere Frauen schon aus zeitlichen Gründen seltener teilnehmen. Außerdem richtete sich das Angebot ganz speziell an junge Mädchen mit geringer haushaltlicher Erfahrung. Ein Wandel in der Teilnehmerstruktur kann aufgrund der unsicheren Datenbasis nur tendenziell abgeschätzt werden. Es zeigt sich allerdings, daß die Gruppe der über 25jährigen zunahm. Gleichzeitig stieg auch der Anteil der verheirateten Frauen an. ${ }^{143}$ Beide Tendenzen deuten in dieselbe Richtung. Die Mütterschulen mußten sich von der familienvorbereitenden auf die familienbegleitende Bildung umstellen. Das hatte nicht nur inhaltliche Konsequenzen für die Arbeit der Mütterschulen. Auch institutionell verlagerten sie sich von der außerschulischen Jugendarbeit immer mehr in den Bereich der Erwachsenenbildung. Für ihre Finanzierung bedeutete diese Entwicklung, daß das ursprüngliche Finanzierungsinstrument des Bundes zur Förderung der Mütterschulen - der Bundesjugendplan - zunehmend seinen Ansatzpunkt verlor.

Spätestens seit Mitte der sechziger Jahre kann man einen Wandel im Erscheinungsbild der Mütterschulen ausmachen. Das war schon äußerlich daran zu er-

141 Vgl. Übersicht über die Teilnehmerinnen an den Angeboten der in der „Arbeitsgemeinschaft der Mütterschulen“ zusammengeschlossenen Mütterschulen im Jahr 1954, in: Schymroch, Mütterschule, S. 68 ff. Die Ergebnisse beruhten auf einer Stichprobenuntersuchung mit 5635 Umfragen.

142 Zahlen nach Lieselotte Nold: Der Beitrag der evangelischen Frauenarbeit zur Erziehung zu Ehe und Familie. Anlage zur Niederschrift über die Sitzung der Sonderkommission „Vorbereitung der Jugend auf Ehe und Familie“ am 13.11.1961 im Bundesfamilienministerium, BAK, B 189/2870. Ein direkter Vergleich mit der oben erwähnten Stichprobenuntersuchung ist nicht möglich, da die Angaben nach unterschiedlichen Altersgruppeneinteilungen erhoben wurden.

143 Schymroch, Mütterschule, S. 69. 
kennen, daß sich die meisten Einrichtungen in „Familienbildungsstätten“ umbenannten oder den Begriff zumindest als Ergänzung ihrem Namen hinzufügten. Die „Arbeitsgemeinschaft zur Förderung katholischer Mütterschulen“ arbeitete bereits seit 1965 offiziell unter dem Namen „Bundesarbeitsgemeinschaft katholischer Familienbildungsstätten“. 1969 wurde die 1954 gegründete paritätische „Arbeitsgemeinschaft der Mütterschulen“ in "Arbeitsgemeinschaft von Einrichtungen für Familienbildung e.V." umbenannt. ${ }^{144}$ Die ebenfalls 1954 ins Leben gerufene „Evangelische Arbeitsgemeinschaft für Mütterschulung“ änderte ihren Namen 1971 in „Bundesarbeitsgemeinschaft Evangelischer Familien-Bildungsstätten“. ${ }^{145}$ Damit waren Anfang der siebziger Jahre die Mütterschulen weitgehend im Bereich der Familienbildung aufgegangen. Mit den Namensänderungen sollte zum Ausdruck gebracht werden, daß sich das Angebot nun nicht mehr ausschließlich an Frauen richtete, sondern alle Familienmitglieder - vor allem auch die Ehemänner und Väter - integrieren wollte. Vorreiter waren hier die paritätischen Einrichtungen, deren Trägerverband bereits 1960 seine Jahrestagung unter das Thema "Die Ansprechbarkeit von Mann und Frau“ stellte. ${ }^{146}$ Außerdem zielte die Arbeit der Mütterschulen nun nicht mehr allein auf den hausfraulichen und mütterlichen Lebensbereich, sondern befaßte sich mit einer Vielzahl von Themen, die Krisen in der Familie hervorrufen konnten.

Das quantitative Übergewicht der katholischen Mütterschulen hatte für die Mütterschullandschaft in der Bundesrepublik in dieser Hinsicht gravierende Konsequenzen, denn die katholischen Einrichtungen vollzogen diesen Wandel zunächst nur nominell. Trotz der offiziellen Umbenennung des Verbandes im Jahr 1965 bildete weiterhin die Frauenbildung den Schwerpunkt der Arbeit in den katholischen Familienbildungsstätten. ${ }^{147}$ Mit ihrem Ansatz der Mädchen- und Frauenbildung für den häuslichen Bereich prägten die katholischen Einrichtungen maßgeblich das Bild der Mütterschulen in der Bundesrepublik. Zu einer Annäherung der unterschiedlichen Konzepte der Trägerverbände kam es kaum. Der $\mathrm{Zu}$ sammenschluß der drei Mütterschulverbände 1959 in einem Dachverband ${ }^{148}$ und

144 Ebenda, S. 108.

145 Ebenda, S. 114.

$146 \mathrm{Vgl}$. Liste der Tagungsthemen der Arbeitsgemeinschaft der Mütterschulen 1947-1988, ebenda, S. 76-79.

147 Noch die „Richtlinien für die Arbeit in katholischen Familienbildungsstätten-Mütterschulen" von 1970 hoben diesen Ansatz hervor. Vgl. Schymroch, Mütterschule, S. 118.

148 Mitte der fünfziger Jahre hatten sich die Mütterschulen in drei bundesweiten Arbeitsgemeinschaften zusammengeschlossen: Die größte war zu diesem Zeitpunkt (1956) bereits die katholische Arbeitsgemeinschaft für Mütterschulbildung, die 35 Einrichtungen umfaßte, die paritätische Arbeitsgemeinschaft zählte im selben Jahr 28 Mitglieder, während in der Arbeitsgemeinschaft der evangelischen Mütterschulen 10 Institutionen organisiert waren. Zur Situation der Mütterschulen 1956 vgl. Bericht der Hessischen Frauenverbandsvorsitzenden Anne Marie Heiler für den Internationalen Frauenrat, Moral Welfare Ausschuß vom Dezember 1956, BAK, B 189/2933. Vgl. dazu auch die Übersichten über Mitgliederzahlen der drei Trägerverbände in Nave-Herz, Elternschule, S. 46. Für 1956 hat Nave-Herz allerdings im katholischen Bereich nur unvollständige Angaben und gibt die Zahl der Mütterschulen mit 12 an. Schymroch, Mütterschule, S. 73, nennt unter Bezug auf einen Tagungsbericht der katholischen Mütterschulen aus dem Jahr 1958 die Zahl von 31 Einrichtungen. 
eine ein Jahr später publizierte gemeinsame Denkschrift zielten weniger auf die innere Einigung zwischen den Verbänden als darauf, verstärkt öffentliche Mittel in Anspruch nehmen zu können, die vom Bundesfamilienministerium im Rahmen des Bundesjugendplanes bereitgestellt wurden. ${ }^{149}$

Anfang der siebziger Jahre konnten sich aber auch die katholischen Einrichtungen dem tiefgreifenden Wandlungsprozeß, der das hausfrauenbezogene Leitbild der Mütterschulen in Frage stellte, nicht mehr verschließen. „Es ist zuviel passiert, als daß man ernsthaft glauben könnte, es sei noch möglich, die nächste Frauengeneration auf die traditionellen Rollen und Funktionen der Frau in Ehe und Familie einzuschwören", erklärte die Referentin Helga Strätling-Tölle im Hauptreferat der Jahrestagung der Arbeitsgemeinschaft katholischer Familienbildung 1972. „Wenn heute Frauen - sicherlich noch eine Minderheit, aber wie lange noch eine Minderheit? - existieren, die aufgrund eines - aus welchen Gründen auch immer gewandelten Selbstverständnisses nicht in der Lage oder nicht mehr bereit sind, sich mit der traditionellen Hausfrauen- und Mutterrolle abzufinden, dann müssen wir uns darauf einstellen." 150

In der Konsequenz bedeutete das eine Umstellung des Kursprogramms. Zunehmend traten auch theoretische Bildungsangebote zu den praktischen Kursen hinzu. Wenn sich auch die Inhalte und das Leitbild der Kursangebote veränderte, so muß dabei festgehalten werden, daß Hauptzielgruppe der katholischen Familienbildung nach wie vor die Frauen waren. Weiterhin waren die Mütterschulen und Familienbildungsstätten tendenziell Frauenbildungseinrichtungen. Es änderte sich das Frauenleitbild der Kursprogramme, die Konzentration auf die Frau blieb aber weitgehend erhalten.

Fragt man nach den Faktoren, die dazu führten, daß die Mütterschulen sich in Familienbildungsstätten verwandelten, dann spielten die zunehmende theoretische Reflexion über die Familienprobleme und die Professionalisierung der Beratungsarbeit eine wichtige Rolle. Gleichzeitig veränderten sich die Problemlagen der Familien und die Ansprüche der Ratsuchenden stiegen. Hinzu kam ein weiterer Punkt, der nicht unterschätzt werden darf: Auch die staatlichen Förderungsmöglichkeiten bestärkten die Entwicklung weg von den praxisbezogenen Kursen für Mütter und Hausfrauen hin zum offenen Bildungsangebot.

Ende der sechziger Jahre wurde es nicht zuletzt aufgrund der virulenten Bildungsdebatte für die Familienbildungsstätten und Mütterschulen strategisch immer wichtiger, den Bildungsaspekt zu stärken, damit die staatliche Förderung weiterhin über den Bildungssektor und die Kultusministerien der Länder erfolgen konnte. Der Übergang der Familienbildungsstätten von einem sozialpädagogischen zu einem stärker akademisch geprägten Angebot rückte die Institutionen zunehmend in die Nähe der Erwachsenenbildung. Der Trend weg von den Näh-, Koch- und Krankenpflegekursen, hin zu sozialpsychologischen Analysen von Partnerschafts- und Erziehungsproblemen und auch hin zu Fragen der Erwerbstätigkeit von Ehefrauen und Müttern war also auch notwendig, um den Anschluß

$149 \mathrm{Vgl}$. Nave-Herz, Elternschule, S. $46 \mathrm{f}$.

150 Helga Strätling-Tölle: Die Emanzipation der Frau - das Ende der Familie?, Referat auf der Jahrestagung der AKF 1972, S. 4, FDK/Berlin, Ordner AKF 1966-73. 
an die Erwachsenenbildung nicht zu verlieren und als Bildungseinrichtung mit wissenschaftlichen Standards anerkannt zu werden. Allerdings wehrte sich manche Familienbildungsstätte gegen die Umstellung - nicht zuletzt auch mit dem Argument, daß die praktischen Kurse sich bei der Klientel einer großen Attraktivität erfreuten und man damit auch kirchenferne Kreise erreichte. Beispielhaft zeigte sich die Problematik in der Diskussion um die Integration der katholischen Familienbildungsstätten in das nordrhein-westfälische Erwachsenenbildungsgesetz von 1974.

Die Novelle sollte das bis dahin geltende „Gesetz über die Zuschußgewährung an Volkshochschulen und entsprechende Volksbildungseinrichtungen“" aus dem Jahr 1953 ablösen. Nach Ansicht der CDU-Landtagsabgeordneten Maria Hölters sollten die Familienbildungseinrichtungen in Nordrhein-Westfalen auch weiterhin in der Erwachsenenbildung ihren Platz finden. Sie erklärte im April 1971: „In Nordrhein-Westfalen legen hundert Einrichtungen [der Familienbildung, C.K.] ein differenziertes, breitgefächertes Bildungsprogramm vor. Das anfänglich weitgehendst praktische Kursusangebot wird abgelöst durch den langfristig geplanten Bildungsplan, der $\mathrm{zwar}$ die praktischen Maßnahmen nicht ausklammert, aber den bildungstheoretischen den Vorrang gibt. " 151 Nach dieser Schwerpunktverschiebung gehörte in Hölters Augen die Familienbildung eindeutig in den Bereich der Erwachsenenbildung und hatte als solche Anspruch auf entsprechende öffentliche Förderung durch das Land. „Wenn die Erwachsenenbildung eine eigenständige Säule im gesamten Bildungssystem ist, werden die Länder in ihren bisherigen und künftigen Gesetzen zur Erwachsenenbildung die finanzielle Garantie für diese Arbeit [der Familienbildungsstätten, C.K.] übernehmen müssen.“

Im Frühjahr 1972 beklagte sich die Leiterin der einflußreichen Bonner Mütterschule Baumgarten beim Zentralkomitee der Deutschen Katholiken, daß Hölters angedroht habe, wer sich der Entwicklung zur stärkeren Betonung der Theorie nicht anschließe, müsse mit einer Streichung der öffentlichen Zuschüsse rechnen. Baumgarten betonte dagegen, daß durch sozialpraktische Kurse „viel Zündstoff innerhalb der Familien" beseitigt werde. Außerdem bildeten die praktischen Themen einen Ansatzpunkt für ein Gespräch über „tiefer liegende Fragen“. 152

Der Anteil der Praxiskurse war nicht das einzige Problem. Die Mütterschulen paßten in mehrfacher Hinsicht nicht in den Anforderungskatalog der Erwachsenenbildung, den der Gesetzentwurf zur Förderungsgrundlage erklärte. ${ }^{153}$ Ein weiterer Streitpunkt war der geforderte „Bildungsabschluß“, denn die Möglichkeit, einen Bildungsabschluß zu erwerben, war eine Bedingung, um als Erwachsenenbildungseinrichtung anerkannt zu werden. Bildungsabschlüsse gehörten nicht zu den zentralen Aufgaben der Familienbildungsstätten, erklärte dagegen die Lei-

151 Hölters, Familienbildung, S. 30. Folgendes Zitat ebenda.

152 Schreiben des Zentralkomitees der Deutschen Katholiken an die Arbeitsgemeinschaft für Katholische Familienbildung vom 18. 1. 1973. In dem Schreiben wird der Hergang der Auseinandersetzung für die AKF geschildert, FDK/Berlin, Ordner Familienbildungsstätten und Gesetz Erwachsenenbildung.

153 Vgl. Stellungnahme des Mütterbildungswerkes Bonn vom 7. 4. 1972 zum CDU-Gesetzentwurf, FDK/Berlin, Ordner Familienbildungsstätten und Gesetz Erwachsenenbildung. 
terin des Bonner Mütterbildungswerks. Zu Prüfungs- und Testverfahren sah sie auch keine Veranlassung: In der Familienbildung sei die Einführung von Zertifikaten nicht angebracht. Der damit verbundene Lernzwang und die Verschulung wirkten sich ungünstig aus. Zudem falle der Sinn eines Zertifikats, nämlich Dritten gegenüber die erworbene Befähigung nachzuweisen, innerhalb der Familien weg. ${ }^{154}$ Das katholische Mütterwerk wandte sich darüber hinaus prinzipiell gegen die alleinige Unterordnung unter die Zuständigkeit des Kultusministeriums. Die Familienbildungsarbeit habe "starke soziale und sozialpädagogische Bezüge", und daher habe sich die Aufgabenverteilung auf Landesebene beim Arbeitsminister und auf Regionalebene beim Landschaftsverband bewährt. ${ }^{155}$ Auch daß die staatlichen Zuschüsse für die Personalkosten auf hauptamtliche Mitarbeiter beschränkt sein sollten, stellte für die Familienbildungsstätten eine weitere inakzeptable Bedingung dar. Die Einrichtungen beschäftigten für die verschiedenen Kurse Referenten aus den unterschiedlichsten Bildungsbereichen. Der Familienbildungsunterricht könne nicht an deren Stelle von einer hauptamtlichen Kraft übernommen werden, erklärte das Bonner Mütterschulwerk. Schließlich monierte das Mütterwerk die Zusammensetzung des im Gesetzentwurf vorgeschlagenen Landesbeirats. Dort sollten nämlich nur zwei der 24 Mitglieder aus der Erwachsenenbildung kommen, und wohl zu Recht vermutete das Mütterwerk, daß darunter kein Vertreter der Familienbildung sein würde.

Im Zentralkomitee der Deutschen Katholiken, das vom Bonner Mütterwerk in die Diskussion eingeschaltet wurde, sah man die Gefahr einer zu engen Anbindung an die Erwachsenenbildung noch in einem größeren Zusammenhang: Letztlich fördere diese Tendenz zur Intellektualisierung sozialistische Vorstellungen, schrieb Paul Becher im April 1972 an den bayerischen Arbeitsminister Pirkl, in dem er einen Verbündeten gegen den Trend zur Akademisierung der Mütterschulkurse, den auch das Bundesfamilienministerium vorantrieb, vermutete. Im Bundesfamilienministerium sei man der Meinung, so Becher, daß die praktischen Kurse der Familien- und Elternbildung zur Zementierung der gesellschaftlichen Strukturen beitrügen und hätte auch aus diesem Grund eine stärkere kritische Reflexion in der Elternbildungsarbeit verlangt. ${ }^{156}$ In Bechers Augen leisteten die theoretischen Mütterschulkurse also letztlich den Vorstellungen der 68er-Bewegung Vorschub, die in traditionellen Familien repressive Strukturen zu erkennen glaubte und daher den Bruch mit dem herkömmlichen Familienideal gefordert hatte.

154 Stellungnahme der Bundesarbeitsgemeinschaft katholischer Familienbildungsstätten zum Erlaß eines Erwachsenenbildungsgesetzes vom März 1973, FDK/Berlin, Ordner Familienbildungsstätten und Gesetz Erwachsenenbildung. Dagegen sprach sich der bayerische Arbeitsminister Fritz Pirkl, den Paul Becher vom Zentralkomitee der Deutschen Katholiken um eine Stellungnahme gebeten hatte, für eine Zertifikatslösung aus. Schreiben des bayerischen Arbeits- und Sozialministers Fritz Pirkl an das Generalsekretariat des Zentralkomitees der Deutschen Katholiken vom 20.10. 1972, FDK/Berlin, Ordner Familienbildungsstätten und Gesetz Erwachsenenbildung.

155 Stellungnahme des Mütterbildungswerkes Bonn vom 7.4. 1972 zum CDU-Gesetzentwurf, FDK/Berlin, Ordner Familienbildungsstätten und Gesetz Erwachsenenbildung.

156 Schreiben Paul Becher an den bayerischen Arbeits- und Sozialminister Fritz Pirkl vom 12. 4. 1972, FDK/Berlin, Ordner Familienbildungsstätten und Gesetz Erwachsenenbildung. 
Schließlich trat am 1. Januar 1974 in Nordrhein-Westfalen aber doch ein Erwachsenenbildungsgesetz in Kraft, das so flexibel gestaltet war, daß sich auch die Familienbildungsstätten mit ihren besonderen Eigenschaften darin wiederfinden konnten. Damit war Nordrhein-Westfalen zwar nicht das erste westdeutsche Bundesland, das ein Erwachsenenbildungsgesetz erließ - das erste derartige Gesetz hatte es in Niedersachsen gegeben. ${ }^{157}$ Im Gegensatz zu anderen Bundesländern förderte Nordrhein-Westfalen jedoch die Familienbildung ab 1974 ganz maßgeblich aus Mitteln, die im Rahmen dieses Gesetzes zur Verfügung gestellt wurden.

\section{Gesundheitsfürsorge: das Müttergenesungswerk als leitbildkonformes Angebot für die „Nur-Hausfrau"}

1950 gründete Elly Heuss-Knapp das Mütter-Genesungswerk. 158 Die Frau des Bundespräsidenten wandte sich damit einem Gebiet der Gesundheitsfürsorge zu, das ihrer Ansicht nach bisher wenig Beachtung gefunden hatte. „Es ist manches aufwärts gegangen bei uns in Deutschland“, erklärte sie. „Aber wer fragt danach, wie es die Mütter schaffen, ihre Kinder satt zu kriegen? Wer fragt danach, ob sie noch die Kraft haben, die Kinder zu erziehen? Und ob sie noch Geduld für ihre Männer haben, Güte und Verstehen - und vor allem Liebe? Das Deutsche MütterGenesungswerk fragt nach ihnen. Es weiß um ihre Not. Die Not hat hundert Gesichter, und die Krisen unserer Familien in dieser Zeit haben viele Namen. Es liegt auch an uns, sie zu überwinden. Wir tragen alle ein Stück Verantwortung. Aus dieser Verantwortung ist das Deutsche Mütter-Genesungswerk geschaffen worden. Um der Familie ihren Mittelpunkt zu erhalten - die Mutter, mit der die Familie steht und fällt. " 159 Diese Zeilen spiegeln den Ansatz der Müttergenesung in der frühen Nachkriegszeit. Sie zielte auf die Regeneration der Mutter, die für das Funktionieren der Familie im zeitgenössischen Verständnis unentbehrlich schien. Gleichzeitig wandten sich die Müttergenesungskuren speziell an die Frauen, deren Probleme primär durch familiäre Faktoren verursacht waren.

$\mathrm{Daß}$ die Müttergenesungswerke von Anfang an nicht nur gesundheitspolitische Einrichtungen waren, sondern auch im Kontext von Familienbildung und -beratung gesehen wurden, belegt beispielsweise eine Stellungnahme zum Thema „Was wird in der Bundesrepublik getan, um junge Menschen auf Ehe und Familie vorzubereiten?", die Anne Marie Heiler, Vorsitzende des hessischen Frauenverbands, als bundesdeutsche Vertreterin beim Internationalen Frauenrat 1956 einreichte. Darin hieß es: „Diese [Müttergenesungsheime, C.K.] helfen der Familie dadurch, daß sie die überbeanspruchte Mutter aus der häuslichen Belastung und den ständigen Sorgen herausnehmen und ihr eine Erholungszeit verschaffen. Sie geben aber auch, wo es nötig ist, Gelegenheit zur Aussprache über Ehenöte und häusliche

157 Vgl. zur Entwicklung in Niedersachsen Raapke, Erwachsenenbildung.

158 Elly Heuss-Knapp leitete das Mütter-Genesungswerk bis zu ihrem Tod im Jahre 1952. Ihr folgte die Bundestagsabgeordnete Helene Weber. 1963 übernahm Wilhelmine Lübke, die Frau des amtierenden Bundespräsidenten, den Vorsitz. Vgl. Hofmann, Mütter, S. 185-197; Pflüger, Entwicklungen.

159 Nopitsch, Mütter-Genesungswerk, S. 218. 
Sorgen und haben auf diese Weise schon manche Ehe, die zu zerbrechen drohte, wieder geheilt." 160 So ging es bei den Müttergenesungskuren nicht nur um die gesundheitliche Heilung, sondern auch um die Lösung familiärer Krisensituationen. In diesem Zusammenhang gewann die weltanschauliche Ausrichtung der Träger, die die Müttergenesungskuren anboten, eine zentrale Bedeutung, denn diese bestimmte die Art der Lösungsansätze und die Form, in der sie vermittelt wurden.

Die Müttergenesungsheime hatten unterschiedliche Traditionen. Zum einen gab es die Mütterfürsorge der konfessionellen Verbände, in Bayern beispielsweise auf evangelischer Seite den bayerischen Mütterdienst in Stein bei Nürnberg und auf katholischer Seite Müttererholungswerke und Einrichtungen der Caritas, deren Wurzeln bis in die zwanziger Jahre zurückreichten. 161 Viele Müttergenesungsheime entstanden aber auch aus Flüchtlingserholungsheimen, die Anfang der fünfziger Jahre, als der Bedarf an reinen Flüchtlingsfürsorgeeinrichtungen langsam zurückging, in Stätten der Müttergenesung umgewandelt wurden. ${ }^{162}$

Von Anfang an ruhte die Finanzierung der Müttergenesungskuren auf einem soliden Fundament, denn sie waren sozialversicherungsrechtlich anerkannt. ${ }^{163}$ Sowohl Kuren zur Wiederherstellung der Gesundheit als auch Präventivkuren wurden von der Sozialversicherung oder Fürsorge finanziell gefördert. Die Aufenthaltskosten für Müttergenesungskuren übernahmen zumindest teilweise die Krankenkassen-, Rentenversicherungs- und Fürsorgeträger. Versicherungstechnisch wurde die Tätigkeit der Hausfrau und Mutter dabei einer Erwerbstätigkeit gleichgestellt. Dies sollte verhindern, „daß die Mütter, die durch eine Reihe schwerster Kriegs- und Nachkriegsjahre ohne die Möglichkeit einer Ausspannung ihre Pflichten erfüllt haben, ihre Leistungsfähigkeit im Haushalt einbüßen und daß dadurch ihre Familien in eine Lage kommen, die im Hinblick auf ihre Folgen auch den BFV [Bezirksfürsorgeverband, C.K.] vor schwierige Aufgaben stellen würde." 164 Im Gegensatz zur Altersrentenversicherung galten hier die „häuslichen Pflichten“ als eine Form von Arbeit, die zur Teilhabe am Sozialversi-

160 Was wird in der Bundesrepublik getan, um junge Menschen auf Ehe und Familie vorzubereiten? Stellungnahme von Anne Marie Heiler für den Internationalen Frauenrat, Moral Welfare Ausschuß vom Dezember 1956, BAK, B 189/2933.

161 Vgl. dazu Rölli-Alkemper, Familie, S. 367f.; Trockel, Mütter. Die ersten Müttergenesungsheime entstanden nach dem ersten Weltkrieg. Im Nationalsozialismus verdrängte das Hilfswerk „Mutter und Kind" die bis dahin konfessionell getragenen Einrichtungen weitgehend. Nach der Auflösung der NS-Einrichtungen stand die Müttergenesungsfürsorge 1945 weitgehend vor einem Neubeginn. Eine Ausnahme bildete der bayerische Mütterdienst in Stein bei Nürnberg. Diese Einrichtung blieb während der NS-Zeit bestehen und konnte daher nach Kriegsende bei der sozialen Arbeit auf bestehende Ressourcen zurückgreifen. Vgl. dazu Hofmann, Mütter, S. 156-184, insbesondere S. 166. Kuller, Stiefkind, S. $311 \mathrm{f}$.

$162 \mathrm{Vgl}$. Vermerk in den Unterlagen des bayerischen Innenministeriums über die Anträge der Flüchtlingsheime Schloß Fellheim, Kipfenberg und Bad Bocklet zur Aufnahme in die Liste der förderungswürdigen Müttergenesungsheime beim Bundesinnenministerium, BayHStA, MInn 81166.

163 Nopitsch, Mütter-Genesungswerk, S. 218 f.; Vgl. auch Hofmann, Mütter, S. $195 \mathrm{f}$.

164 Schreiben des Bundesinnenministeriums an das bayerische Innenministerium vom 14. 3. 1952 über die Verrechnungsfähigkeit von Müttergenesungskuren nach dem Überleitungsgesetz, BayHStA, MInn 81166. 
cherungssystem berechtigte. War die Arbeitsfähigkeit beeinträchtigt, dann berechtigte dies Hausfrauen ähnlich wie Berufstätige zu Kuren. Die Pflichtaufgabe der Fürsorge, die Arbeitskraft zu erhalten, bezog sich damit nicht nur auf die Berufstätigkeit, sondern auch auf die Haus- und Erziehungsarbeit. Die Anerkennung durch die Krankenkassen- und Rententräger bedeutete einen symbolischen Schritt für die soziale Sicherung der nichterwerbstätigen Frauen, die nicht mehr nur in den Bereich der Kriegsfolgenhilfe und Fürsorge abgeschoben, sondern in das Versicherungsnetz der Erwerbstätigen eingegliedert wurden.

Diese Regelung bildet eine seltene Ausnahme in der Sozialpolitik der frühen Bundesrepublik. Hier war zumindest ansatzweise eine Form der Gleichberechtigung von Familienarbeit und Erwerbsarbeit in Gesetzestext gegossen, die dem christlichen Leitbild entsprach: Die Arbeit der Frauen in Haushalt und Familie wurde als nicht gleichartig, aber gleichwertig anerkannt. Dadurch bestätigte die Regelung die Rollenverteilung in den Familien, denn eine "Vätergenesungskur" war zu dieser Zeit undenkbar. Auf die Arbeit der Müttergenesungsheime wirkte sich die Verankerung im Sozialversicherungsrecht stabilisierend aus, da sie eine sichere finanzielle Grundlage schuf.

Zunächst erhielten die Müttergenesungswerke vor allem von den Ländern $\mathrm{Zu}$ schüsse. Die Gründung des Müttergenesungswerkes 1950 war maßgeblich auf eine Initiative des evangelischen bayerischen Mütterdienstes zurückzuführen und hatte die durch die Währungsreform in Schwierigkeiten geratenen Finanzen der Mütter-Sozialarbeit dieses Verbands wieder auf eine solide Basis gestellt. Zudem gelang es nun auch, öffentliche Unterstützung einzuholen. ${ }^{165}$ Zwischen 1949 und 1952 gewährte beispielsweise Bayern Zuschüsse in Höhe von 162000 DM, davon waren allerdings etwa drei Viertel für die sechs evangelischen Heime bestimmt, so daß sich die restlichen 20 Heime anderer Träger in Bayern mit insgesamt 44500 DM Zuschüssen begnügen mußten. 1953 vergab das bayerische Innenministerium seine Mittel proportional zur Heimanzahl, so daß die evangelischen Träger auch nur noch rund ein Drittel der Fördersumme bekamen. 166

Neben den staatlichen Zuschüssen wurde werbewirksam jedes Jahr am Muttertag eine Straßensammlung durchgeführt, die erhebliche Summen einbrachte: Schon bei der ersten Sammlung 1950 gingen 2,4 Mio. DM ein, ${ }^{167} 1951$ wurden rund drei Mio. DM gesammelt. ${ }^{168} 1963$ deckten die Einnahmen durch die Sammlung mit gut sieben Mio. DM immerhin rund ein Viertel der Kosten der Müttergenesungsfürsorge. 1691970 finanzierte das Müttergenesungswerk seine Gesamtkosten von rund 45,5 Mio. DM zu einem Sechstel (7,6 Mio. DM) aus der Straßensammlung. ${ }^{170}$ In diesem Jahr finanzierte das Müttergenesungswerk seine Arbeit neben den Einnahmen aus der Straßensammlung etwa zu einem weiteren Sechstel

165 Hofmann, Mütter, S. $197 \mathrm{f}$.

166 Vgl. dazu die Vermerke des Staatssekretärs im bayerischen Innenministerium vom 14. 9. und 28. 9. 1953, BayHStA, MInn 81166.

167 Vgl. Rückblick in Welter, Muttertag, S. 2.

168 Nopitsch, Mütter-Genesungswerk, S. $218 \mathrm{f}$.

169 Die Erholung der Mutter, in: Die Familie fordert uns, 2 (1963), H. 5, S. 6; Welter, Muttertag, S. 2.

170 Zahlen aus der Müttergenesung, in: Die Familie fordert uns, 11 (1972), Nr. 3, S. 20. 
(7,6 Mio. DM) aus Mitteln der Träger. Rund 6,8 Mio. DM kamen durch Eigenbeteiligungen der Familien in die Kassen. Bund und Länder gaben insgesamt gut 6 Mio. DM als Zuschüsse. Das restliche Drittel brachten Zuzahlungen von Krankenkassen, Sozialhilfeträgern oder Rentenversicherungen. ${ }^{171}$

Staatliche Zuschüsse vom Bundesinnenministerium gab es ab 1955. ${ }^{172}$ Bis 1963 erhielt die Müttergenesung jährlich zwei Mio. DM, nach 1963 wurde die Summe auf drei Mio. DM erhöht. Diese Mittel waren jedoch zweckgebunden und durften nur für die Ausstattung der Einrichtungen beispielsweise mit medizinischen Geräten verwendet werden, nicht jedoch für Bau- oder Personalkosten. Gerade die Baukosten drohten jedoch den Trägern im Zuge der Umstrukturierung Mitte der sechziger Jahre über den Kopf zu wachsen. Erst ab 1970 aber gab das Bundesinnenministerium seine Mittel auch für größere Bauvorhaben frei.

Unter dem Dach des Müttergenesungswerkes schlossen sich 1950 in der Bundesrepublik 42 Müttergenesungsheime zusammen. Einen regionalen Schwerpunkt bildete Bayern, wo es 1952 insgesamt 17 Müttergenesungsheime gab. Über die Hälfte davon (neun Heime) wurden von der Caritas sowie katholischen Frauen- oder Mütterverbänden getragen, sechs unterstanden dem evangelischen bayerischen Mütterdienst, jeweils eines unterhielten das Rote Kreuz und die Arbeiterwohlfahrt. ${ }^{173}$ Ein Jahr später gab es in Bayern bereits 26 Heime, und bis 1957 war die Zahl der Heime in Bayern auf 28 angewachsen. Vor allem die kleineren katholischen Träger hatten hier ihr Kontingent ausgebaut. Während neben Bayern auch Nordrhein-Westfalen mit 35 Heimen und Niedersachsen mit 28 Institutionen inzwischen recht gut ausgestattet waren, gab es beispielsweise in Hessen und Rheinland-Pfalz nur jeweils 13 Einrichtungen zur Müttergenesung. 174 Hierfür spielte neben der unterschiedlichen Förderfreudigkeit der Länder auch eine Rolle, daß die Müttergenesungsheime vornehmlich in Erholungsorten errichtet worden waren. Zudem war auch die räumliche Distanz zwischen Wohnort und Kurort für den Erfolg der Kur wichtig, so daß der Ort des Heimes noch nicht unbedingt einen Anhaltspunkt dafür gibt, aus welcher Region die Erholungsuchenden kamen.

Schon während der Aufbauphase stieg die Zahl der Kuren nicht in gleichem Maße wie die Bettenzahl an. Im Gegenteil: Die Belegungsdichte der Heime hatte zwischen 1950 und 1965 um 22 Prozent abgenommen. ${ }^{175}$ Diese Tendenz ist bereits ein Hinweis auf den Wandel, den die Müttergenesungsheime vollziehen mußten, um den Übergang von der Nachkriegssituation in die Friedensgesell-

171 Ebenda.

172 Mitteilung des Müttergenesungswerkes, Antonie Nopitsch, an das Bundesinnenministerium vom 7. 1. 1969, BAK, B 189/4521.

$173 \mathrm{Vgl}$. zu den Zahlenangaben: Liste der anerkannten Müttergenesungsheime in Bayern vom März 1952; Vermerk des Staatssekretärs im bayerischen Innenministerium vom 14. 9. 1953; Liste der Müttergenesungsheime in Bayern von 1957. Alle drei in BayHStA, MInn 81166.

174 Vgl. Tabelle der Müttergenesungswerke (1957) im Anhang der Richtlinien für die Müttergenesungsheime, BayHStA, MInn 81166.

175 Bericht der Bundesregierung über die Situation der Frauen in Beruf, Familie und Gesellschaft vom 14. 9. 1966, S. 35 f., BT-Drs. 5/909. 
schaft zu bewältigen. Die Probleme der kurbedürftigen Frauen veränderten sich, und die Ansprüche an Ausstattung und Professionalität stiegen mit wachsendem Wohlstand und zunehmendem wissenschaftlichen Fortschritt. Anfang der sechziger Jahre gerieten die aus der Nachkriegssituation heraus entstandenen Müttergenesungsheime in eine existentielle Krise. Mit dem Aufblühen des Kurwesens erwuchs ihnen zudem ein starker, modern ausgestatteter Konkurrent. Die Müttergenesungsheime mußten daher ihre Position zwischen Tourismus, Krankenbehandlung und Bildungsanspruch neu definieren. ${ }^{176}$

Das häufigste Krankheitssymptom der Mütter, die in den fünfziger Jahren zu einem Kuraufenthalt eingewiesen worden waren, hatte Erschöpfung gelautet. Sie war in den Augen der Geschäftsführerin des Müttergenesungswerkes Antonie Nopitsch ${ }^{177}$ verursacht durch die pausenlosen Belastungen infolge der politischen Entwicklungen von den zwanziger bis in die fünfziger Jahre: Arbeitslosigkeit der Männer und Überlastung der Frauen vor 1933, „schwere seelische Schäden im Dritten Reich“, Kriegseinsatz, Bombennächte, Flüchtlingsnot, Hunger, Währungskrise, erzwungene Erwerbstätigkeit der Frauen und die Not der Kriegswitwen und Flüchtlinge. ${ }^{178} \mathrm{Hinzu}$ kam nach Ansicht von Nopitsch ein sozialer Strukturwandel und eine damit verbundene Krise der Familie. Nur der Wille der Frauen halte die Familien oft noch zusammen. Das Müttergenesungswerk sollte den erschöpften Müttern Gelegenheit geben, die nötige äußere und innere Kraft zu regenerieren. Neben ärztlicher und pflegerischer Betreuung ging es den Trägern der Müttergenesungsheime auch darum, den Müttern "Lebenshilfe“ zu geben, indem sie "Heimat und Geborgenheit" vermittelten, und „alles das [zu] tun, was den Mut zum Leben stärkt“. Unter „Mut zum Leben“ verstand man nicht individuelle Selbstverwirklichung, sondern die Zuversicht, die Rolle der Hausfrau und Mutter gut zu erfüllen. Während der Müttergenesungskur sollten daher nicht nur Krankheiten bekämpft, sondern auch die Opferbereitschaft und der Wertekanon der Frauen wieder aktiviert werden.

Einige Beispiele sollen genügen, um ein Bild von der Situation der Mütter zu vermitteln, die Müttergenesungskuren machten. Die ausgewählten Fälle aus dem Jahr 1957 zeigen noch eindeutig kriegs- und kriegsfolgenbedingte Einweisungsgründe. Das Müttergenesungswerk meldete diese Beispiele an das bayerische Innenministerium, um zu belegen, wie schlecht die finanzielle Kooperation mit den Fürsorgeverbänden funktionierte. In keinem der folgenden Fälle hatte der zuständige Fürsorgeverband die Förderungswürdigkeit einer Müttergenesungskur anerkannt. ${ }^{179}$

176 Vgl. dazu Britt-Thomsen, Müttererholung, S. 34.

177 Antonie Nopitsch, geb. 3. 8. 1901, 1920 Abitur, 1925 Promotion in Nationalökonomie als eine der ersten Frauen in diesem Fach, 1927 Lehrerin an der neu gegründeten sozialen Frauenschule in Nürnberg, 1933 Kündigung wegen Konflikten mit der Schulleitung und Gründung des bayerischen Mütterdienstes, 1933-1965 Leitung des bayerischen Mütterdienstes, gestorben 1975. Zur Biographie vgl. Diestel, Nopitsch; Hofmann, Mütter, S. 128-138.

178 Nopitsch, Mütter-Genesungswerk, S. 218, folgende Zitate ebenda.

179 Beispiele aus einem Bericht des Müttergenesungswerkes an das bayerische Innenministerium, ohne Datum (1957), BayHStA, MInn 81166. 
Da war beispielsweise der Fall von Käthe K., 41 Jahre alt, drei Kinder, von denen eines verstorben und die beiden anderen 18 und 15 Jahre alt waren. Nach ihrer Flucht kam die Familie in einem Massenlager unter. Die Familie hatte kein Einkommen und lebte von der Fürsorge. Käthe K. litt unter Anämie. Ein anderer Fall war die 33jährige Ruth H. Auch sie war Flüchtling, hatte ihre beiden Kinder im Alter von sechs Jahren auf der Flucht verloren. Der Ehemann war erst spät aus der russischen Gefangenschaft zurückgekehrt. Ruth $\mathrm{H}$. litt an Erschöpfungszustand und Hypotonie. Die Witwe Helene K., 43 Jahre alt, hatte drei Kinder im Alter von 19, 18 und $15 \mathrm{Jahren}$. Sie beantragte die Kur aufgrund von allgemeiner Erschöpfung und Anämie. Lydia W. litt ebenfalls unter Erschöpfung und Hypertonie. Sie war 43 Jahre alt, hatte zwei Kinder im Alter von 21 und 16 Jahren. Da der Ehemann als Hilfsarbeiter arbeitslos war, lebte die Familie in ärmlichen Verhältnissen, es fehlte am Notwendigsten. Die 50jährige Betti $H$. versorgte ihren aufgrund einer Kriegsverletzung gelähmten Ehemann und hatte zwei Kinder. Zur Finanzierung des Lebensunterhalts trug Betti $\mathrm{H}$. Zeitungen aus. Sie litt unter Krampfadergeschwüren und Herzkranzstörungen und war „dringend erholungsbedürftig“.

Zunächst fällt ins Auge, daß es sich bei den Frauen in der Regel um Mütter handelt, die schon ältere Kinder hatten. Das Müttergenesungswerk war ein Angebot an Mütter in einer relativ späten Familienphase. Nicht selten waren die Kinder schon aus dem Haus, wenn die Mütter die Genesungskur antraten. Statistische Erhebungen wiesen zudem ein typisches Symptomprofil auf: Die meisten der Frauen, die eine Müttergenesungskur machten, zeigten körperliche und nervöse Erschöpfung. Gut ein Drittel der Frauen, die in den fünfziger Jahren in ein Müttergenesungsheim aufgenommen wurden, litt zudem an Herz- und Kreislaufstörungen. Konkrete Krankheiten wie Anämie, Rheuma, Arthrose, Gallen-, Magenund Leberleiden oder Krankheiten der Atmungsorgane waren dagegen relativ selten. Entsprechend waren auch die Müttergenesungsheime überwiegend darauf eingerichtet, reine Erholungskuren ohne oder mit nur geringer ärztlicher Behandlung anzubieten. In Bayern waren 1952 beispielsweise von 17 Müttergenesungsheimen neun Heime nur für die Behandlung von „körperlicher und seelischer Erschöpfung" und „nervösen Leiden" ausgestattet. 180

Die Mütter brauchten nach Ansicht der Betreiber der Müttergenesungsheime in den ersten Nachkriegsjahren vor allem "viel Ruhe und Sattessen “. ${ }^{181}$ Mindestens ebenso wichtig war nach dem Konzept der Müttergenesungsheime jedoch die Vermittlung eines Gemeinschaftserlebnisses für die Mütter, die ihre Überanstrengung auch als Folge von Isolation empfanden. Schon die Einsicht, daß andere noch schwerere Lasten trugen, verschaffe den Frauen Erleichterung, so lautete die Philosophie der Müttergenesungsheime. In Mehrbettzimmern sollten die Frauen gleichzeitig Ruhe und die Gemeinschaft mit vermeintlichen Schicksalsgenossinnen finden. Die Frauen reisten gruppenweise am selben Tag an und drei bis vier

180 Liste der anerkannten Müttergenesungsheime in Bayern vom März 1952, BayHStA, MInn 81166.

181 Neue Sonderkuren im Rahmen des Müttergenesungswerkes, in: Evangelische Kinderpflege, 13 (1962), H. 3, S. 122-124, S. 123. 
Wochen später gleichzeitig wieder ab. Auch Spiele und Sport dienten weniger therapeutischen als gemeinschaftsstiftenden Zwecken. Erst in zweiter Linie wurden in den Kuren Anregungen und Beratung in Erziehungsfragen gegeben.

In einem Bericht aus dem Alltag eines norddeutschen Heimes, das Erholungskuren für erwerbstätige Mütter durchführte, spiegelt sich dieser Ansatz: „Viele Frauen kommen zum ersten Male in ein Heim und müssen erst erfahren, wie gut und heilsam das Leben in einer Gemeinschaft sein kann. Sie haben oft mehr als zehn Jahre rastlosen Mühens hinter sich ohne einen ,Urlaub - und auch dies wird nun zur Aufgabe: sich fallen und einmal verwöhnen zu lassen. [...] Nicht immer bilden sich sofort echte Gemeinschaften - oft sind in den Zimmern kleine Krisen zu überwinden, weil man nicht genügend $\mathrm{Kraft}$ in seiner eigenen Müdigkeit aufbringen kann, den fremden Anderen anzuerkennen. [...] Es ist nun die Aufgabe eines Genesungsheimes, solche $Z$ wischenfälle zu beobachten und zu verhindern, daß sie zu Schwierigkeiten werden. Deshalb ist es notwendig, schon in den ersten Tagen die Frauen zu gemeinsamen Unterhaltungen zusammenzufassen. Im Sommer ist die weite, sanft abfallende Liegewiese der Platz, wo sich das Leben abspielt. Dort stehen die Liegestühle, dort wird Gymnastik mit Ball und Spiel durchgeführt, dort tanzen wir am Abend die alten Volkstänze. Die Terrasse vorm Speisesaal verlockt zum Sitzen, die Stillen und die Alten genießen die Ruhe und Gottes schöne Welt bei Sonnenuntergang und Dämmerung. Sie lernen allmählich, wieder in ein Gespräch zu kommen und machen die heilsame Erfahrung, daß ihre Last noch nicht die allerschwerste ist. Die langen Abende im Herbst und Winter vereinigen alle im Kreis, da wird vorgelesen und erzählt - Kindererlebnisse Naturschilderungen - Frauenschicksale. [...] Rundgespräche über Erziehungsfragen führen den Kreis junger und erfahrener Mütter und Großmütter an neue Gesichtspunkte heran. [...] Erholungskuren haben die Aufgabe, diese bildenden Kräfte aufzuzeigen und die Mütter an Quellen zu führen, die auch für sie ständig fließen. Die religiöse Betreuung durch Abendandachten und Feierstunden, die Geburtstagsfeiern und Abschiedsfeste müssen der gleichen Aufgabe dienen. "182

Das Gruppenerlebnis war für die Müttergenesungsheime durchgehend ein wichtiger Faktor, durch den sie sich von anderen Kurformen abgrenzten. In der Profilierungsphase der sechziger Jahre spielte diese therapeutische Methode eine entscheidende Rolle. Auch noch 1973 bestand nach Ansicht der Träger die typische Hauptaufgabe der Müttergenesungskur darin, einen intensiven Gruppenprozeß anzuregen: „Müttergenesungskur ist im wesentlichen ,Gruppentherapie ““. .83

Mit der Überwindung der schlimmsten Notsituationen der Nachkriegszeit und einer „Normalisierung des Alltags" nahmen bei den Kurteilnehmerinnen die Zivilisationskrankheiten, vor allem Herz-Kreislaufschäden, Gallen-, Magen- und Leberleiden sowie Rheuma und Arthrosen, zu. Der Befund war wohl zum Teil auf Veränderungen im Meldeverfahren der Ärzte zurückzuführen, die differenziertere Diagnosen stellten. So ist es fraglich, ob sich wirklich die Befindlichkeit der Kurteilnehmerinnen so gravierend veränderte, wie es aufgrund der statistischen

182 Hofstaetter, Leben. Der Artikel bezog sich auf das 1950 gegründete Elsa-BrändströmHaus in Blankenese.

183 Vgl. Kneffel, Müttergenesung, S. 180. 
Tabelle 8: Gesundheitliche Situation der Mütter vor einer Genesungskur (in Prozent, Mebrfachnennung möglich): 184

\begin{tabular}{lcc}
\hline & $1955 / 56$ & $1965 / 66$ \\
\hline Herz-/Kreislaufschäden & 36,6 & 45,7 \\
Gallen-, Magen- und Leberleiden & 8,8 & 17,9 \\
Rheuma und Arthrosen & 7,0 & 14,4 \\
Erkrankungen der Atmungsorgane & 3,8 & 8,4 \\
Anämie & 3,9 & 4,2 \\
Folgen überstandener Erkrankungen und Operationen & 18,6 & 17,5 \\
Körperliche und nervöse Erschöpfung & 69,3 & 77,3 \\
\hline
\end{tabular}

Daten erscheint. Selbst wenn es sich aber zumindest teilweise um eine Maßstabverschiebung handelte, blieb aus der Sicht der Müttergenesungsheime das Problem bestehen: Sie mußten ihre Kuren zunehmend auf die professionelle Behandlung von spezifischen Krankheiten einstellen.

Die Träger des Müttergenesungswerkes erwarteten auch mit der Normalisierung der Lebensverhältnisse einen Rückgang der von Erschöpfung geplagten $\mathrm{Pa}$ tientinnen. Aber das Gegenteil trat ein. Waren nach Angaben des Müttergenesungswerkes 1949/50 30 Prozent der Frauen, die eine Müttergenesungskur machten, aufgrund körperlicher und seelischer Erschöpfungen bzw. neurovegetativer Störungen in die Heime geschickt worden, so nahm ihr Anteil bis Mitte der fünfziger Jahre bereits auf knapp 70 Prozent, bis 1959 sogar auf 80 Prozent zu und blieb dann auf diesem Niveau nahezu konstant. ${ }^{185}$ Stark verändert hatten sich jedoch die Ursachen dieser Erschöpfung. Statt der krisenhaften gesellschaftlichen Ausnahmesituation rückten Alltagsprobleme und „normale" Familienstrukturen als Gründe in den Blick. Überraschenderweise waren es auch nicht nur die erwerbstätigen Mütter, die eine Kur besuchten. 1960 waren nur knapp die Hälfte der Patientinnen in den Müttergenesungsheimen berufstätig. ${ }^{186}$

Der Problemkreis, der sich hier zeigte, erweckte die Aufmerksamkeit der Bundesregierung. 1960 beauftragte das Bundesinnenministerium den Deutschen Verein für öffentliche und private Fürsorge (DV), Dachverband der bundesdeutschen Wohlfahrtsverbände, mit der Durchführung einer Studie „Zur Lage der Mütter in Westdeutschland“. Der DV arbeitete für die Studie sehr eng mit dem Müttergenesungswerk zusammen. Helene Weber, die Vorsitzende des Müttergenesungswerkes, nahm an den Beratungen über die Konzeption der Studie teil, deren Ergebnisse zu einem erheblichen Teil auf Befragungen von Teilnehmerinnen an Müttergenesungskuren beruhten. Die Ergebnisse des Forschungsprojektes sollten am Ende einer Neuorientierung des Müttergenesungswerks zugute kommen. ${ }^{187}$

184 Tabelle nach den Angaben des Nachrichtendienstes des Deutschen Vereins für öffentliche und private Fürsorge (1967), BAK, B 189/2933.

$185 \mathrm{Vgl}$. Tabelle 8 sowie: Ein Werk für Mütter. 10 Jahre Deutsches Müttergenesungswerk, in: Sozialer Fortschritt, 9 (1960), H. 4, S. 88.

186 Freiwillige Hilfe - den Müttern gewährt, in: Sozialer Fortschritt, 10 (1964), H. 4, S. 98.

187 Vermerk des Bundesinnenministeriums über die Projektvorstellung Reinhold Junkers vom 18. 6. 1962, BAK, B 189/4540. In der Besprechung erklärte der Projektleiter auch 
Erste Ergebnisse des Forschungsprojektes präsentierte der Projektleiter Reinhold Junker auf dem Deutschen Fürsorgetag im Oktober 1963 in München, der „Die Mutter in der heutigen Gesellschaft" zum Thema hatte. Dort betonten Junker, Nopitsch und Nold ${ }^{188}$ die Probleme der nichtberufstätigen Mütter. Sie lenkten damit den Blick auf ein Problemfeld, das bis dahin im Schatten der Frage der „Doppelbelastung“ von Frauen durch Beruf und Familie gestanden hatte. Auf die Frage: „Welche Frauen haben es heute bei uns am schwersten?" nannte die Studie von Junker an erster Stelle die Landfrauen, an zweiter aber überraschend die „Nur-Hausfrauen" mit mehr als drei Kindern, und erst an dritter Stelle folgten die berufstätigen Mütter. ${ }^{189}$ Eine der sechs Arbeitsgruppen auf dem Deutschen Fürsorgetag beschäftigte sich ausschließlich mit Problemen der "Nur-Hausfrauen“. ${ }^{190}$ Hier wurden Fragen angeschnitten, die genau das Arbeitsfeld des Müttergenesungswerkes betrafen.

Offenbar gab es Veränderungen in der Gesellschaft, die die Hausfrauen und Mütter psychisch und physisch in unerwarteter Weise unter Druck setzten. Dies war erstaunlich, da doch in Zeiten des Heirats- und Babybooms das traditionelle Familienleitbild eine Hochkonjunktur erlebte. Gerade das erzeugte aber erhöhte Erwartungen und führte zu Enttäuschungen und Belastungen, wenn Ideal und Wirklichkeit auseinanderklafften. Die Hausfrauen und Mütter sahen sich vor der Aufgabe, Widersprüche zu überbrücken, auseinanderstrebende Faktoren zu integrieren und eine harmonische Grundlage für die Familie zu schaffen.

Die Eigeninteressen des Müttergenesungswerkes dürfen bei dieser Untersuchung Junkers aber nicht übersehen werden. Ein nur aus der "normalen" Familiensituation begründeter Erholungsbedarf von Müttern rechtfertigte auch die Arbeit des Müttergenesungswerkes wesentlich besser als die bisherigen Argumente, die sich auf zusätzliche Belastungen wie Kriegsfolgen oder Erwerbstätigkeit der Frau beriefen. Diese Legitimation war zudem mit dem konservativen Leitbild der Hausfrauenehe vereinbar. Im familiären Alltag jeder Mutter erkannte Junker eine „chronische Kluft zwischen Streben und Erreichen“. ${ }^{191}$ Er beobachtete bei den Müttern eine „Identifikation mit dem Unzumutbaren“. Der Fürsorgetag forderte

seinen Ansatz, daß die Ursache für Probleme der Mütter vor allem seelischer Natur seien. Daher träten sie auch nicht nur im Falle einer Doppelbelastung der berufstätigen Mutter, sondern auch bei einer „Nur-Hausfrau“ auf; Vgl. auch Junker, Lage, Bd. 1/1, S. 11.

188 Lieselotte Nold war unter anderem 1959-1975 geschäftsführende Vorsitzende der Evangelischen Arbeitsgemeinschaft für Mütterschulung, ab 1971 umbenannt in Bundesarbeitsgemeinschaft evangelischer Familien-Bildungsstellen. 1965 übernahm sie auch die Leitung des Mütterdienstes in Stein bei Nürnberg. Zur Biographie von Lieselotte Nold vgl. Hofmann, Mütter, S. 146-156, insbesondere S. $152 \mathrm{f}$.

189 Vgl. Die Lage der Mütter in Westdeutschland. Alarmierende Zahlen beim Deutschen Fürsorgetag 1963, in: Die Familie fordert uns, 3 (1964), Nr. 5, S. 35.

190 Weitere Gruppen gab es zu den Themen: Vorbereitung auf die Ehe, berufstätige Mütter, die Mutter als Erzieherin, Gefahren und Hilfen für die Gesundheit der Mutter und die Mutter im Recht. Vgl. dazu auch Muthesius, Mutter.

191 Reinhold Junker, Die Lage der Mütter in Westdeutschland - kritische Gruppen, Nachrichtendienst des DV, 1964, Nr. 4, Sonderdruck in BAK, B 189/2938. Der Artikel ist der Abdruck eines Kurzreferats, das Junker vor Stiftungsrat und Kuratorium des Müttergenesungswerkes am 29. 1. 1964 im Berliner Schloß Bellevue hielt. Folgende Zitate ebenda. 
daher einen Ausbau der Müttergenesungsvorsorge in familienpädagogischer und gesundheitserzieherischer Hinsicht.

1965 erschien der erste Band der Ergebnisse des Forschungsprojektes zur Lage der Mütter in Westdeutschland. Im Zentrum der Untersuchung standen zehn stichwortartige Hypothesen, die die Probleme der Mütter in neuem Licht erscheinen ließen: 1. Die Schichtunabhängigkeit der Nöte, 2. Eine chronische Kluft zwischen Wollen und Erreichen bei allen Müttern, 3. Gesundheitliche Schäden infolge der ständigen Überforderung, 4. Eine falsche Opferhaltung, 5. Eine ungenügende Vorbereitung der Frauen auf Ehe und Familie, 6. Eine fehlende Bindung an die Berufstätigkeit jenseits vom Einkommensmotiv, 7. Die Einengung der außerhäuslichen Lebenswelt auf die Berufstätigkeit im Drei-Phasenmodell, 8. Ungenügende Hilfen innerhalb der Familie, 9. Die Isolierung durch Mangel an Zeit und Überschätzung der Einflüsse der Massenkommunikation und 10. Der Rückzug in die geschlossene Privatheit und ungeklärte Partnerschaft. ${ }^{192}$ Angesichts dieser vielschichtigen Probleme kam Junker zu dem Schluß: „Breiten Schichten können die modernen Aufgaben in den kleinen und größeren Gruppen, in Ehe, Familie und Daseinsverband nicht ohne die Hilfe ,dritter Institutionen ' gelingen. "Junkers politische Forderungen zielten daher auf eine Stärkung der „dritten Institutionen“. Darunter verstand er solche Einrichtungen, die weder der Erwerbssphäre oder der Verwaltung, noch dem Schulsektor zugerechnet werden können. ${ }^{193}$

$\mathrm{Zu}$ den „dritten Institutionen" gehörten unter anderem Mütter- und Elternschulen, Erziehungs- und Eheberatungsstellen und eben auch die Müttergenesungsheime. In Junkers Bewertung spielten die "dritten Institutionen" eine Schlüsselrolle. Sie stellten in seinen Augen "Hauptinstanzen einer demokratischen Gesellschaft" dar, indem sie zwischen Familie und Gesellschaft vermittelten. Die geistigen und methodischen Grundlagen der "dritten Institutionen" sowie ihr eigenständiger, demokratischer Charakter müsse daher gefördert und ausgebaut werden. ${ }^{194}$ Auch die Frauenenquete des Bundestages, die 1966 fertiggestellt wurde, stand im Ansatz der Studie von Junker nahe und betonte die zentrale gesellschaftliche Rolle des Müttergenesungswerkes. ${ }^{195}$

Im Müttergenesungswerk nahm man diese Gedanken bereitwillig auf. Die Ergebnisse der Junker-Studie dienten der Legitimation einer Müttergenesungshilfe auch für „Nur-Hausfrauen“: „Das alte Bild von der zurückgezogen lebenden, sich aufopfernden, aber immer glücklichen Mutter stimmt einfach nicht mehr. Auch diese Frauen, nicht nur die berufstätigen, werden doppelt gefordert, ohne daß ihnen immer die nötigen Garantien gegeben werden." Daher habe sich das Müttergenesungswerk entschlossen, „auch für diese Frauen Sonderkuren einzuführen“. 196 Schon Ende 1960 hatte das Kuratorium des Müttergenesungswerkes beschlossen, künftig nicht nur Sonderkuren für bestimmte gesellschaftliche Grup-

192 Vgl. Junker, Lage, Bd. 1/1, S. 114-118, und Bd. 1/2, S. 270-281.

193 Junker, Lage, Bd. 1/1, S. $112 \mathrm{f}$.

194 Junker, Lage, Bd. 1/2, S. 274 f. und $280 f$.

195 Bericht der Bundesregierung über die Situation der Frauen in Beruf, Familie und Gesellschaft vom 14. 9. 1966, S. 35 f., BT-Drs. 5/909.

196 Becker, Gesetzgeber, S. 74. 
pen wie Heimkehrerinnen aus sowjetischer Gefangenschaft oder Mütter in Flüchtlingslagern anzubieten, sondern auch für Mütter in besonderen familiären Belastungssituationen - wie beispielsweise bei einer Schwangerschaft oder in kinderreichen Familien. ${ }^{197}$ Das Angebot einer Erholungskur für schwangere Frauen war zunächst erklärungsbedürftig. "Ganz sicher ist die Schwangerschaft bei Normalverlauf keine Krankheit", hieß es in der Presseerklärung des Müttergenesungswerkes zu den ersten Sonderkuren für Schwangere. „Sie stellt aber ungewöhnlich hohe Anforderungen an die körperliche und seelische Leistungsfähigkeit der Frau, die bei vielen Müttern nicht vorhanden ist." 198 Sowohl Schwangere als auch Mütter kinderreicher Familien sollten während der Kur in der Gruppe „eine Bejahung des Mutterseins“ erleben und erlernen.

Um die neuen Aufgaben wahrnehmen zu können, mußten die Heime des Müttergenesungswerkes sich grundsätzlich reformieren. Aufwendige medizinische Einrichtungen mußten angeschafft werden, die Pflege wurde professioneller, statt der „erfahrenen, möglichst sozial-pädagogisch geschulten mütterlichen Persönlichkeit “ der Heimleiterin ${ }^{199}$ brauchte man nun qualifizierte Mitarbeiter im wirtschaftlichen, pflegerischen, therapeutischen und ärztlichen Bereich. Die Heime wurden „behaglicher und geschmackvoller" eingerichtet, was ganz konkret damit begann, daß die in den fünfziger Jahren üblichen Drei- und Vierbett-Zimmer in Einzelzimmer umgebaut wurden.200

Bereits der Fürsorgetag 1963 forderte die Heime auf, ihr Angebot auch in familienpädagogischer und gesundheitserzieherischer Hinsicht auszubauen. Sie sollten sich verstärkt Bildungs- und Beratungsaufgaben widmen. ${ }^{201}$ Die eingeforderte Bildungshilfe boten die Heime in Form von Sonderkuren an. Neben der normalen Erholungskur gab es Ende der sechziger Jahre Kuren für Landfrauen, für erwerbstätige Mütter, für kinderreiche Mütter, für werdende Mütter, für behinderte Frauen und für Mütter behinderter Kinder, für Frauen mit suchtkranken oder suchtgefährdeten Familienangehörigen, für Studentenehefrauen und für Frauen von Binnenschiffern. ${ }^{202}$ Im Rahmen der Spezialkuren wurden thematische Fachvorträge gehalten, Gruppen- und Einzelgespräche geführt und die Mütter über Hilfsinstitutionen informiert. Außerdem stand auf dem Programm: basteln, werken, musizieren, Theater spielen und andere kreative Anregungen, die die Frauen mit in den Alltag nehmen sollten. 203

197 Bericht der Bundesregierung über die Situation der Frauen in Beruf, Familie und Gesellschaft vom 14. 9. 1966, S. 35 f., BT-Drs. 5/909.

198 Neue Sonderkuren im Rahmen des Deutschen Müttergenesungswerkes. Presseerklärung des Müttergenesungswerkes, abgedruckt in: Evangelische Kinderpflege, 13 (1962), H. 3, S. 122-124, S. 123. Folgendes Zitat ebenda.

$199 \mathrm{Vgl}$. Richtlinien für Müttergenesungsheime vom 18. 1. 1951, BayHStA, MInn 81166.

200 Bericht des Müttergenesungswerkes, Antonie Nopitsch, an das Bundesinnenministerium vom 7. 1. 1969, BAK, B 189/4521.

201 Vgl. Referat Reinhold Junkers vor dem Bundestagsausschuß für Familie und Jugend am 28. 11. 1968, BAK, B 189/4521.

202 Pflüger, Entwicklung, S. 9.

203 Bericht des Müttergenesungswerkes, Antonie Nopitsch, an das Bundesinnenministerium vom 7.1.1969, BAK, B 189/4521. 
Mit der neuen Legitimationsgrundlage durch die Studie Junkers konnten die Heime des Müttergenesungswerkes auf großzügige staatliche Unterstützung hoffen. Sie entsprachen in ihrer Zielsetzung dem christlich-traditionellen Leitbild und propagierten nicht die erwerbstätige Mutter als weibliche Lebensform. Gleichzeitig erfüllten sie die Ansprüche einer professionellen Versorgung, sowohl im Beratungs- als auch im Gesundheitssektor. Nach der Studie von Junker gab es eine potentielle Anwärtergruppe von rund vier Millionen Frauen in der Bundesrepublik. Die Müttergenesungsheime konnten mit ihren 6800 Betten jährlich rund 90000 Mütter aufnehmen. Rein rechnerisch hätten sich daher lange Warteschlangen bilden müssen. In Wirklichkeit hatten die Heime jedoch zunehmend Mühe, ihre Plätze ausreichend zu belegen. ${ }^{204}$ Schon als das Müttergenesungswerk im Frühjahr 1965 stolz die millionste Mutterkur meldete, ${ }^{205}$ hatte sich ein leichter Rückgang in den Teilnehmerzahlen abgezeichnet. Dieser Trend setzte sich in den folgenden Jahren fort. ${ }^{206} \mathrm{Z}$ wischen 1957 und 1971 wurde in Bayern nur ein weiteres Müttergenesungsheim in Betrieb genommen. ${ }^{207}$ Auch bundesweit kann man eine ähnliche Tendenz beobachten: Bis 1965 stieg die Zahl der Müttergenesungsheime in der Bundesrepublik auf 186, 1970 war die Zahl wieder auf 165 gesunken. 208

Über die Ursachen dieses paradoxen Zustandes machte man sich auch im Müttergenesungswerk Gedanken. Anscheinend wurde das Angebot „nicht mit der Unbefangenheit in Anspruch genommen, die der heutigen sozialen Realität entspricht". Vor allem die mittleren gesellschaftlichen Schichten erreichte man nicht. Nicht einmal 20 Prozent der Teilnehmerinnen der Müttergenesungskuren 1967 stammten aus dieser Bevölkerungsgruppe. Die Müttergenesungskur galt immer noch als Fürsorgemaßnahme für Bedürftige. Außerdem gab es offenbar Widerstände, vor allem seitens der Väter. Diese Widerstände waren nicht unbegründet. Schließlich entstand bei einem Kuraufenthalt der Mutter das Problem, wer in dieser Zeit die Familie versorgen sollte. In verschärftem Maße stellte sich diese Frage bei den Sonderkuren, wenn beispielsweise behinderte oder suchtgefährdete Angehörige alleine zu Hause zurückblieben. Das Problem der Dorf- und Familienhelferinnen, die während der Kur die Familie betreuen sollten, wurde nicht befriedigend gelöst.

Im Müttergenesungswerk zog man daraus Konsequenzen und formulierte neue Ziele: $\mathrm{Da}$ die familiären Probleme schichtunabhängig auftraten, ging es darum,

$204 \mathrm{Vgl}$. Arbeitsbericht der Geschäftsstelle des Deutschen Müttergenesungswerkes für 1968, Manuskript, BAK, B 189/4521. Die folgenden Überlegungen zu den Ursachen ebenda.

205 Müttererholung - jetzt immer noch?, in: Evangelische Kinderpflege, 13 (1962), H. 3, S. 75-76.

$206 \mathrm{Vgl}$. Schreiben der Evangelischen Arbeitsgemeinschaft für Mütter-Genesungsfürsorge an das Deutsche Mütter-Genesungswerk vom 8.11. 1968 über den Rückgang der Belegungszahlen in evangelischen Müttergenesungsheimen seit 1964, BAK, B 189/4521.

2071971 gab es in Bayern 29 Müttergenesungsheime, vgl. Bayerisches Staatsministerium für Arbeit und Sozialordnung, Familie, S. 24.

208 Angaben nach Junker, Lage, Bd. 2, S. 12; Bericht der Bundesregierung über die Situation der Frauen in Beruf, Familie und Gesellschaft vom 14. 9. 1966, S. 35 f., BT-Drs. 5/909; Zahlen aus der Müttergenesung, in: Die Familie fordert uns, 11 (1972), Nr. 2, S. 20. 
auch neue Müttergruppen aus allen Schichten zu erreichen. ${ }^{209}$ Das Vermittlungsverfahren sollte ausgebaut und ebenso wie der Arbeitsstil in Beratung, Pflege und medizinischer Versorgung professionalisiert werden. Dazu brauchte man gut ausgebildete Mitarbeiter im pflegerischen, wirtschaftlichen und gruppenpädagogischen Bereich. Insgesamt müsse das Müttergenesungswerk, so hieß es zusammenfassend, ein klares eigenständiges Profil bilden, das mehr und anders war als eine „normale Kassenerholung“. Mit der Formulierung von Reformzielen war es jedoch nicht getan. Das Müttergenesungswerk hatte ein Imageproblem. Im Frühjahr 1971 beauftragte das Müttergenesungswerk das Münchner Institut für Motivforschung mit einer Analyse. ${ }^{210}$ Es zeigte sich, daß der Bedarf an Mütterkuren weiterhin quantitativ das Angebot des Müttergenesungswerkes weit übertraf. In der Sache erwarteten die befragten Frauen von einem Kuraufenthalt auch in etwa das, was das Müttergenesungsheim tatsächlich anbot: Ruhe, Entspannung, Ungebundenheit von familiären Belastungen, Abwechslung, Anregung, Beratung in Erziehungs-, Ernährungs-, Gesundheits- und Familienplanungsfragen. Der Bedarf war also da, und das Angebot war da. Aber viele derjenigen, die der Hilfe bedurften, hatten infolge des Images und mangelhafter Information das Gefühl, für sie komme dieses Angebot nicht in Frage. Die meisten befragten Frauen glaubten nicht, daß das Müttergenesungswerk ein Angebot für sie sei: Man wolle keine Almosen, eine Müttergenesungskur sei nur etwas für soziale Randgruppen. Außerdem hatten die befragten Frauen große Bedenken, daß ihre individuelle Freiheit bei einem Kuraufenthalt eingeschränkt würde, beispielsweise durch Mehrbettzimmer, gemeinsame Mahlzeiten, gemeinsame Aufsteh- und Bettruhezeiten. Rosemarie Pflüger stellte 1974 in einer Bilanz vom Müttergenesungswerk fest, daß der schon jahrealte Ausspruch einer Caritasmitarbeiterin immer noch Gültigkeit besaß: „Eine richtige Mutter in Erholung zu vermitteln, ist eine mühsame Aufgabe. Man kommt sich beinahe wie ein Überredungskünstler vor.“211

Widerstände von Betroffenen, Ärzten, Sozialarbeitern, Versicherungsträgern, Seelsorgern und die abschätzige Haltung der öffentlichen Meinung stellten die Öffentlichkeitsarbeit des Müttergenesungswerkes in den siebziger Jahren vor erhebliche Probleme. Offenbar hatte das Müttergenesungswerk den Übergang von Kriegsfolgenhilfe und Bedürftigenfürsorge zum allgemeinen Kurangebot nicht bewältigt. Noch in der ersten Hälfte der sechziger Jahre schien es, als ob die Müttergenesung zu einem zentralen Bereich der westdeutschen Faunilienpolitik avancieren würde. Mit der Schwerpunktverschiebung ab Mitte der sechziger Jahre paßte die fürsorgeorientierte Maßnahme der Genesungskur jedoch immer weniger in das familienpolitische Gesamtkonzept. Zwar blieb sie als ein Zweig der sozialen Sicherung für Frauen jenseits der Erwerbssphäre weiterhin bestehen, zur breitenwirksamen Institution des „dritten Sektors“, wie es die Studie von Junker gefordert hatte, wurden die Müttergenesungsheime aber nicht.

209 Neue Zielvorstellungen in der Mütter-Genesung, Entwurf vom 16. 9. 1969, BAK, B 189/ 4521.

$210 \mathrm{Vgl}$. Neises, Müttergenesung, S. 19-20.

211 Pflüger, Widerstände, S. 332. 


\section{Abtreibungsdebatte: \\ die "umfassende" Familienberatung in Bayern als Gegenentwurf zum Modellprojekt der Schwangerschaftskonfliktberatung der Bundesregierung}

Bayern bildete im Bereich der Familienbildung und -beratung bis Anfang der siebziger Jahre das Schlußlicht unter den westdeutschen Bundesländern. Zwar hatten vor allem die Kirchen auch hier seit 1963 begonnen, Ehe- und Familienberatungsstellen einzurichten. Seit Ende 1968 bestand auch eine enge Kooperation zwischen den Trägerverbänden und ein übergreifender „Arbeitskreis für Ehe- und Familienberatung in Bayern". ${ }^{212}$ Einen eigenen Haushaltsposten „Ehe- und Familienberatungsstellen" gab es aber in Bayern erst ab 1970.213 Im Familienprogramm von 1974 zeigte sich jedoch, daß seit Anfang der siebziger Jahre vor allem dieser Bereich massiv ausgebaut worden war. Gab es 1970 nur zwölf Ehe- und Familienberatungsstellen in Bayern, so war ihre Zahl bis 1974 auf 63 angestiegen. Nach Angaben des "Arbeitskreises für Ehe- und Familienberatung in Bayern“ wurden 1974 rund 40000 Ratsuchende betreut. ${ }^{214}$ Nach der Höhe der staatlichen Zuschüsse lag Bayern nach eigener Aussage im Ländervergleich 1974 inzwischen an zweiter Stelle hinter Nordrhein-Westfalen.215 Auch in der oppositionellen SPD mußte man zugestehen, daß Bayern in der Beratung für Familienfragen mittlerweile wesentlich besser als andere Länder abzuschneiden schien. ${ }^{216}$

Die Gründe für den späten aber dafür um so kräftigeren Aufschwung des bayerischen Engagements auf diesem Gebiet lagen nicht zuletzt in der Diskussion um die Reform des $\$ 218.217$

Im Jahr 1969 war der $\$ 218$ nach langer Zeit wieder Gegenstand einer parlamentarischen Beratung. Durch die Reform des Strafrechts vom 25. Juni 1969 wurde der Straftatbestand der Abtreibung zu einem Vergehen herabgestuft. 218 Damit war eine neue Runde in der langen Diskussion über die Abtreibung eröffnet. Weit mehr öffentliches Aufsehen als diese strafrechtliche Reform erregte ein Jahr später der Alternativ-Entwurf liberaler Strafrechtsjuristen: Bis zum dritten Monat sollte danach die Abtreibung generell straffrei sein, wenn die Schwangere zuvor eine Beratungsstelle aufgesucht hatte und die Abtreibung durch einen Arzt vorgenommen wurde. Dieser Vorschlag eines „Fristenmodells“ stand im Gegensatz zu anderen Vorstellungen, die eine Abtreibung nur im Falle einer wie auch immer definierten „Indikation“ erlaubten („Indikationsmodell“).

212 Vgl. Bericht des Arbeitskreises für Ehe- und Familienberatung in Bayern vom 14. 6. 1969, BayHStA, MArb 3238.

213 Bayerisches Staatsministerium für Arbeit und Sozialordnung, Familie, S. 17.

214 Selbstdarstellung des Landesarbeitskreises für Ehe- und Familienberatung in Bayern vom 30. 6. 1975, ACSP, NL Prümmer, 5.16.1. Vgl. zu den Angaben zu 1970-1974 auch Bayerisches Staatsministerium für Arbeit und Sozialordnung, Familie, S. 17; Bayerische Staatsregierung, Familienprogramm, S. 17.

$215 \mathrm{Vgl}$. Entwurf des Familienprogramms vom 15. 2. 1974, BayHStA, MArb VII/125.

216 Schreiben von Ursula Schleicher an Fritz Pirkl vom 17. 8. 1973, BayHStA, MArb 3239.

217 Die Debatte um den $\$ 218$ reichte weit über den Untersuchungszeitraum hinaus und ist im Grunde bis heute nicht zur Ruhe gekommen.

218 Vgl. zum folgenden Gante, Rechtspolitik; ders., $\$ 218$; Tallen, Auseinandersetzung. 
Die heftige Diskussion um die Reform der Abtreibungsgesetzgebung war mehr als eine Facette der Liberalisierungsdebatte im Strafrecht in den sechziger und frühen siebziger Jahren. Sie berührte zentrale Forderungen der Frauen in der Gesellschaft und gilt als die Geburtsstunde der neuen Frauenbewegung in der Bundesrepublik. Das öffentliche Klima erhitzte sich im Frühjahr 1971 vor allem dadurch, daß in der Zeitschrift „Stern“ eine spektakuläre Selbstanklage-Kampagne erschienen war. ${ }^{219}$ Nach französischem Vorbild ließen sich 274 Frauen namentlich im Juni 1971 in der Zeitschrift "Stern“ nennen bzw. abbilden und erklärten öffentlich: „Wir haben abgetrieben!“ Die Abtreibungen verstießen gegen geltendes Recht - die Frauen mußten mit einer Gefängnisstrafe von einem bis fünf Jahren rechnen - und die Selbstbezichtigung stellte einen gesellschaftlichen Tabubruch dar. Mit der Aktion erreichten die Frauen zum ersten Mal eine breitere Öffentlichkeit, nachdem die früheren Aktionen im Umfeld der 68er-Bewegung kaum über das sehr enge Milieu der Studentenrevolte hinausgekommen waren.220 Im Laufe von nur sechs Wochen gab es 2345 weitere Selbstanzeigen und 86100 Solidaritätsbekundungen (von Männern und Frauen). ${ }^{221}$ Große Demonstrationen begleiteten die Kampagne der Abtreibungsbefürworterinnen, die unter anderem mit dem Slogan "Mein Bauch gehört mir" auf ihrem körperlichen Selbstbestimmungsrecht beharrten. Nachdem 1976 die Indikationslösung in Kraft trat, ebbte der Streit zwischen Abtreibungsbefürworterinnen und -gegnerinnen ab. Die vielerorts entstandenen Gruppen und Netzwerke bildeten aber eine tragfähige Grundlage für weitere Aktivitäten der neuen Frauenbewegung, auch wenn sie nur noch selten so spektakulär und einstimmig auftrat wie bei der Debatte um die Abtreibungsreform.

In der Frage des Schwangerschaftsabbruchs mußte sich die Bundesrepublik auch dem Vergleich mit der DDR stellen. Dort war 1972 die Fristenregelung eingeführt worden. ${ }^{222}$ Begleitet war dies jenseits der Mauer von einem ganzen Bündel flankierender familienfördernder Maßnahmen, wie Ehekrediten, dem Ausbau von Kinderbetreuungsplätzen und der Einbeziehung von Kinderzeiten in die Rentenberechnung. Wie eng hier die Konkurrenz zwischen den beiden deutschen Staaten von manchen politischen Akteuren in der Bundesrepublik wahrgenommen wurde, zeigt beispielsweise eine Broschüre der Friedrich-Ebert-Stiftung.223 Dort betonen die Autoren im Kapitel „Familienplanung“ die Parallelen zwischen beiden deutschen Staaten in der Zielsetzung: Beide deutsche Staaten befürworteten die Geburt von Kindern: "Jedes Kind hat ein Recht, erwünscht zu sein", so lautete der Leitspruch einer Aufklärungskampagne in der Bundesrepublik, und auch die DDR propagierte das "Wunschkind“. Auf der anderen Seite müßten beide deutschen Staaten das Selbstbestimmungsrecht der Frau wahren, so argu-

219 Vgl. dazu Schulz, Bräute, S. 113-116.

220 Zum internationalen Kontext vgl. Anderson/Zinsser, Geschichte, S. 482-490.

221 Frevert, Frauen-Geschichte, S. $278 \mathrm{f}$.

222 Gerhard, Geschlechterverhältnisse, S. $390 \mathrm{f}$. Dabei ist besonders bemerkenswert, daß der Reform in der DDR anscheinend keine gesellschaftlichen Demonstrationen vorausgegangen waren. Allerdings war es eine der wenigen politischen Entscheidungen, die in der Volkskammer nicht einstimmig beschlossen wurden.

223 Friedrich-Ebert-Stiftung, Familienpolitik, S. 34-40 und $60 \mathrm{f}$. 
mentierten die Autoren der Broschüre weiter. Die DDR habe mit ihrer Reform des Abtreibungsrechts ihr Ziel erreicht, während die Bundesrepublik durch das Stoppen der Reform „zurückgeworfen" worden sei.

Einer Reform des Abtreibungsrechts standen in der Bundesrepublik vor allem die Unionsparteien und die Kirchen entgegen. Das konservative Argument war vor allem der Schutz des ungeborenen Lebens. Den hatten zwar auch die Vertreter des "Fristenmodells" auf ihre Fahnen geschrieben, die argumentierten, nur durch eine Rücknahme der Strafandrohung könne der Weg zur Beratung geebnet werden, wo die Schwangere über Hilfsmöglichkeiten aufgeklärt und dadurch zur Fortsetzung ihrer Schwangerschaft bewegt werden sollte. Die bisherige, vermeintlich hohe Zahl der illegalen Abtreibungen ließ sich allerdings statistisch nicht erfassen, und die Erfahrungen mit der „Fristenlösung “ in der DDR deuteten nicht in diese Richtung. 224

Durch diese Parallelisierung von Zielen der SPD und der DDR-Politik gewann der Kampf um die „Fristenlösung“ über die Sachargumente hinaus eine weiterreichende politische Dimension und nicht selten einen polemischen Charakter. Das „Fristenmodell“" wurde von den Gegnern als sozialistische Lösung gebrandmarkt, auf der anderen Seite schien ein Bekenntnis zur harten Abtreibungsbestrafung gleichzeitig eines zur freiheitlichen, westlichen Gesellschaftsordnung zu sein eine Zuordnung, die die ursprüngliche Reformabsicht der Juristen, die ja gerade auf eine Liberalisierung des Strafrechts hinauslief, in ihr Gegenteil verkehrte.

Durch die hohe politische Aufladung stand das Reformvorhaben unter sehr großem öffentlichen Druck. Das betraf nicht nur die Kernfrage der strafrechtlichen Verfolgung, sondern auch die damit verbundenen sozialpolitischen Rahmenregelungen. In ihrem Gesetzentwurf zur Fristenregelung hatte die SPD-Fraktion "flankierende Maßnahmen" angekündigt - die Parallele zur Entwicklung in der DDR war dabei deutlich zu sehen. Noch bevor das Gesetz zur Reform des $\$ 218$ verabschiedet wurde, gab das Bundesfamilienministerium 1972 als erste der in Aussicht gestellten "flankierenden Maßnahmen“ eine Broschüre mit dem Titel „Eine Zeit für Wunschkinder" heraus. Darin ging es vor allem um die Information über Verhütungsmethoden. Die Aufklärungskampagne sollte nach Ansicht der Familienpolitiker dazu beitragen, daß es gar nicht erst zu Konfliktschwangerschaften kam.

Es war wohl kaum ein Zufall, daß diese Aktion bis in den Titel hinein den im offiziellen DDR-Schrifttum verwendeten Begriff "Wunschkind-Pille“ statt der bisher gebräuchlichen Bezeichnung "Anti-Baby-Pille" sowie den Duktus der ostdeutschen Regierung aufgriff. ${ }^{225}$ So hieß es in der offiziellen Ankündigung, die Bundesregierung trete „für Familienplanung als die bessere Alternative zur Abtreibung" ein. ${ }^{226}$ Auch diese Argumentation konnte man in der DDR in offiziellen Stellungnahmen lesen. Pro Familia hatte sich in ihrer offensiven Aufklärungsund Verhütungspolitik seit den fünfziger Jahren ebenfalls auf dieses Argument

224 Gante, Rechtspolitik, S. 189.

225 Vgl. Mehlan, Wunschkinder; Schwarz, Wunschkindpille, S. 149, 155-157.

226 Flankierende Maßnahmen zum \$218: Unsere Kinder sollen Wunschkinder sein. Was können wir tun?, in: Informationen des Bundesfamilienministeriums vom 12. 5. 1972. 
gestützt. 1973 erschien eine neue, erweiterte Auflage der inzwischen als Teil der "Aktion Familienplanung" verbreiteten Broschüre unter dem Titel „Jedes Kind hat ein Recht erwünscht zu sein - Information über Empfängnisverhütung und Möglichkeiten, den Zeitpunkt für ein Kind selbst zu bestimmen“. ${ }^{227}$ Das Aufklärungsheft wandte sich nicht nur an Ehepaare, sondern in einem speziellen Kapitel auch an Jugendliche unter 17 Jahren. Diese Zielgruppe der Jugendlichen hatte auch eine weitere Aktion im Blick: Gemeinsam mit der Jugendzeitschrift „Bravo“ entwickelte die Bundeszentrale für gesundheitliche Aufklärung eine Informationsbroschüre und Handzettel zum Thema „Empfängnisverhütung für junge Paare in Bildern“. ${ }^{228}$ Die Aufklärungskampagnen der Bundesfamilienministerinnen waren ein neues Verfahren, mit dem sich die Politiker direkt und breitenwirksam an die Bevölkerung wandten. Im Familienministerium, das eine lange Tradition in der Frage der Öffentlichkeitsarbeit hatte, hatte es Aktionen von vergleichbarem Ausmaß noch nicht gegeben. ${ }^{229}$

Hatten sich SPD und FDP in den Koalitionsverhandlungen zum sechsten Bundestag noch auf ein Indikationsmodell geeinigt, so rückten beide Parteien im Laufe des Jahres 1971 davon ab. Am 9. Februar 1972 brachten SPD und FDP einen gemeinsamen Entwurf zur Fristenregelung in den Bundestag ein. In Form eines Gruppenantrags von SPD- und FDP-Abgeordneten lag auch der Regierungsentwurf, der ein Indikationsmodell mit "medizinischer", „kindlicher", „kriminologischer" und "sozialer" Indikation vorsah, den Bundestagsabgeordneten vor. Von der Opposition kamen ebenfalls zwei Gesetzentwürfe: der Fraktionsantrag, der eine weite medizinische Indikation befürwortete, und ein Gruppenantrag, der unter maßgeblichem Einfluß des ehemaligen Familienministers Bruno Heck ausgearbeitet worden war, und der die medizinische Indikation restriktiv formulierte. 1974 verabschiedete der Bundestag ein Gesetz, das das Fristenmodell vorsah. Es trat jedoch nie in Kraft, da die CDU/CSU-Bundestagsfraktion vor das Bundesverfassungsgericht ging. Am 25. Februar 1975 erklärte das Bundesverfassungsgericht das Gesetz für verfassungswidrig. Im Mai 1976 wurde schließlich ein Abtreibungsgesetz verabschiedet, das nur eine medizinische Indikation anerkannte, die jedoch weit interpretiert werden konnte.

Mit der Einführung der Reform sollte nach den Vorstellungen der Bundesregierung auch ein massiver flächendeckender Ausbau der Familienberatungseinrichtungen einhergehen. ${ }^{230}$ Das Modellprogramm aus Bundesmitteln sollte rund

227 Bundeszentrale für gesundheitliche Aufklärung im Auftrag des Bundesministers für Jugend, Familie und Gesundheit, Jedes Kind hat ein Recht erwünscht zu sein - Information über Empfängnisverhütung und Möglichkeiten, den Zeitpunkt für ein Kind selbst zu bestimmen. Vgl. dazu auch die Ankündigung der Broschüre in den Informationen des Bundesfamilienministeriums vom 27. 11. 1973.

228 Helfferich, Pille, Abb. und Bildtext S. 218.

229 Münch konstatiert dagegen für die siebziger Jahre einen Niedergang der direkten Informationstätigkeit, vor allem im Vergleich zur familienpolitischen Praxis Wuermelings. Münch, Familienpolitik, S. 171. Zu diesem Ergebnis kommt sie vermutlich, weil die erwähnten Aufklärungskampagnen als Initiativen der Bundeszentrale für gesundheitliche Aufklärung außerhalb ihres institutionellen Untersuchungsfeldes liegen.

230 Ergänzende gesellschaftliche Maßnahmen zur Reform der Strafrechtsvorschriften zum Schwangerschaftsabbruch vom 8. 8.1973, BAK, B 189/14698. Nach dem Ausbau der Be- 
50 ausgewählte Beratungsstellen fördern und damit den weitere Ausbau anregen. $\mathrm{Zu}$ diesem Zweck wurden 1973 die Haushaltsmittel für Familienbildung und -beratung von 2,35 auf fünf Mio. DM aufgestockt. Das Modellprojekt war auf drei Jahre angelegt. Sieben der ausgewählten Beratungsstellen sollten bereits $1973 \mathrm{mit}$ ihrer Arbeit beginnen, die restlichen sollten ihre Tätigkeit 1974 aufnehmen. Der Förderungsplan der Familienministerin umfaßte 25 Einrichtungen der Pro Familia, 16 Einrichtungen kirchlicher Träger, sechs Gesundheitsämter, drei Einrichtungen der Arbeiterwohlfahrt und zwei andere Einrichtungen. Fast die Hälfte der Modellberatungsstellen gehörten demnach zu Pro Familia. Außerdem war ein Teil der Beratungsstellen versuchsweise an ärztliche Praxen angeschlossen. ${ }^{231}$

Die Bundesfamilienministerin wählte zur Finanzierung ihrer Vorhaben den Weg der „Modellprojekte“, der die eigentlich gegebene Zuständigkeit der Länder elegant umging. Das Engagement der Länder sollte durch eine Anschubfinanzierung geweckt werden, gleichzeitig präformierte die Regelung aber auch de facto den Aufbau bestimmter Einrichtungen, etwa indem sie die Förderung der Beratungsstellen der Pro Familia in den Vordergrund stellte. Dies berührte einen zentralen Konfliktpunkt zwischen Bund und Ländern. In der Frage, welche Art von Familienbildungs- und -beratungsstellen zu fördern seien, wichen nämlich die Positionen von Bund und manchen Ländern deutlich voneinander ab. Während die sozialliberale Bundesregierung eher die Beratungsstellen, die sich auf die Schwangerschaftsberatung spezialisiert hatten, für die Pflichtberatung einsetzen wollte, war nach Ansicht der konservativ regierten Länder bevorzugt die ganzheitliche Familienbildung zu stärken.

„In diesem Zusammenhang sind auch die Bemühungen des Bayerischen Staatsministeriums für Arbeit und Sozialordnung zu sehen, das die Einrichtung reiner Sexual- und Familienplanungsberatungsstellen verhindern will zugunsten von umfassenderen, die tieferen menschlichen Zusammenhänge würdigenden und dementsprechend zu konzipierenden Beratungsdiensten", hieß es im Entwurf zum bayerischen Familienprogramm: „Bayern fördert neue Beratungsmodelle, fragt aber vor der Bewilligung von Steuergeldern nach dem Wie der Beratung. "232 Diese Frage nach dem "Wie" bezog sich auf einen schwerwiegenden inhaltlichen Konflikt zwischen traditionellen, wertkonservativen Familienberatungsstellen und einer neuen Form von Schwangerschaftskonfliktberatung im engen Sinn, die im Zuge der Reform des Abtreibungsrechts von der Bundesregierung gefördert wurde.

ratungseinrichtungen folgte ein Abschnitt über die Kostenfreiheit von Beratung, Verhütungsmitteln und Schwangerschaftsabbruch. Schließlich war eine Erweiterung der traditionellen familienpolitischen Maßnahmen vorgesehen, um die Entwicklungsbedingungen für Kinder zu verbessern. An letzter Stelle der flankierenden Maßnahmen stand die Sicherstellung eines „von belastenden Umständen weitgehend befreiten und medizinisch einwandfreien Schwangerschaftsabbruchs“.

231 Zusammenstellung der familienpolitischen Modellversuche zwischen 1969 und 1976, AdsD, NL Katharina Focke, 419; Modellprogramm für 50 Beratungsstellen, in: Familienpolitische Informationen der EAF, 13 (1974), Nr. 4, S. 31.

232 Entwurf des bayerischen Familienprogramms vom 15. 2. 1974, S. 29, BayHStA, MArb VII/125. 
Der bayerische Arbeitsminister Fritz Pirkl führte über diesen Streitpunkt intensive Gespräche mit dem Familienministerium, an deren Ende schließlich eine stärkere Beteiligung kirchlicher Stellen bei der „Modellprojekt“-Förderung der Bundesregierung in Bayern stand. Von den acht bayerischen Beratungsstellen, die zunächst in das Bundesprogramm aufgenommen wurden, waren vier in katholischer und zwei in evangelischer Trägerschaft. Dies war in Pirkls Augen ein Kompromiß, der die Beteiligung des Landes am Modellprojekt vertretbar machte. 233

In Bayern begnügte man sich jedoch nicht mit einer Beteiligung an dem Vorhaben der Bundesregierung. Gleichzeitig unternahm das bayerische Arbeits- und Sozialministerium große Anstrengungen, um eine von der Bundespolitik finanziell unabhängige Infrastruktur für die Familienberatung in Bayern zu errichten. Die bayerische Staatsregierung wollte sich offenbar nicht durch die Modellförderung vom Bund die Initiative aus der Hand nehmen lassen. Es war das erklärte Ziel des bayerischen Familienprogramms von 1974, sich durch den eigenen Ausbau eines Netzes von Familienbildungsstätten die „Unterbrechungsberatungsstellen" des vom Bund initiierten Modellprojektes „vom Leib zu halten“.234 Familienberatung sollte so arbeiten, daß Konfliktschwangerschaften von vornherein vermieden würden. Das schien den bayerischen Unionspolitikern bei der Beratung nach dem Bundesmodell, wonach im Prinzip ein und derselbe Arzt die Diagnose der Indikation stellen und im Anschluß daran das Beratungsgespräch führen konnte, nicht gewährleistet. Der Familiengedanke trete dabei hinter die medizinischen Aspekte zu sehr zurück, lautete die Argumentation.

Mit ihrem Ansatz, der Schwangerschaftsberatung und Familienberatung verband, wollte die bayerische Staatsregierung wohl auch den konfessionellen Trägern eine Brücke bauen, damit sie ihre Beratungsarbeit fortsetzen und ausbauen konnten. Bei ihnen führte die ausschließliche Konzentration auf die „ergebnisoffene" Schwangerschaftsberatung in den Modelleinrichtungen der Bundesregierung nämlich von Anfang an zu Problemen. Hörten die christlichen Berater auf der einen Seite, sie seien für die professionellen Standards nicht ausreichend qualifiziert, mußten sie sich auf der anderen Seite von ihren Trägerverbänden sagen lassen, daß sie "nicht fromm genug“ seien.235

Seit 1970 wurden Ehe- und Familienberatungsstellen vom bayerischen Staat mit $50000 \mathrm{DM}$ jährlich gefördert. 1973 verdoppelte man den Haushaltsansatz. Als 1974 die Modellförderung des Bundesfamilienministeriums für "flankierende Maßnahmen zum $\$ 218^{\prime \prime}$ auch in Bayern einsetzte, wurde der Haushaltsposten noch einmal erhöht. $190000 \mathrm{DM}$ standen nun zur Verfügung, mehr als die auf Bayern entfallende Fördersumme aus dem Bundesmodellprojekt. Auch im Jahr darauf versuchte die Staatsregierung in München durch die Förderung eigener

233 Vgl. Bayerisches Staatsministerium für Arbeit und Sozialordnung, Sozialpolitik 1975, S. 198; Schreiben Fritz Pirkls an das bayerische Ministerium für Bundesangelegenheiten vom 13. 6. 1975, ACSP, NL Pirkl, 152.

${ }^{234}$ Formulierungen von Fritz Pirkl bei der Vorstellung des bayerischen Familienprogramms, Vgl. Riedel-Martiny, Anke: Familienbewußtsein vor der Landtagswahl. CSU-Landesregierung schielt auf die Wahlurne, in: SPD-Pressedienst vom 7.3. 1974, BAK, B 189/ 14698.

235 Vgl. Keil, Gedanken, S. 89 f. 
Projekte finanziell die Oberhand zu behalten. ${ }^{236}$ Ende 1975 richtete Bayern auch ein eigenes Landesmodellprojekt „Beratung und Hilfe für Mutter und Kind“ ein, das mit seinen neun Einrichtungen ebensoviele Beratungsstellen förderte wie das Bundesprogramm. ${ }^{237}$ Ein eigenes bayerisches "Schwangerenberatungsgesetz" war schon 1974 angekündigt worden, kam aber erst 1978 zustande. Das finanzielle Rückgrat für dieses Gesetz bildete eine eigene „Stiftung zum Schutz des ungeborenen Lebens". ${ }^{238}$

Bilanziert man die Entwicklung, dann erreichten die sozialdemokratischen Familienministerinnen mit ihrer Initiative der Modellprojekte zwar das Ziel, die Länderregierungen, die eigentlich für die Finanzierung der Familienberatungsstellen zuständig waren, zum Ausbau dieses Bereiches anzuregen. So bewirkte die Einmischung des Bundes in die Länderkulturhoheit, daß sich in Bayern aus der noch Ende der sechziger Jahre bestehenden Brachlandschaft eine verhältnismäßig gut funktionierende Infrastruktur an Beratungseinrichtungen entwickelte. Treibender Faktor für diese Entwicklung war aber nicht eine positive gegenseitige Ergänzung zwischen Bundes- und Länderinteressen, sondern im Gegenteil der scharfe inhaltliche Abgrenzungskampf, den die bayerischen Familienpolitiker ausfochten. Er führte zum einen dazu, daß der bayerische Arbeitsminister Pirkl sich in die Ausgestaltung des Bundesmodells für Bayern einschaltete und sich bei dessen Durchführung engagierte. Außerdem provozierte die Modellförderung des Bundes die bayerischen Politiker zu einer großangelegten eigenen Kampagne, die ein Gegengewicht zum Bundesprojekt bilden sollte.

In der Frage der inhaltlichen Umgestaltung der Beratungsstellen zu gezielter Schwangerschaftsberatung unter ärztlicher Kontrolle, wie sie die Bundesregierung anstrebte, verweigerten sich Bayerns Politiker mit allen ihnen zur Verfügung stehenden Mitteln. Der Vorstoß des Bundesfamilienministeriums führte also zwar zu einer quantitativen Verbesserung der Versorgungssituation für Ratsuchende, inhaltlich konnten die sozialdemokratischen Familienministerinnen aber im konservativ regierten Bayern keinen Richtungswechsel durchsetzen.

236 Vgl. dazu Vermerk des Familienreferenten Hans Stützle vom 19.2. 1975 über die Situation der Förderung der Ehe- und Familienberatung in Bayern, BayHStA, MArb 3239.

237 Vgl. Bayerisches Staatsministerium für Arbeit und Sozialordnung, Sozialpolitik 1976, S. 126.

238 Handreichung zur Darstellung und Erläuterung der bayerischen Politik für die Familie vom Juli 1978, ACSP, NL Prümmer, 5.16.1. 